\title{
STUDY ON AIRFLOW AND VIBRATION IN A \\ CUTTING/COLLECTION/DISCHARGE \\ LAWN CARE SYSTEM
}

\author{
By \\ Evan D. Davidge \\ B.Eng. (Mechanical Engineering) \\ Ryerson University, 2004
}

\begin{abstract}
A thesis presented to Ryerson University in partial fulfillment of the requirements for the degree of

Master of Applied Science in the

Program of Mechanical Engineering
\end{abstract}

Toronto, Ontario, Canada, 2006

(C) Evan D. Davidge 2006 
UMI Number: EC53816

\section{INFORMATION TO USERS}

The quality of this reproduction is dependent upon the quality of the copy submitted. Broken or indistinct print, colored or poor quality illustrations and photographs, print bleed-through, substandard margins, and improper alignment can adversely affect reproduction.

In the unlikely event that the author did not send a complete manuscript and there are missing pages, these will be noted. Also, if unauthorized copyright material had to be removed, a note will indicate the deletion.

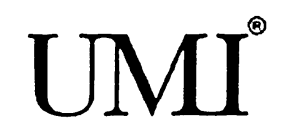

UMI Microform EC53816

Copyright 2009 by ProQuest LLC

All rights reserved. This microform edition is protected against unauthorized copying under Title 17, United States Code.

ProQuest LLC

789 East Eisenhower Parkway

P.O. Box 1346

Ann Arbor, MI 48106-1346 
I hereby declare that I am the sole author of this thesis.

I authorize Ryerson University to lend this thesis to other institutions or individuals for the purpose of scholarly research.

I further authorize Ryerson University to reproduce this thesis by photocopying or by other means, in total or in part, at the request of other institutions or individuals for the purpose of scholarly research. 


\title{
STUDY ON AIRFLOW AND VIBRATION IN A \\ CUTTING/COLLECTION/DISCHARGE LAWN CARE SYSTEM
}

Evan D. Davidge

Master of Applied Science (M.A.Sc.)

Mechanical Engineering

Ryerson University, 2006

\begin{abstract}
Airflows in the cutting/discharge/collection system of a professional lawn care system were studied numerically and experimentally in this thesis. Various three-dimensional and two-dimensional computational fluid dynamics models were developed in order to investigate the complex airflow created by a pair of counter-rotating blades. The threedimensional models were used to study the actual flows; the two-dimensional models were developed to investigate the optimal shapes of the rotating blades using the mass flow rate per unit power consumption as the objective function. Experiments were carried out mainly to validate the computer models developed in this study for airflow velocity and power usage for an actual cutting system.
\end{abstract}

Vibrations of a cutting blade were studied using the finite element method and experiments. It was found that the blades will experience resonance under normal operating conditions. 


\section{Acknowledgments}

The author wishes to thank Dr. Shudong Yu for his wisdom and guidance throughout the thesis work, Mr. Bill Czeban and Mr. Bob Ernst of GP-Turfcare Inc. for their ongoing support of the project and valuable advice. The author also acknowledges the financial support from OCE-MMO and NSERC. In addition, thanks go to Mr. Chris Siemicki and Mr. Evan Martin for their professional work in assembling a test rig for the experiments. The author also appreciates the enthusiastic support from the following technical support staff in the Department of Mechanical and Industrial Engineering: Roy Churaman, Joseph Amankrah, Alan Machin, Andrew Heim and Devin Ostrom. 
This thesis is dedicated to my fiancée Tricia and my family, who have given me their support and understanding throughout my graduate studies. 
Abstract..........................................................................................................................................

Acknowledgments .................................................................................................................... iv

Table of Contents ............................................................................................................................... vi

List of Tables ............................................................................................................................. viii

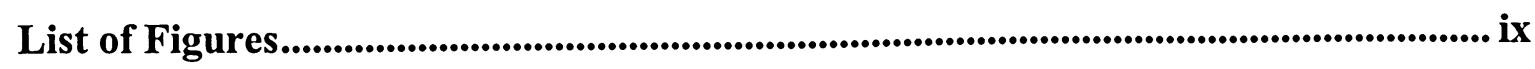

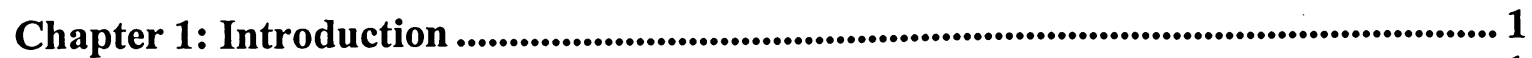

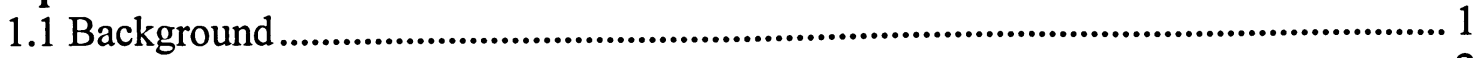

1.2 System Description ............................................................................................. 2

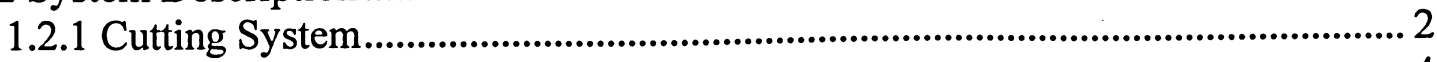

1.2.2 Conveying Tunnel.............................................................................................. 4

1.2 .3 Collector............................................................................................................. 5

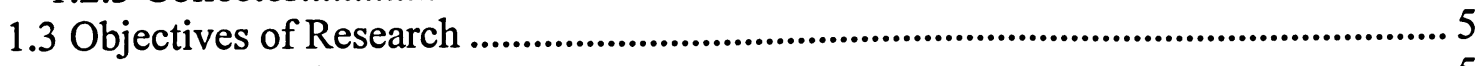

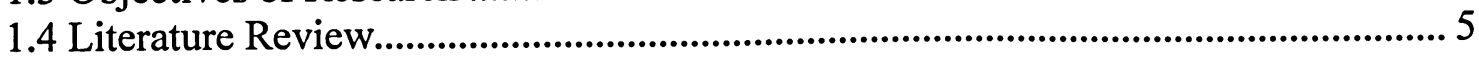

Chapter 2: Cutting System Flow Analysis................................................................6 6

2.1 Flow Analysis Experiments on Test Rig ................................................................. 6

2.1.1 Experimental Test Rig Set-up................................................................................. 6

2.1.2 Experimental Test Rig Airflow Results (Without Collector) .............................. 9

2.1.3 Experimental Test Rig Airflow Results (With Collector) .................................. 11

2.1.4 Collector Outlet Velocity Readings (All Vents Open) ....................................... 12

2.1.5 Collector Outlet Velocity Readings (Centre Rear Vent Closed) ....................... 14

2.1.6 Experimental Test Rig Power Consumption (With Collector) ........................... 16

2.2 Three-Dimensional Computational Flow Analysis ..................................................... 17

2.2.1 Capabilities of the Software.................................................................................. 18

2.2.2 Single Blade Model................................................................................................ 21

2.2.3 Twin-Blade Cutting System Model with a Widened Cutting Pan...................... 36

2.2.4 Twin-Blade System Modeling Techniques......................................................... 37

2.2.5 Computational Schemes Used in the Twin-Blade Model Using Collector with

Normal Vents ................................................................................................................. 40

2.2.6 Airflow through Inlets in Twin-Blade Model ....................................................... 41

2.2.7 Airflow inside the Cutting Pan ............................................................................ 43

2.2.8 Airflow through Tunnel in Twin-Blade Model ................................................. 44

2.2.9 Airflow inside Collector and Through Outlet Vents in Twin-Blade Model .... 44

2.2.10 Twin-Blade Model with a Closed Vent ........................................................... 50

2.2.11 Results of the Twin-Blade Model with Varying Rotational Speed ................ 51

2.2.12 Results of the Twin-Blade Model without collector for Blade Comparison . 53

2.3 Three-Dimensional Computational Flow Results: Comparison and Discussion.... 55 
Chapter 3: Two-Dimensional Blade Flow Analysis ............................................................. 57

3.1 Introduction of Two-Dimensional Blade Flow.................................................... 57

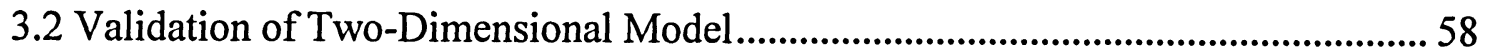

3.2.1 Two-Dimensional Validation Model set-up ........................................................ 59

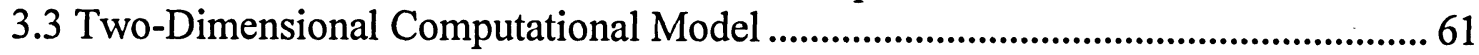

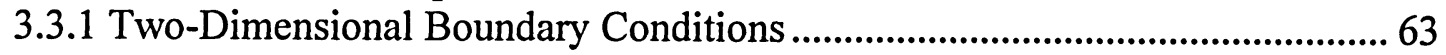

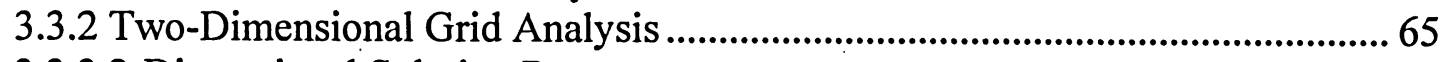

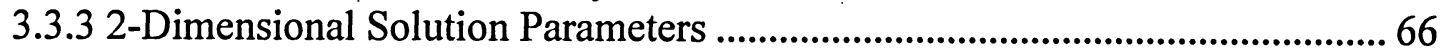

3.4 Blade Profile Shapes:................................................................................................. 67

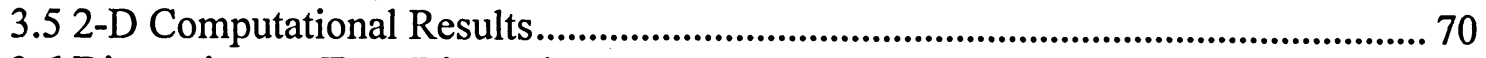

3.6 Discussion on Two-Dimensional Computational Flow.............................................. 72

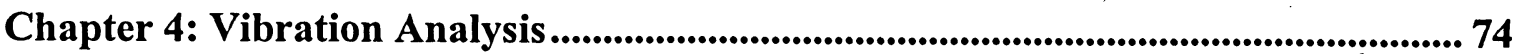

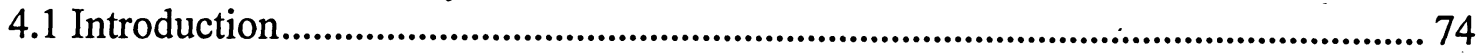

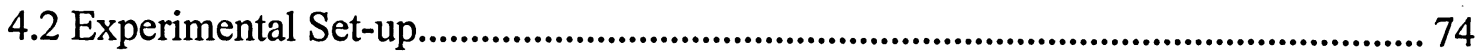

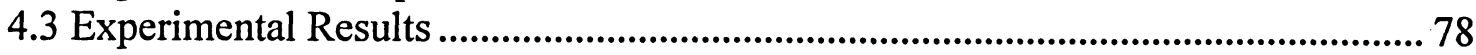

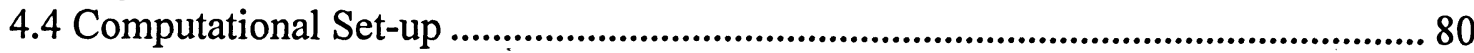

4.5 Modal Analysis Results of Static Frequencies...................................................... 82

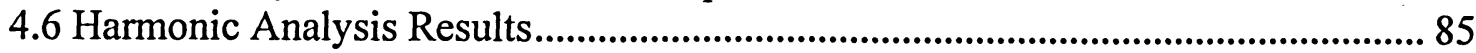

4.7 Modal Analysis Results of Dynamic Frequencies ................................................. 86

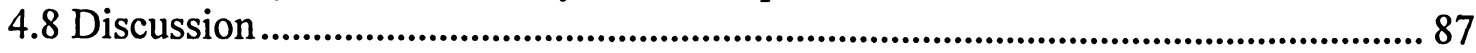

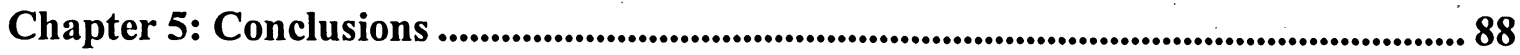

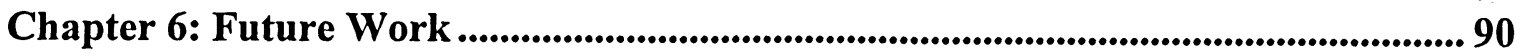

Chapter 7: References ........................................................................................................ 91 


\section{List of Tables}

Table 1 Experimental Tunnel Velocity Measurements (Serrated blades, Without Collector) 10

Table 2 Experimental Tunnel Velocity Measurements (Paddle Blades, Without Collector)

Table 3 Experimental Tunnel Velocity Measurements (With Collector).......................... 12

Table 4 Experimental Velocities through Collector Vents with All Vents Open.............. 14

Table 5 Experimental Velocities Through Collector Vents (Centre Vent Closed) ........... 16

Table 6 Measurements of Motor Power Consumption .......................................................... 17

Table 7 Tunnel Velocities of Single Blade Model with Symmetry ....................................... 35

Table 8 Average Tunnel Velocities of Single Blade Model with Errors............................ 36

Table 9 Tunnel Velocities of Twin-Blade Model ................................................................ 44

Table 10 Velocities through Collector Vents (All Vents Open)....................................... 47

Table 11 Velocities through Collector Vents with Centre Vent Closed........................... 52

Table 12 Angular Speed Variation Results...................................................................5 52

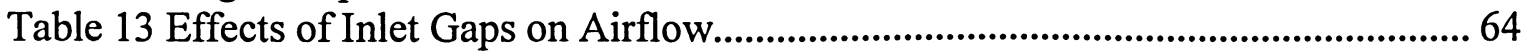

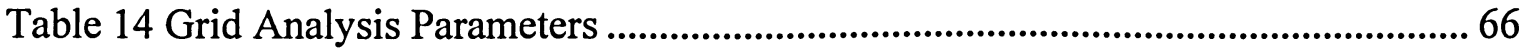

Table 15 Results for Conventional Blades................................................................... 71

Table 16 Tail Shape Modification Results......................................................................... 71

Table 17 Tail Length Modification Results .................................................................. 71

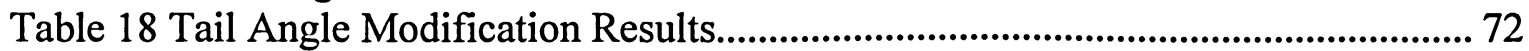

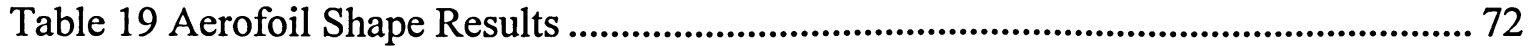

Table 20 Comparison of Static and Dynamic Frequencies................................................ 86 


\section{List of Figures}

Fig. 1 Underside view of the cutting pan with counter-rotating blades................................ 3

Fig. 2 Serrated blade tip ............................................................................................................ 3

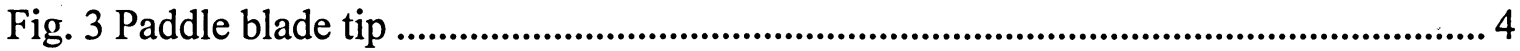

Fig. 4 Test rig setup without collector .................................................................................. 7

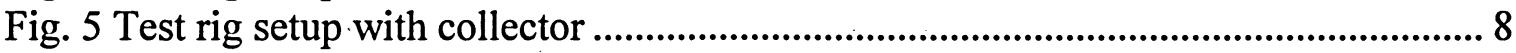

Fig. 6 Probing holes in test rig tunnel (probe inserted in third hold from the right)........... 9

Fig. 7 Pitot tube inserted into tunnel .................................................................................. 10

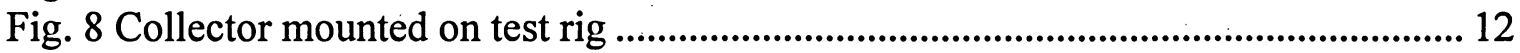

Fig. 9 Velocity measurement locations on collector...................................................... 13

Fig. 10 Velocity measurement locations on collector (centre vent closed) ........................ 15

Fig. 11 2-D computer model of centrifugal blower ............................................................ 19

Fig. 12 Velocity vectors inside a 2-D blower with no blade rotation and $200 \mathrm{~Pa}$ inlet-

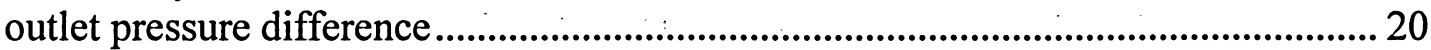

Fig. 13 Velocity vectors inside 2-D blower with $100 \mathrm{rad} / \mathrm{s}$ blade rotation and zero inletoutlet pressure difference............................................................................................... 20

Fig. 14 Overlapping area between the two cutting blades................................................. 22

Fig. 15 Model of single blade flow space with plane of symmetry ..................................... 23

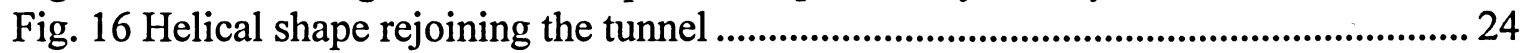

Fig. 17 Inlet gap around the base of the cutting pan......................................................... 26

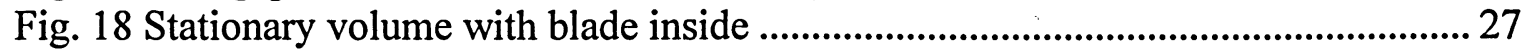

Fig. 19 Rotational MRF volume closely surrounding the blade..................................... 28

Fig. 20 Faces between the upper and lower volumes .......................................................... 29

Fig. 21 The three volumes of the single blade model ............................................................ 30

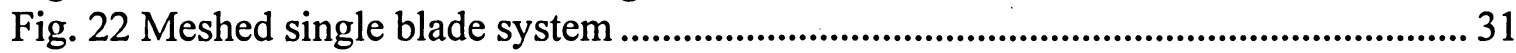

Fig. 23 Boundary conditions of single blade system .......................................................... 32

Fig. 24 Velocity vectors $(\mathrm{m} / \mathrm{s})$ of airflow inside the tunnel with blade oriented $90^{\circ}$ with

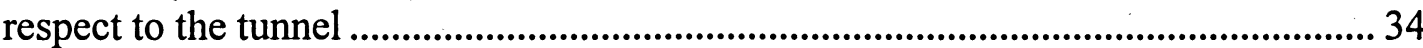

Fig. 25 Twin-blade cutting system overall geometry .............................................................. 38

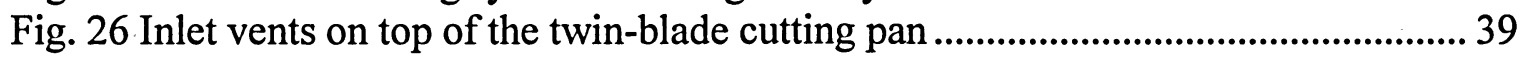

Fig. 27 Velocity vectors $(\mathrm{m} / \mathrm{s})$ through inlet boundaries .............................................. 42

Fig. 28 Velocity vectors $(\mathrm{m} / \mathrm{s})$ inside cutting pan ..................................................................... 43

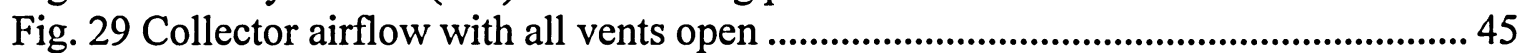

Fig. 30 Collector vent airflow with all vents open................................................................ 46

Fig. 31 Side view of air entering the collector (all vents open) ......................................... 48

Fig. 32 Top view of air entering the collector (all vents open)....................................... 49

Fig. 33 Collector airflow with centre rear vent closed............................................................ 51

Fig. 34 Velocity vectors $(\mathrm{m} / \mathrm{s})$ through tunnel using serrated blade................................. 54

Fig. 35 Velocity vectors $(\mathrm{m} / \mathrm{s})$ through tunnel using paddle blade ...................................... 54

Fig. 36 Conventional blade 1 inside cutting pan........................................................................ 57

Fig. 37 Conventional blade 1 with raised trailing fins and sharp cutting edge................... 58

Fig. 38 Cascade of CDA-43 compressor blades ...........................................................5 59

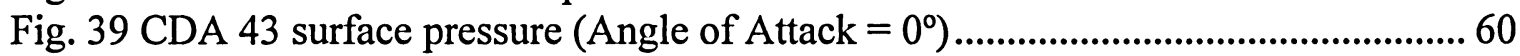

Fig. 40 CDA 43 surface pressure (angle of attack $=22^{\circ}$ ) ................................................ 61

Fig. 41 Linearly transformed cutting pan housing.................................................................... 62 
Fig. 42 Total pressure contours around blade with inlet gaps of (a) $1 \mathrm{~cm}$ (b) $15 \mathrm{~cm}$....... 64

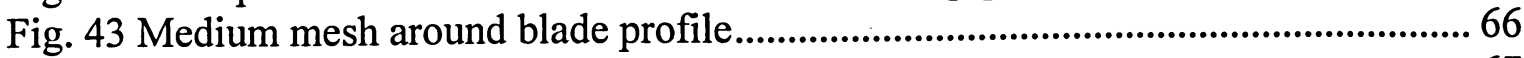

Fig. 44 Two blade profiles currently used in industry ......................................................... 67

Fig. 45 Tail shape modifications: (a) ground rear, (b) the first conventional profile, and

(c) ground front 68

Fig. 46 Tail length modifications, (a) extended length, (b) the first conventional profile,

(c) decreased length 68

Fig. 47 Tail angle modifications: (a) extended, $75^{\circ}$, (b) the first conventional profile, $60^{\circ}$,

(c) reduced, $30^{\circ}$ 69

Fig. 48 Aerofoil shapes: (a) initial aerofoil, (b) decreased tail length, (c) decreased tail angle, (d) increased tail length ....................................................................................... 70

Fig. 49 Accelerometer mounted on serrated blade .............................................................. 75

Fig. 50 Computer model of T-shaped flange clamping the top of the blade ..................... 76

Fig. 51 Computer model of bottom plate and bolt clamping the bottom of the blade...... 76

Fig. 52 Blade mounted to the bottom plate with gap between them................................... 77

Fig. 53 Accelerometer mounting location for normal operation vibration reading........... 78

Fig. 54 Fourier transform of the blade tip free flexural vibration........................................ 78

Fig. 55 Detailed view of spectrum in the vicinity of the first peak ................................... 79

Fig. 56 Fourier transform of test rig vibration data .............................................................. 79

Fig. 57 Meshed blade in ANSYS........................................................................................ 80

Fig. 58 DOF constraints on blade (constraint symbols are in black)............................... 81

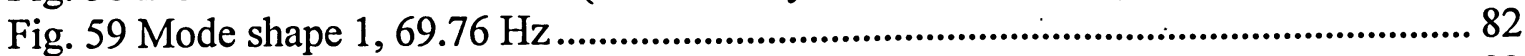

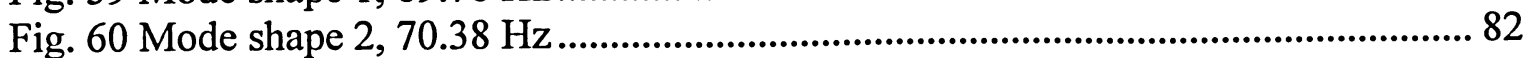

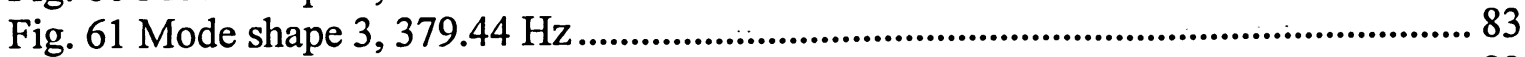

Fig. 62 Mode shape 4, $380.03 \mathrm{~Hz}$................................................................................ 83

Fig. 63 Mode shape 5, $396.83 \mathrm{~Hz}$.............................................................................. 83

Fig. 64 Mode shape 6, $399.77 \mathrm{~Hz}$................................................................................ 83

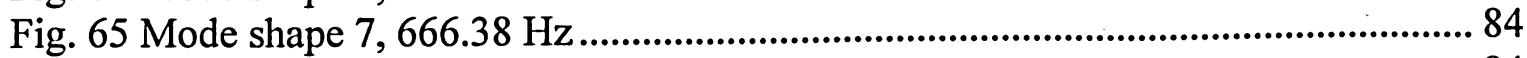

Fig. 66 Mode shape 8, $666.46 \mathrm{~Hz}$................................................................................. 84

Fig. 67 Mode shape 9, $1023.7 \mathrm{~Hz}$.................................................................................. 84

Fig. 68 Mode shape 10, $1030.7 \mathrm{~Hz}$................................................................................... 84

Fig. 69 Harmonic response of blade between $0 \mathrm{~Hz}$ and $500 \mathrm{~Hz}$....................................... 85

Fig. 70 Harmonic response of blade between $60 \mathrm{~Hz}$ and $80 \mathrm{~Hz}$....................................... 86 


\section{Chapter 1: Introduction}

\subsection{Background}

In North America, commercial landscape companies and municipalities collect less than eight percent of grass clippings and lawn debris. Leaving clippings on lawns is not a good solution in the Canadian climate since the clippings do not have adequate decomposition time. Accumulated clippings and lawn debris left on the ground create a mat, which stifles new growth unless frequently aerated.

In a professional lawn care system, blades are designed to rotate inside a cutting pan for cutting grass, drawing air into the system, and propelling the air and grass clipping mixtures into a collector. Some large professional lawn care systems require the usage of an impeller to produce adequate airflow. However, impellers often get clogged with clippings, which require frequent maintenance. To eliminate the need for impellers, GPTurfcare Inc. introduced a type of blade that cuts grass and generates sufficient airflow at the same time for moving the clippings from the cutting system into the collector through a tunnel.

In early design and testing, GP-Turfcare observed that sections of the tunnel had "dead spots" where there was no flow of air or clippings. As a result, clogging happened frequently during operations, especially in wet conditions. Clogging is highly undesirable because the operator must stop the operation to clean the clogged location manually. This usually reduces the cutting/collection efficiency considerably. In addition, clogging reduces the collection capacity and often leaves a trail of grass clippings uncollected. This is considered not acceptable, e.g., when cutting grass in a sports field.

Research work was required in order to examine properties of the flow field throughout the cutting pan, tunnel and collector. Of particular interest are the effectiveness of the blade shape in airflow, various design issues for removal of dead spots, vibration and noise issues. 


\subsection{System Description}

GP-Turfcare's lawn care system consists of three main components: a cutting system, a conveying tunnel, and a collector. Each component has its own functionality.

\subsubsection{Cutting System}

The cutting component consists of two counter-rotational cutting blades and a cutting pan. As the tractor moves along, an area of grass and other vegetation are cut by the two rotating and translating blades. At the same time, the high-speed rotational blades create a sufficient flow of air, which is responsible for transporting the clippings and forcing them into a central-rear exit and then into the conveying tunnel. A bottom view of the cutting system is shown in Fig. 1. Using the blades for both cutting and airflow generation is beneficial because of the elimination of an additional impeller, which is otherwise required for moving the air-clipping mixtures.

The two blades are attached to a metal housing that supports the hydraulic drive system and the internal plastic liner. The purpose of the plastic liner is to surround the path of the rotating blades and ensure that the airflow is smooth around the cutting pan. The blade tips come very close to the edge of the liner to minimize the amount of air that "leaks" through the gap. The plastic liner is also easily replaceable if it gets worn or damaged during cutting.

There are two types of blades that are used by GP-Turfcare on this machine: serrated blades (Fig. 2) and paddle blades (Fig. 3). It is observed in field tests that the serrated blades offer better compaction of clippings; they may not produce the necessary airflow through the system to prevent clogging in harsh conditions. The paddle blades produce sufficient airflow, but consume a great deal of power and can slow the motor down in harsh conditions. 


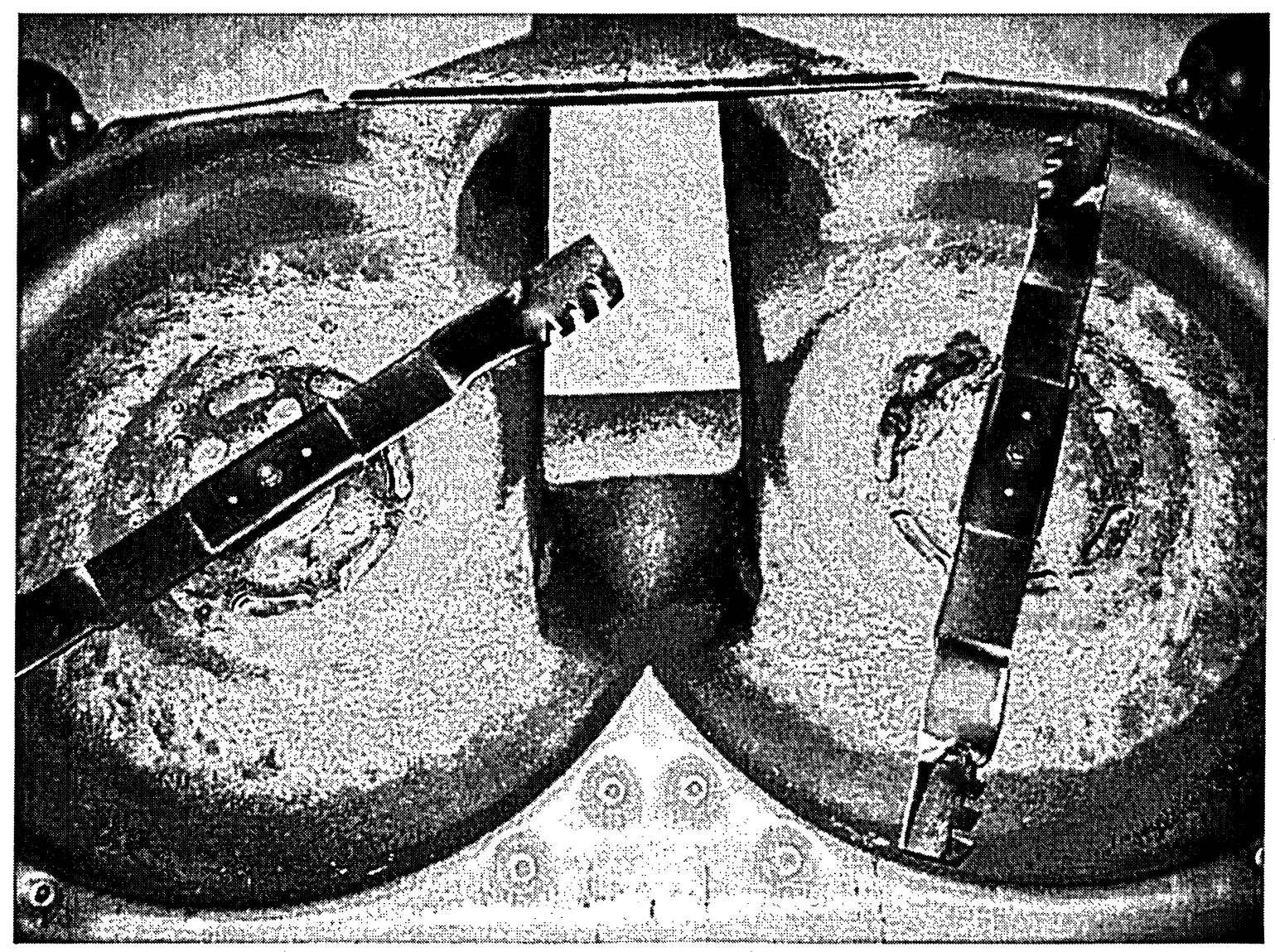

Fig. 1 Underside view of the cutting pan with counter-rotating blades

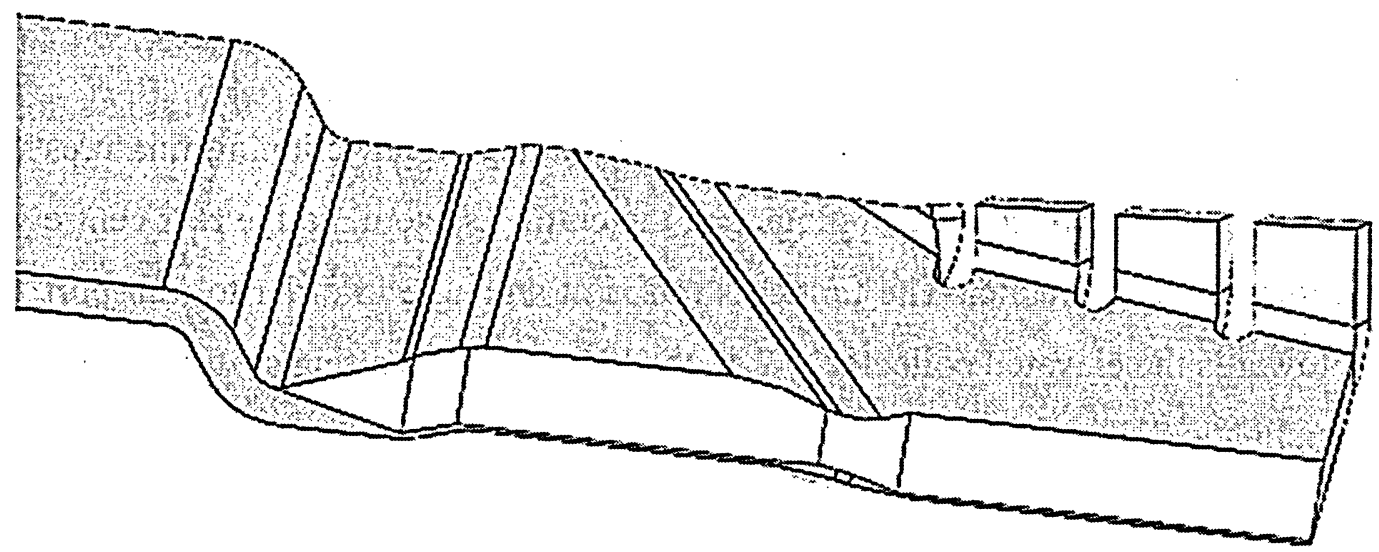

Fig. 2 Serrated blade tip 


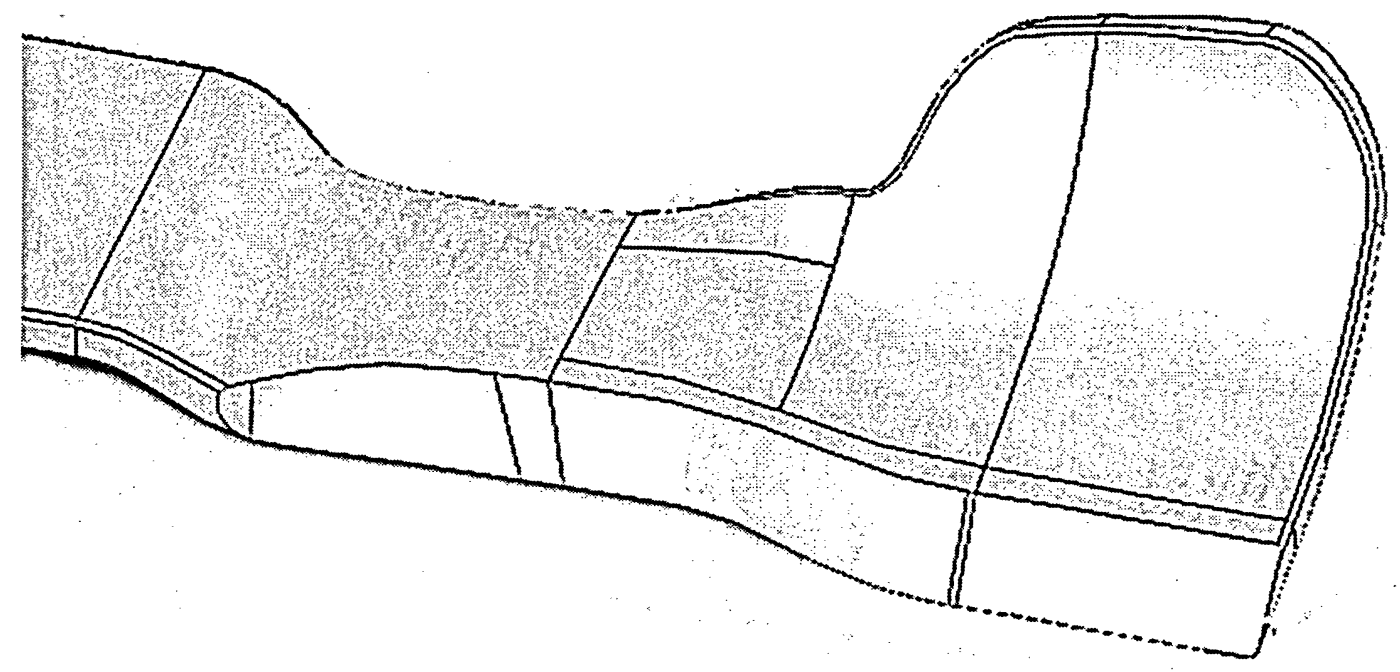

Fig. 3 Paddle blade tip

The cutting system is adjustable between 0.5-6 inches to allow for various cutting heights. The tunnel and cutting pan are connected. When the cutting pan is lowered, the angle of the tunnel is steeper. Simulations and experiments were conducted for the lowest cutting position, which is considered in the industry as the worst-case scenario for airflow and clogging problems.

\subsubsection{Conveying Tunnel}

The conveying tunnel, as part of the lawn care system, transports air-clipping mixtures from the cutting pan to the collector. Clippings exit the cutting system via the rear centre exit path and then enter the tunnel. The tunnel is raised at an angle in order to transport the clippings towards the elevated collector. When the height of the cutting system varies, this angle of inclination changes slightly.

During initial tests, it was observed that some clippings tended to build up in the tunnel about a third of the way through the tunnel. The build-up reduced airflow and led to clogging. This required that the clippings be removed manually and caused significant amount of downtime. 


\subsubsection{Collector}

The collector stores all the clippings from the tunnel. The collector is covered in perforated metal vents that allow air to escape while retaining the clippings. A hydraulicdriven mechanism is used to raise the collector and unload the clippings onto a truck for further processing.

\subsection{Objectives of Research}

The objectives of the project were to carry out a number of research activities in the area of grass-cutting blade design and functionality evaluations based on an existing twinblade rear collection cutting system.

\subsection{Literature Review}

There is no research work available in the literature on grass-cutting blade design, or airflow and vibration produced by grass-cutting blades. Aside from cutting grass, the purpose of the blades is to develop as much airflow as possible; thus, they act like fan blades. The pressure increase of the air is not as critical as the generated airflow, so the grass-cutting blades have a different purpose than compressor blades; however, some basic theory between fan and compressor blades is shared [1]. This relationship to fan and compressor blades was the basis of Chapter 3 where conventional 2-D axial blade analysis is conducted. 


\section{Chapter 2: Cutting System Flow Analysis}

\subsection{Flow Analysis Experiments on Test Rig}

\subsubsection{Experimental Test Rig Set-up}

Experiments were conducted mainly to validate the computer models. The experimental studies were performed at Ryerson using a test rig that was also designed and fabricated at Ryerson. The test rig consists of a complete cutting system supplied by GP-Turfcare. The rig includes one cutting pan with liner, two sets of blades, one conveying tunnel, one collector, one hydraulic drive motor, and a 10 -hp electric motor. The test rig is modular and allows testing of the system with and without the collector. In order to achieve the standard blade tip linear speed of $19,000 \mathrm{fpm}$ at $2,569 \mathrm{rpm}$, a belt with the required pulley ratio was added between the electric motor and the blades. The rig without the collector is pictured in Fig. 4.

The test rig was set up with the tunnel fully raised $\left(30^{\circ}\right)$ and with a $1^{\prime \prime}$ gap between the ground and the bottom of the cutting pan. Early test rig experiments did not have the collector attached in order to concentrate on the cutting pan and tunnel. The first computational models did not incorporate the collector. Testing of airflow with the collector integrated is done in the later experimental and computational models. A picture of the test rig with the collector attached can be seen in Fig. 5. Both the "serrated" and "paddle" style blades supplied by GP-Turfcare were used in the tests which did not include the collector. With the collector added, only the serrated blade was used.

The dimensions of the cutting pan are $141 \mathrm{~cm}$ by $82 \mathrm{~cm}$. The tunnel is $128 \mathrm{~cm}$ long, and has an interior width of $24 \mathrm{~cm}$. The height of the tunnel interior varies along the length of the tunnel, from $35 \mathrm{~cm}$ at the base to $28 \mathrm{~cm}$ at the top. 


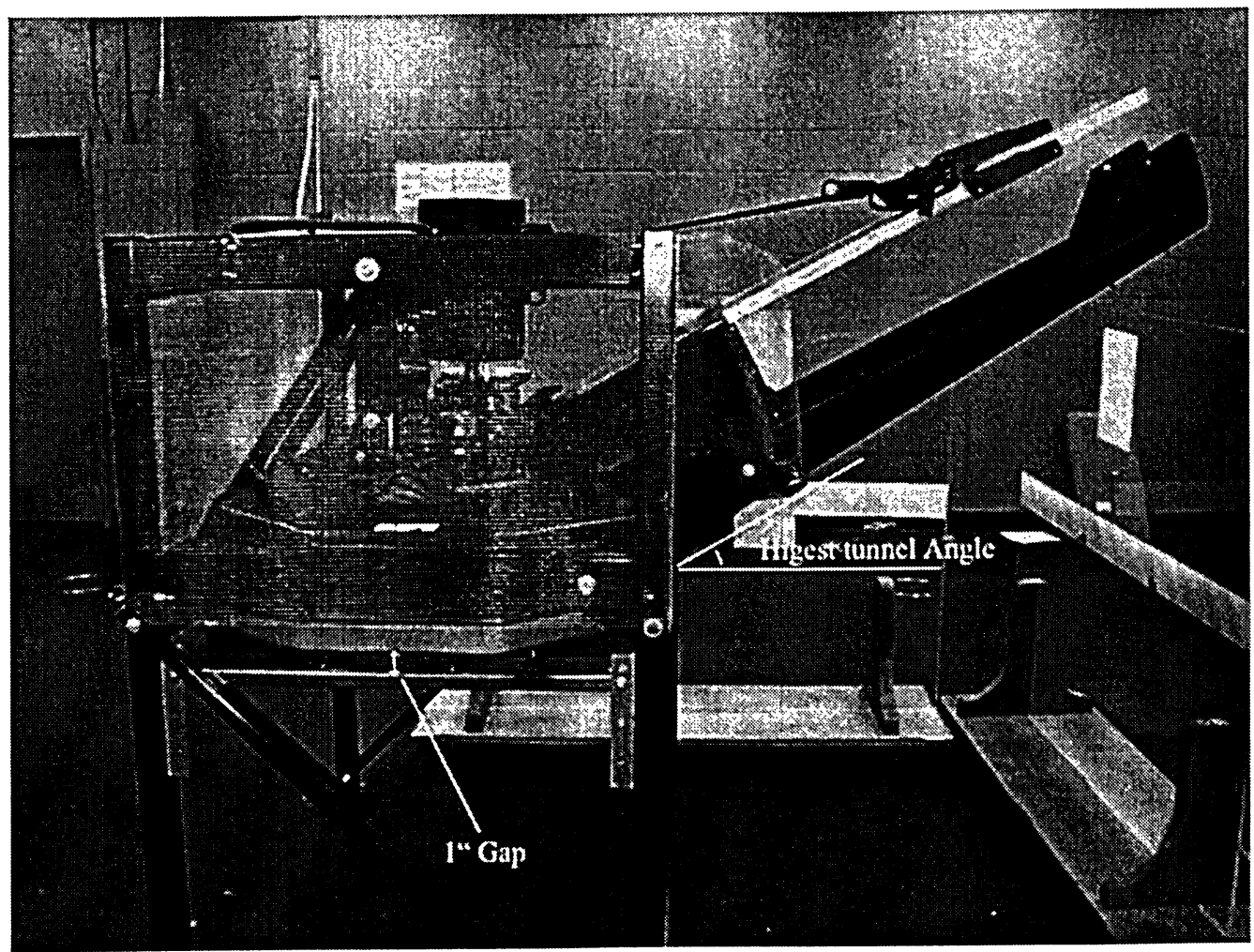

Fig. 4 Test rig setup without collector

The base of the cutting pan and blades are raised $4.5 \mathrm{ft}$ off the ground. The cutting pan is fixed to the support frame. The air inlet gap at the bottom of the pan is adjusted by moving a clear plastic sheet up and down in relation to the fixed cutting pan. This simulates the gap between the ground and the cutting pan in the lawn-care tractor. The tunnel is held in place by straps fastened to the frame. The inclination angle of the tunnel can be adjusted easily by tightening the straps. 


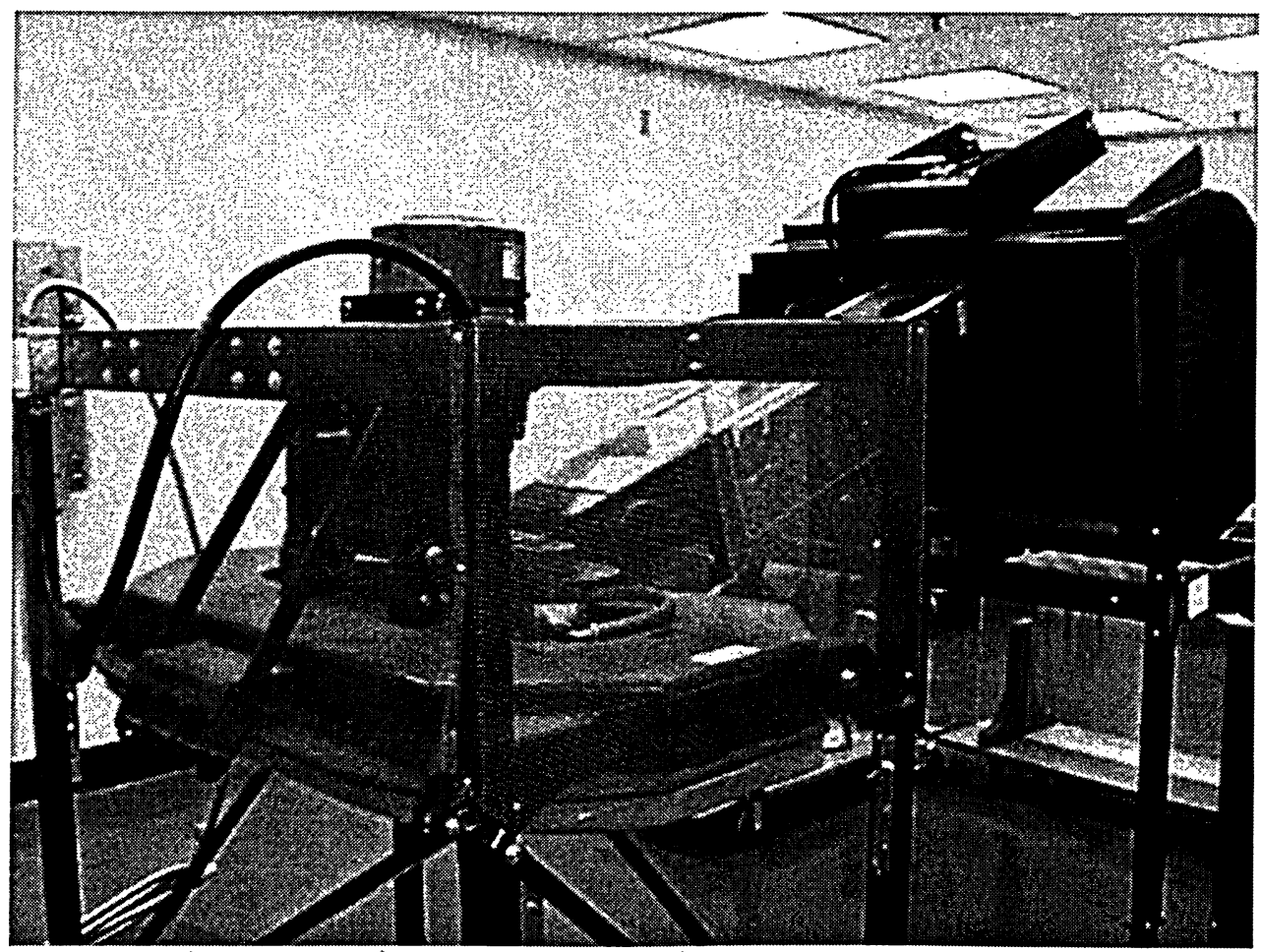

Fig. 5 Test rig setup with collector

In order to take readings inside the tunnel, holes were drilled in the plastic cover. The holes were drilled in a line that is perpendicular to the airflow so that a cross-section grid of airflow measurements could be taken. The orientation of the holes is shown in Fig. 6. The holes were covered with duct tape when not in use so as to not disrupt the airflow and change the results unnecessarily. 


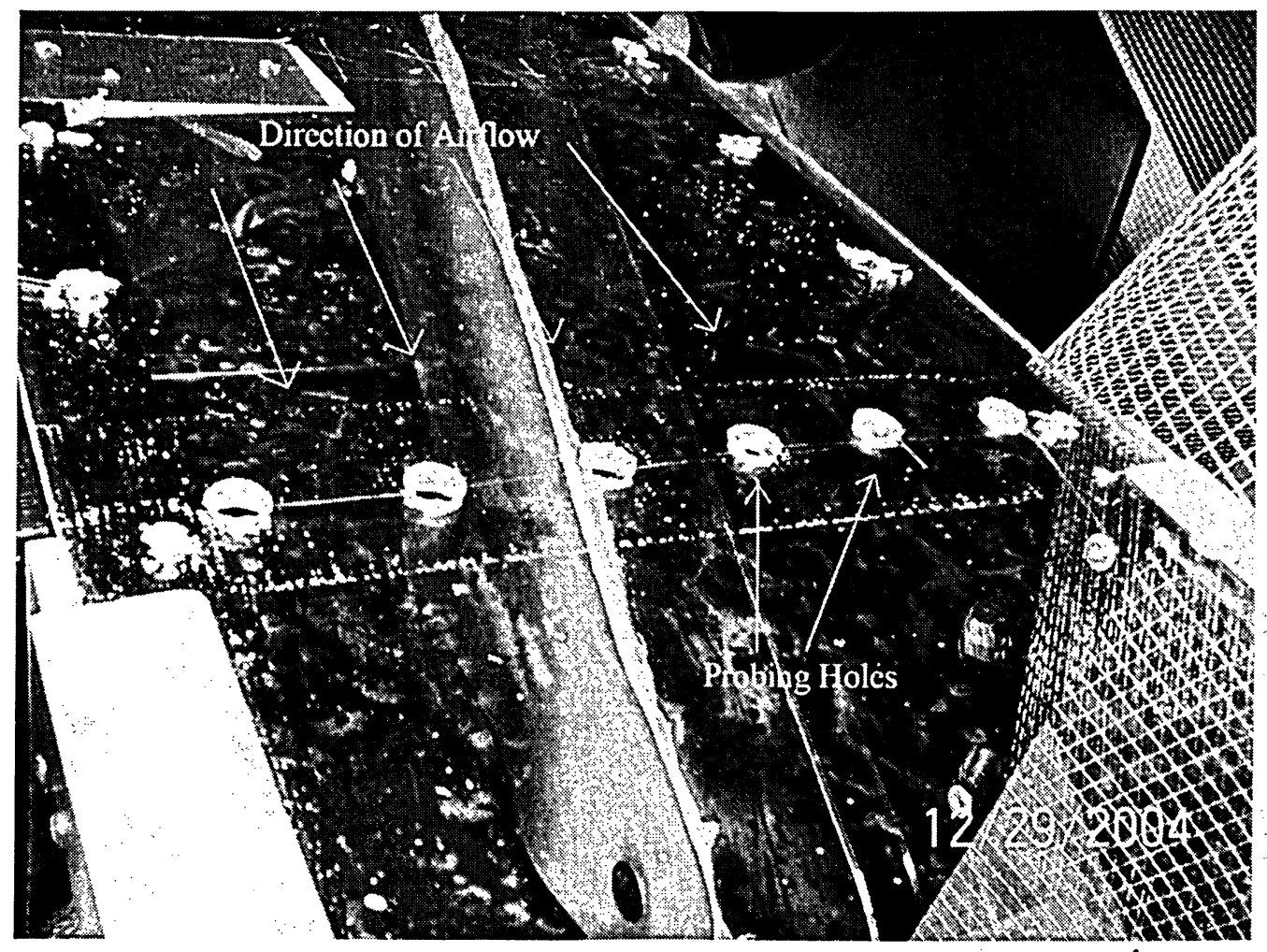

Fig. 6 Probing holes in test rig tunnel (probe inserted in third hold from the right)

Measurements were not taken from inside the cutting pan for several reasons. The main reason is that the probe must be protected from any damage. Another reason is that a large amount of turbulence was expected within the cutting pan and readings may be unreliable because the Pitot tube sensor used does not accurately measure heavily turbulent flows [2]. The Pitot tube must be aligned with the flow to obtain optimal readings. A $10^{\circ}$ misalignment with the flow may result in an error of 5\%; a $5 \%$ error should be considered in all test rig measurements.

\subsubsection{Experimental Test Rig Airflow Results (Without Collector)}

Readings were taken from the base of the tunnel where the air exits the cutting pan and the very end of the tunnel. Six readings were taken, three from an area near the blades at the base of the tunnel, and three from the end of the outlet. The readings at each location were taken in a vertical path in the centre of the tunnel. There was a high reading $(5 \mathrm{~cm}$ or 2 in from the top of the tunnel), a medium reading $(17.8 \mathrm{~cm}$ or 7 in from the top of the tunnel), and a low reading ( $28 \mathrm{~cm}$ or 11 in from the top of the tunnel). Fig. 7 shows how 
the Pitot tube sensor is positioned through the hole and its orientation with respect to the tunnel. The results of the serrated blade velocity measurements are shown in Table 1, paddle blade results are shown in Table 2.

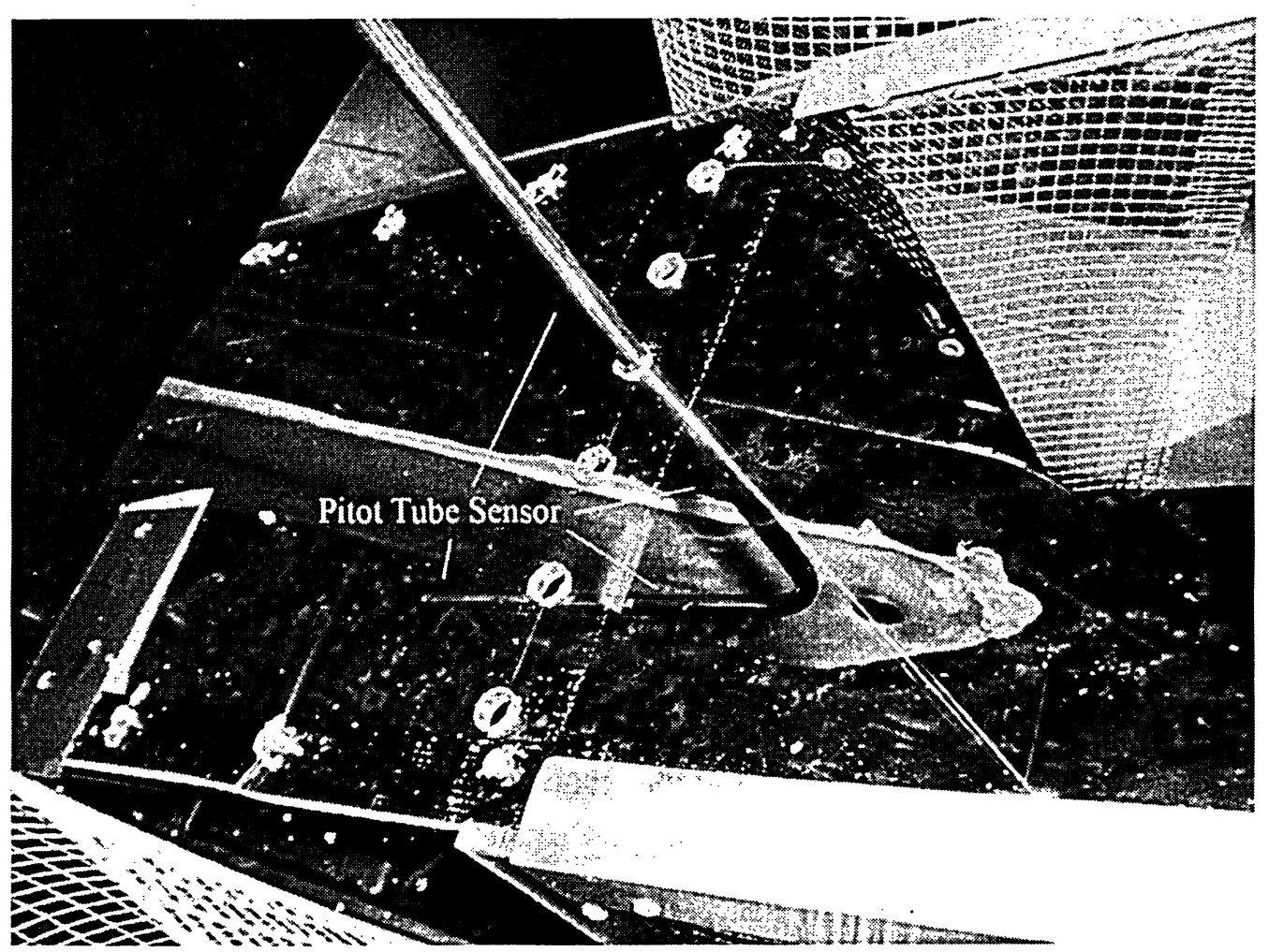

Fig. 7 Pitot tube inserted into tunnel

Table 1 Experimental Tunnel Velocity Measurements (Serrated blades, Without Collector)

\begin{tabular}{|c|c|c|}
\hline $\begin{array}{c}\text { Distance } \\
\text { From Top of } \\
\text { Tunnel, cm } \\
\text { (inch) }\end{array}$ & $\begin{array}{c}\text { Tunnel } \\
\text { Velocity Near } \\
\text { Blades, } \mathrm{m} / \mathrm{s} \\
(\mathrm{fpm}),+/-5 \%\end{array}$ & $\begin{array}{c}\text { Tunnel } \\
\text { Velocity at } \\
\text { Outlet, } \mathrm{m} / \mathrm{s} \\
(\mathrm{fpm}),+/-5 \%\end{array}$ \\
\hline $5.0(2)$ & $18(3600)$ & $12(2400)$ \\
\hline $17.8(7)$ & $15(3000)$ & $13(2500)$ \\
\hline $28.0(11)$ & $14(2800)$ & $13(2500)$ \\
\hline
\end{tabular}


Table 2 Experimental Tunnel Velocity Measurements (Paddle Blades, Without Collector)

\begin{tabular}{|c|c|c|}
\hline $\begin{array}{c}\text { Distance } \\
\text { From Top of } \\
\text { Tunnel, } \mathrm{cm} \\
\text { (inch) }\end{array}$ & $\begin{array}{c}\text { Tunnel } \\
\text { Velocity Near } \\
\text { Blades, } \mathrm{m} / \mathrm{s} \\
(\mathrm{fpm}),+/-5 \%\end{array}$ & $\begin{array}{c}\text { Tunnel } \\
\text { Velocity at } \\
\text { Outlet, } \mathrm{m} / \mathrm{s} \\
(\mathrm{fpm}),+/-5 \%\end{array}$ \\
\hline $5.0(2)$ & $14(2800)$ & $17(3400)$ \\
\hline $17.8(7)$ & $16(3200)$ & $21(4200)$ \\
\hline $28.0(11)$ & $20(4000)$ & $19(3800)$ \\
\hline
\end{tabular}

\subsubsection{Experimental Test Rig Airflow Results (With Collector)}

In this experiment, the complete test rig assembly was used, which includes the collector, cutting pan, and tunnel. Velocity measurements using a Pitot tube were recorded at three points within the tunnel as well as at numerous points around the vents on the collector.

The measurements of the tunnel flow velocity are presented in Table 3. The speeds with the Pitot tube measuring the flow moving parallel to the tunnel direction. Measurements were again taken at $5.0 \mathrm{~cm} \mathrm{(2} \mathrm{in),} 17.8 \mathrm{~cm}$ (7. in), and $28 \mathrm{~cm}$ (11 in) inches from the top of the tunnel. The velocities showed a trend of decreasing in magnitude from top to bottom in the experiment.

The experimental velocities found in the tunnel with the collector were nearly the same as those found in the system that did not have the collector. This is because the collector is very well ventilated and air appears to be moving freely out of it. 
Table 3 Experimental Tunnel Velocity Measurements (With Collector)

\begin{tabular}{|c|c|}
\hline $\begin{array}{c}\text { Distance From Top of Tunnel, } \\
\mathrm{cm} \text { (inch) }\end{array}$ & $\begin{array}{c}\text { Tunnel Velocity Near Blades, } \\
\mathrm{m} / \mathrm{s}(\mathrm{fpm}),+/-5 \%\end{array}$ \\
\hline $5.0(2)$ & $18.5(3700)$ \\
\hline $17.8(7)$ & $15(3000)$ \\
\hline $28.0(11)$ & $14(2800)$ \\
\hline
\end{tabular}

\subsubsection{Collector Outlet Velocity Readings (All Vents Open)}

This section deals with the airflow velocity through the outlet vents that surround the collector. The vents that are measured are shown in Fig. 8. The specific locations on the collector are illustrated on the computer model of the collector in Fig. 9. Due to symmetry, only one side of the collector velocities are documented, the other side has mirrored values.

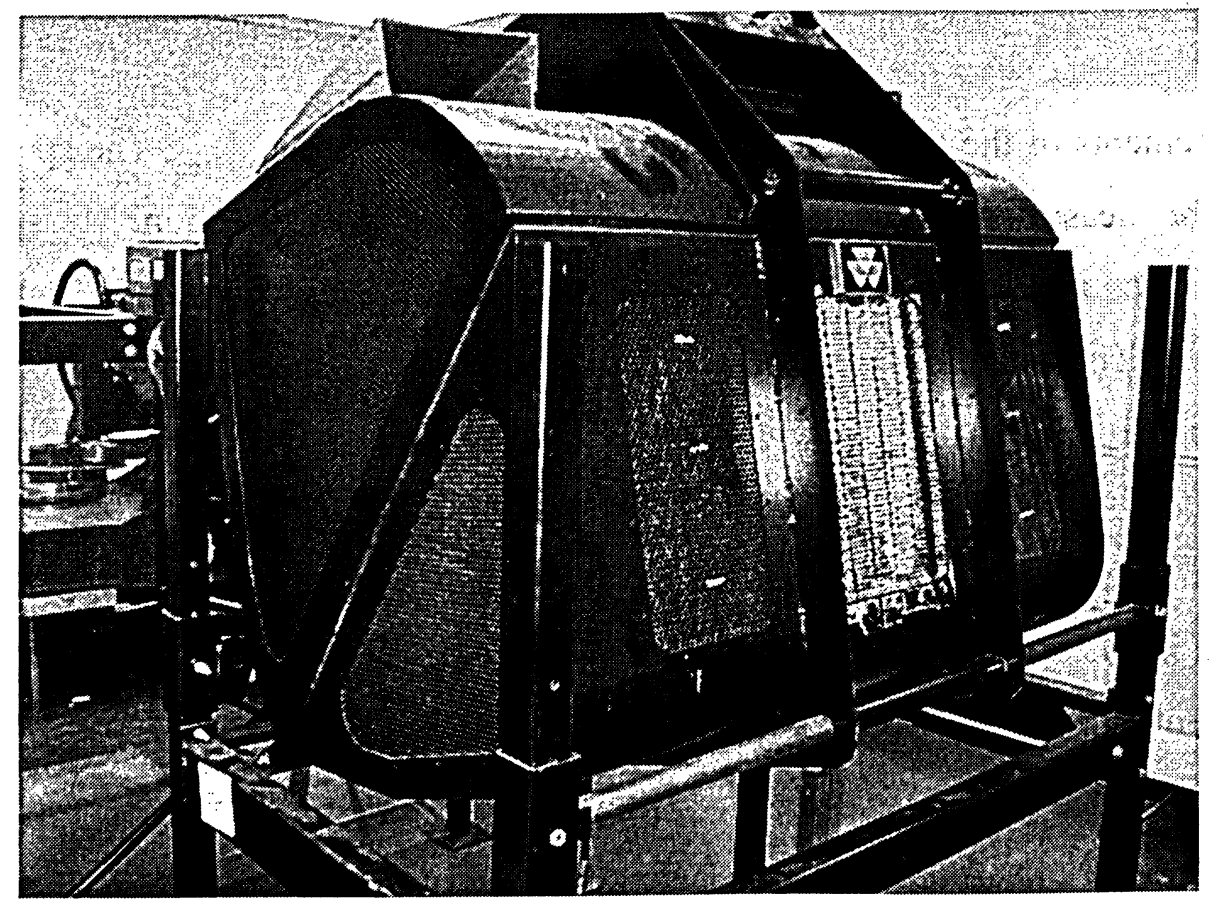

Fig. 8 Collector mounted on test rig 


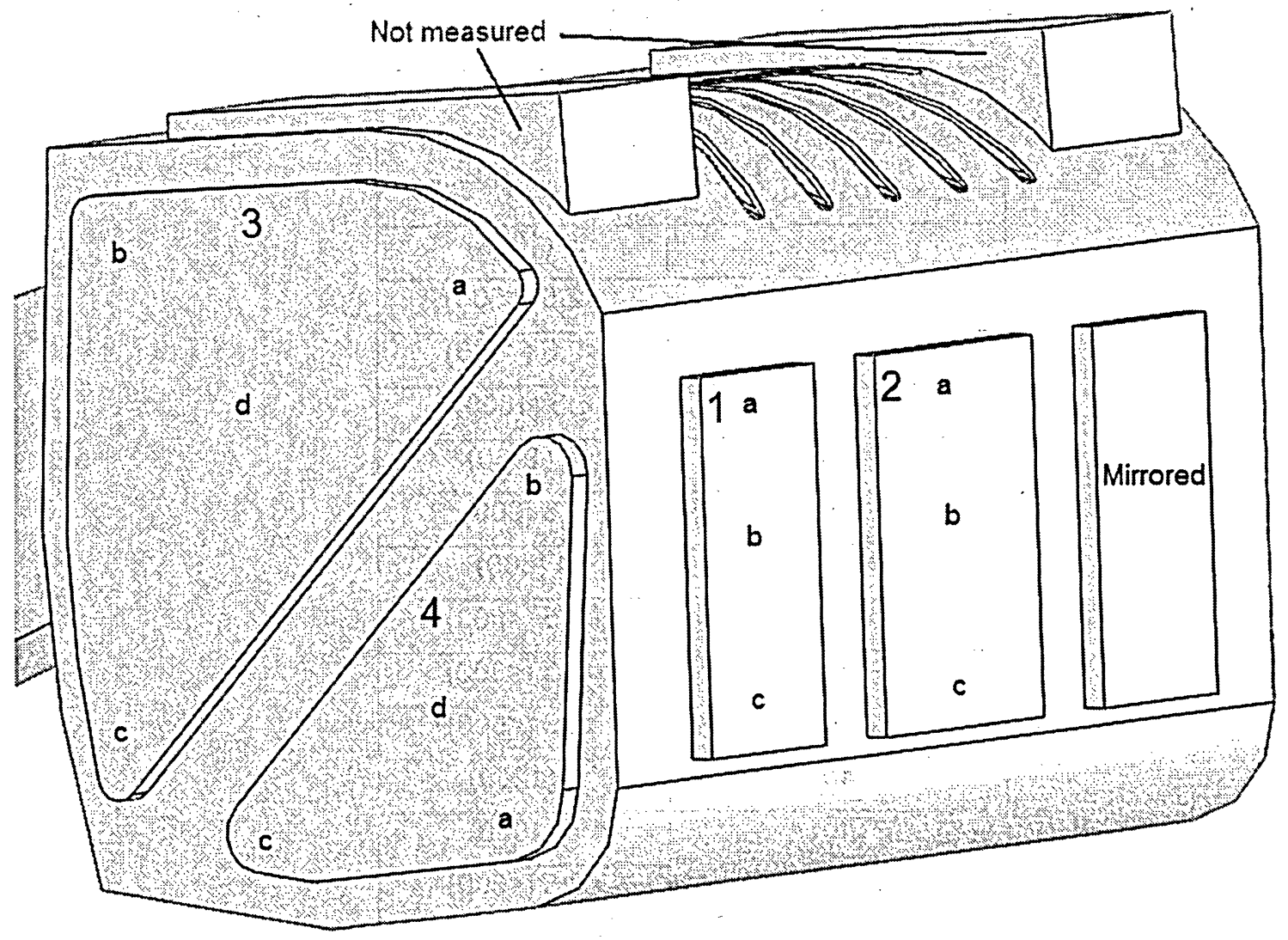

Fig. 9 Velocity measurement locations on collector

It is important to note that the vents on the top side of the collector were not measured because deflectors were added to the test rig that prevented the Pitot tube from getting into position. However, the majority of the vent surfaces remained to be measured for purposes of validation.

The air velocity through the vents is listed in Table 4. Vent points 1a and $2 \mathrm{a}$ were taken 5 $\mathrm{cm}$ from the top of the vent, $1 \mathrm{~b}$ and $2 \mathrm{~b}$ were taken $18 \mathrm{~cm}$ from the top of the vent, and $1 \mathrm{c}$ and $2 \mathrm{c}$ were taken $33 \mathrm{~cm}$ from the top of the vent. $3 \mathrm{a}, 3 \mathrm{~b}$, and $3 \mathrm{c}$ were all measured 7.5 $\mathrm{cm}$ in from the corners and $3 \mathrm{~d}$ was taken in the centre of vent $3.4 \mathrm{a}, 4 \mathrm{~b}$, and $4 \mathrm{c}$ were $5 \mathrm{~cm}$ in from the corners and $4 \mathrm{~d}$ was located in the centre of vent 4.

Any value in Table 4 that is listed as " $<2.5(<500)$ " indicates an estimate. The Pitot tube, designed for high speed airflow applications, has scales starting from $500 \mathrm{fpm}$. 
Table 4 Experimental Velocities through Collector Vents with All Vents Open

\begin{tabular}{|c|c|}
\hline $\begin{array}{c}\text { Collector Vent } \\
\text { Position }\end{array}$ & $\begin{array}{c}\text { Vent Velocity, m/s } \\
\text { (fpm) },+/-5 \%\end{array}$ \\
\hline $1 \mathrm{a}$ & $5(1000)$ \\
\hline $1 \mathrm{~b}$ & $<2.5(<500)$ \\
\hline $1 \mathrm{c}$ & $<2.5(<500)$ \\
\hline $2 \mathrm{a}$ & $6.5(1300)$ \\
\hline $2 \mathrm{~b}$ & $5(1000)$ \\
\hline $2 \mathrm{c}$ & $4.5(900)$ \\
\hline $3 \mathrm{a}$ & $4(800)$ \\
\hline $3 \mathrm{~b}$ & $<2.5(<500)$ \\
\hline $3 \mathrm{c}$ & $<2.5(<500)$ \\
\hline $3 \mathrm{~d}$ & $<2.5(<500)$ \\
\hline $4 \mathrm{a}$ & $6(1200)$ \\
\hline $4 \mathrm{~b}$ & $5(1000)$ \\
\hline $4 \mathrm{c}$ & $<2.5(<500)$ \\
\hline $4 \mathrm{~d}$ & $<2.5(<500)$ \\
\hline
\end{tabular}

The flow through the collector vents seemed to pulse very rapidly and provided a "jittery" feel, which made it more difficult to measure. This rapid unsteadiness in magnitude affected the accuracy of the sensor measurements. The directions of air velocity at various points in the experimental readings are the same as the directions of air velocity in the computer model results in section 2.2 .9 .

\subsubsection{Collector Outlet Velocity Readings (Centre Rear Vent Closed)}

It was observed in the computational results (which will be discussed in section 2.2) that much of the air escaped the collector very quickly via the rear centre vent. It has been reported by GP-Turfcare that the collector does not fill to capacity before clogging problems arise. The rear centre vent on the collector was covered to study its effects. This was done in order to validate the computer model that had the vent closed. The computer model pictured in Fig. 10 details the vent positions and the vent that was closed. 


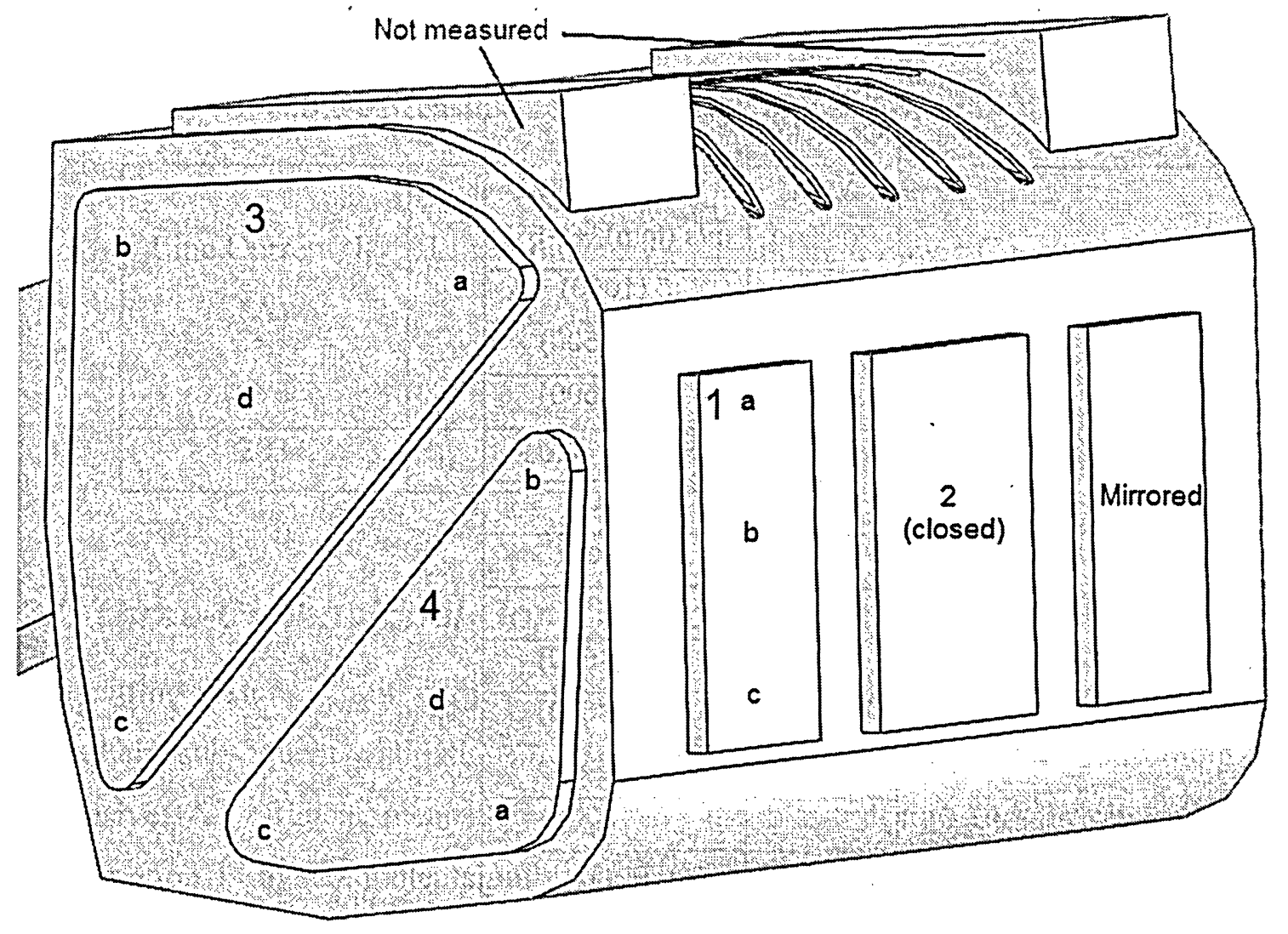

Fig. 10 Velocity measurement locations on collector (centre vent closed)

The results of the velocity measurements are tabulated in Table 5. The closing of the rear vent did not dramatically affect the flow velocity out of the collector vent locations that were measured. The only location with a significant change was $3 \mathrm{a}$, where the outlet flow velocity increased by $1 \mathrm{~m} / \mathrm{s}$, or $25 \%$. 


\begin{tabular}{|c|c|}
\hline $\begin{array}{c}\text { Collector } \\
\text { Vent } \\
\text { Position }\end{array}$ & $\begin{array}{c}\text { Vent Velocity, } \\
\mathrm{m} / \mathrm{s}(\mathrm{fpm}),+/-5 \%\end{array}$ \\
\hline $1 \mathrm{a}$ & $5(1000)$ \\
\hline $1 \mathrm{~b}$ & $<2.5(<500)$ \\
\hline $1 \mathrm{c}$ & $<2.5(<500)$ \\
\hline $2 \mathrm{a}$ & Closed \\
\hline $2 \mathrm{~b}$ & Closed \\
\hline $2 \mathrm{c}$ & Closed \\
\hline $3 a$ & $5(1000)$ \\
\hline $3 \mathrm{~b}$ & $<2.5(<500)$ \\
\hline $3 \mathrm{c}$ & $<2.5(<500)$ \\
\hline $3 \mathrm{~d}$ & $<2.5(<500)$ \\
\hline $4 \mathrm{a}$ & $6(1200)$ \\
\hline $4 \mathrm{~b}$ & $4.5(900)$ \\
\hline $4 \mathrm{c}$ & $<2.5(<500)$ \\
\hline $4 \mathrm{~d}$ & $<2.5(<500)$ \\
\hline
\end{tabular}

\subsubsection{Experimental Test Rig Power Consumption (With Collector)}

The power consumption of the test rig (with collector and serrated blades) was determined by measuring the voltage and current in the three-phase wires that were external to the three-phase, $10 \mathrm{hp}$ motor. The measured voltage and current were $203 \mathrm{~V}$ and 16.5 A, respectively, in each phase wire. The apparent power calculation for a threephase motor was obtained from [3].

The electric motor consumes $7.8 \mathrm{hp}$ when the blades rotate at $2560 \mathrm{rpm}$. The blade speed reduction from $3500 \mathrm{rpm}$ to $2560 \mathrm{rpm}$ is achieved in the experimental through a belt drive. The $7.8 \mathrm{hp}$ measurement takes into account all the inefficiencies of the system which include the electric motor, hydraulic drive, belts, bearings, etc., since the power was measured at the wall before the rig's systems. The actual power required to spin the blades alone is less than $7.8 \mathrm{hp}$. 
Table 6 Measurements of Motor Power Consumption

\begin{tabular}{|c|c|c|}
\hline $\begin{array}{c}\text { Line Current, } \mathrm{I}_{\mathrm{L}} \\
\text { (A) }\end{array}$ & $\begin{array}{c}\text { Line Voltage, } \mathrm{V}_{\mathrm{L}} \\
\text { (V) }\end{array}$ & $\begin{array}{l}\text { Apparent Power Consumption } \\
\begin{array}{l}\text { (W) } \quad \text { (HP) } \\
P=\sqrt{3} \cdot V_{L} \cdot I_{L}\end{array}\end{array}$ \\
\hline 203 & 16.5 & 5801.5 \\
\hline
\end{tabular}

\subsection{Three-Dimensional Computational Flow Analysis}

The cutting system is quite large and complex. Implementations of design modifications and their subsequent validations experimentally can be very time consuming and expensive. An efficient means of evaluating the blade design for airflow and power consumption is by computer simulation. The software tool used in carrying out the computations of the airflow generated by a pair of counter-rotating blades is Fluent, a commercially available computational fluid dynamics (CFD) software package. In order for the computer simulation results to be acceptable to the industry, the computer models must be validated against experimental data for a typical setup and a typical operating condition.

A typical application of Computational Fluid Dynamics (CFD) is to simulate how air flows through or around a given shape or complex geometry. It is necessary to set proper boundary conditions at the inlet and the outlet where the system of immediate interest interacts with its surrounding systems, which are not part of the computer model. Common boundary conditions include specified mass flow, velocity or pressure differential. In the case of lawn mowers, both the inlet and outlet are exposed to the atmosphere, which is the basis for applying $0 \mathrm{~Pa}$ gauge pressure at the inlet and outlet. The airflow is driven from the inlet (the gap between cutting pan rim and the ground) to the outlet (the vents and the escape holes on the collector) by a pair of counter-rotating blades inside the cutting chamber. 
To model the airflow in the lawn care system, two additional pieces of software are required - Gambit and Solidworks. The capabilities and purposes of the three commercially available programs are described briefly below.

Solidworks is a 3-D modeling software package, which can create complex geometries (e.g., cutting blades, cutting pan, tunnel, etc.). These geometries can then be exported as an IGES file that can later be used in the other two programs.

Gambit is a pre-processor to Fluent, which is required to mesh the geometry (composed of vertices, edges, faces, and volumes). Gambit can be used to define the boundary conditions, solids, and fluid continuum within a model. It can also be used to clean up the raw geometry data that is imported from Solidworks (in IGES format). It can smooth unnecessarily complex faces and edges that would have negligible impact on the final solution. However, if unchanged, the raw geometry could restrict the formation of the mesh.

Fluent is a CFD solver for 2-D and 3-D flow problems of complex systems. Prior to solving the system, Fluent configures the parameters of a system, such as the type of solver (2-D or 3-D, segregated or coupled equations, time dependence or independence), viscous parameters (inviscid, laminar, turbulent), materials, and boundary conditions (pressure, rotation, symmetry, etc.).

\subsubsection{Capabilities of the Software}

In order to evaluate the capabilities of the software for the intended applications, an existing 2-D centrifugal blower model was obtained from [4]. Fig. 11 shows the blower with all of its key components labeled. The blower fins rotate and force air to flow from the inlet to the outlet. The inlet is a pressure inlet; the outlet is a pressure outlet. This means that the inlet and outlet each can be set to any specific values of (gauge) pressures. With no fin rotation, air flows from areas of high pressure to areas of lower pressure. 
The fins of the centrifugal blower were then set to rotate counter clockwise at $100 \mathrm{rad} / \mathrm{s}$. The inlet was set to $0 \mathrm{~Pa}$, and the outlet was set to $0 \mathrm{~Pa}$. The Fluent simulation results verify that the rotating fins indeed created the airflow within the system without any inlet-outlet pressure differential. The velocity vectors of the airflow induced by the rotating fins are shown in Fig. 13.

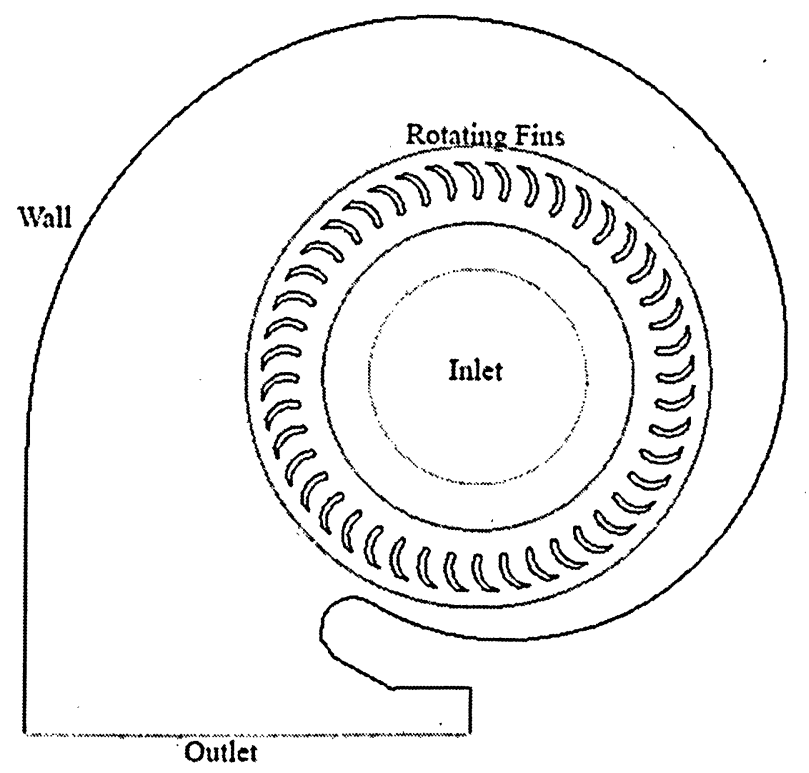

Fig. 11 2-D computer model of centrifugal blower [4] 


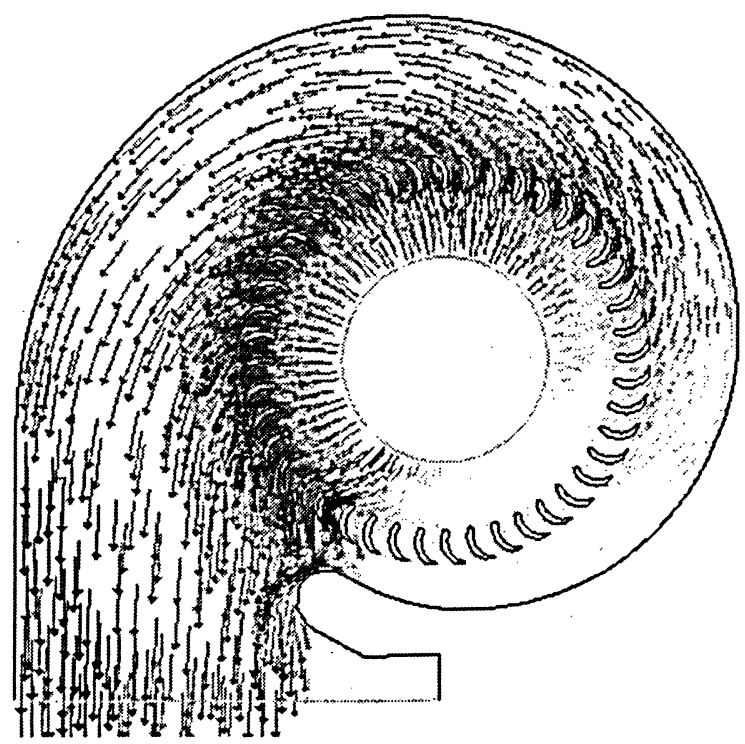

Fig. 12 Velocity vectors inside a 2-D blower with no blade rotation and $200 \mathrm{~Pa}$ inletoutlet pressure difference

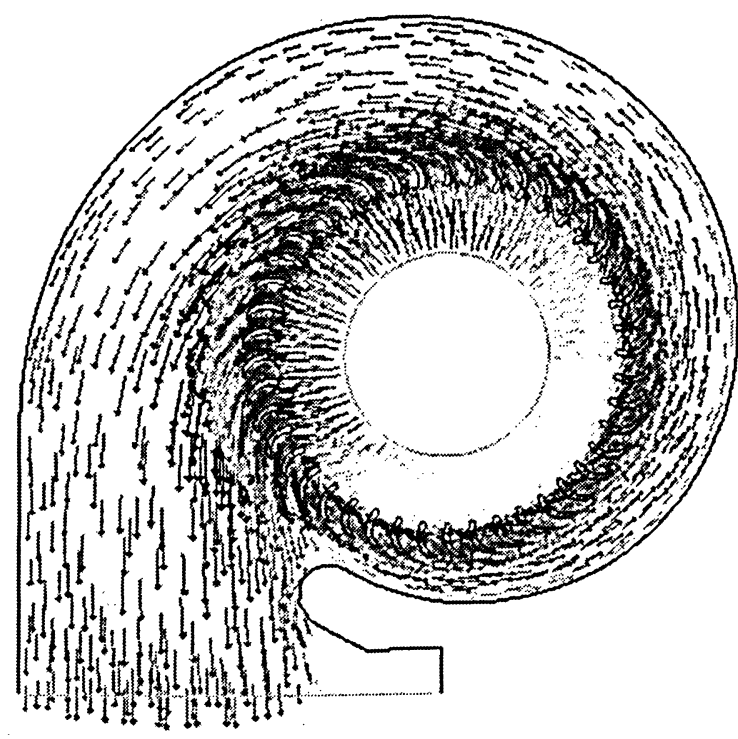

Fig. 13 Velocity vectors inside 2-D blower with $100 \mathrm{rad} / \mathrm{s}$ blade rotation and zero inletoutlet pressure difference

These results provided confidence that Fluent could be used to model airflow that is developed entirely by rotating blades. 
After much research and experimentation, the capabilities of the programs become apparent for flow studies in the lawn care system. The following summarizes the modeling process:

- Model complex geometry with Solidworks or other solid modelers

- Import geometry in IGES format into the Gambit preprocessor

- Modify geometry

- Create and link individual volumes

- Mesh resulting volumes

- Define boundary conditions and continuum types

- Configure Fluent

- Solve

- Post-process numerical results

\subsubsection{Single Blade Model}

The major difficulty in modeling the real lawn care system is that it has two counterrotating blades whose swept volumes or paths overlap, as shown in Fig. 14. It is not possible to model this overlap with the most current version of Gambit/Fluent in 3D flow simulations. The difficulties lie in the fact that each rotating blade requires a unique surrounding rotating volume in Gambit/Fluent called a Multiple Reference Frame (MRF), which increases solution stability. These volumes, if introduced, would end up overlapping in space and violate the uniqueness requirement of all rotating volumes by Fluent in a model. The mesh of each individual volume would overlap the same space; the nodes would not interact or connect with one-another, thus making the results in that region inaccurate.

The initial solution to this problem was to only model one blade and half the cutting pan and tunnel. A "symmetry" boundary condition would then be used to simulate the twinblade flow. The symmetry boundary condition is a special kind of wall that will mirror any effects on the wall to the other side. This technique is often used to simplify models. It is realized that there would be interaction in the real system between the two blades as one blade passes through the wake of the other. The results will therefore vary more in 
the region of the blade. The expectation was that the blade interaction effects would not be apparent in the end sections of the tunnel, where readings would be taken. This model was created without a collector, so results should match the early test rig experiments without the collector.

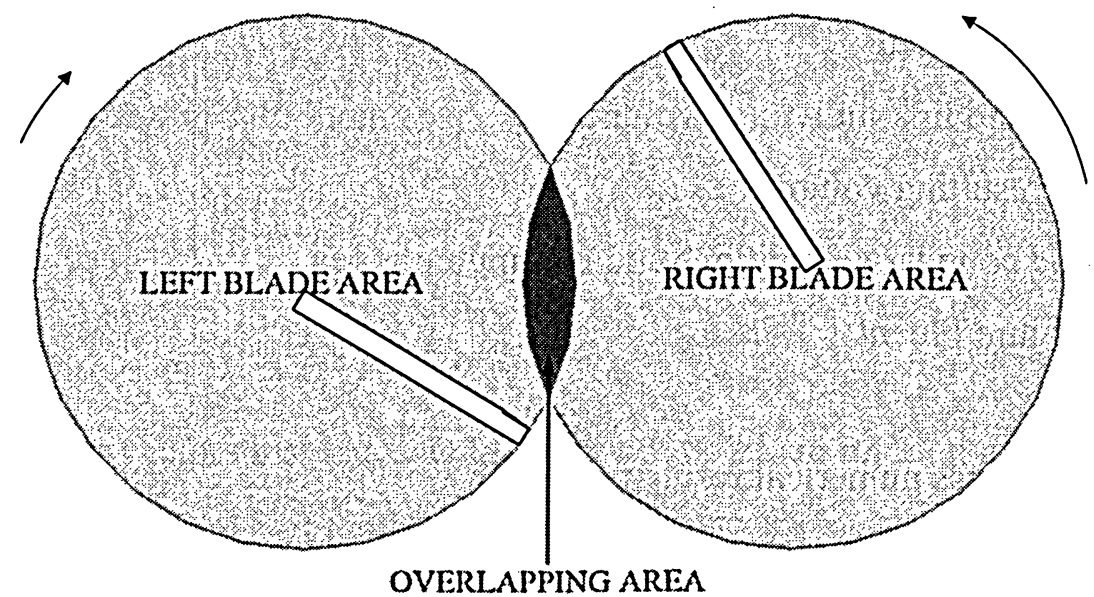

Fig. 14 Overlapping area between the two cutting blades

The issue with the single blade model was that the blade would rotate and extend beyond the symmetry plane. Therefore, it was necessary to make an assumption of how the cutting chamber edge would extend beyond the symmetry plane so that the airflow would not disrupt the bulk of the flow.

The geometry of the cutting system created in Solidworks should accurately represent the volume of space in which fluid flows. The solid geometry created in the single blade model represents only half of the cutting pan and tunnel. Thus, the symmetry boundary condition could be applied. A deficiency of this model is that the blade rotates and crosses over the midplane of the cutting chamber. This problem was resolved by slightly extending the helical shape of the cutting pan to enclose the blade's rotation. The main design point would be to allow air to flow over the midplane with minimal disruption of the overall flow. A picture of the model in Solidworks is shown in Fig. 15. 


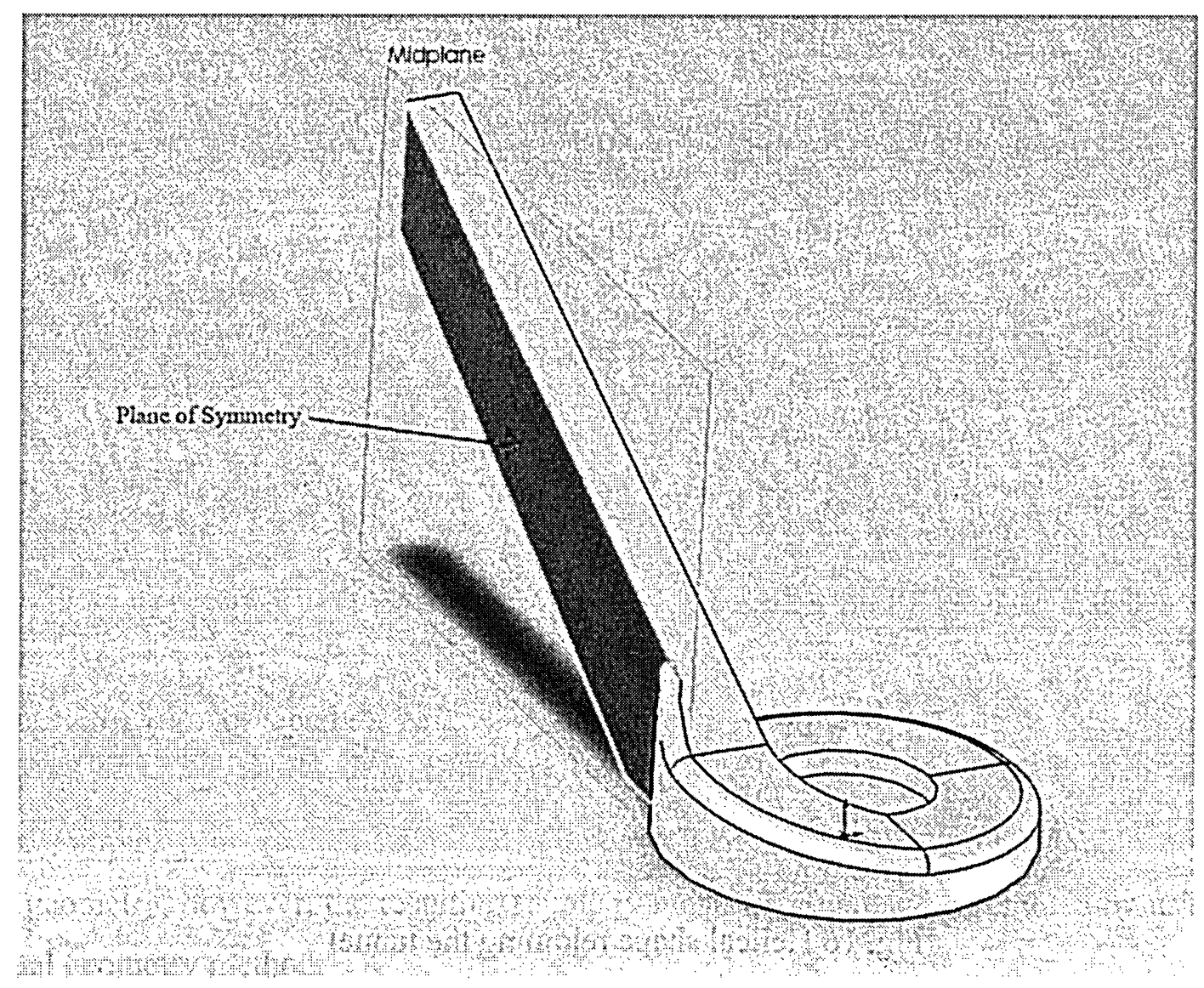

Fig. 15 Model of single blade flow space with plane of symmetry

The interior sections of the cutting pan contained a molded liner that helps redirect the airflow. A computer model of this liner was not available therefore measurements were taken by hand from the test rig. The height of the top of the cutting pan liner increased in an upwards-helical fashion, clockwise. The measurements taken were used in creating the helical shape needed. The portions of the solid that extended beyond the midplane were modeled so that they simply continued the helical shape clockwise until it rejoined with the tunnel. Fig. 16 shows the estimated cutting pan extension rejoining the tunnel. The outer edges of the tunnel were filleted to a radius that closely matched the test rig (3.8 $\mathrm{cm})$. 


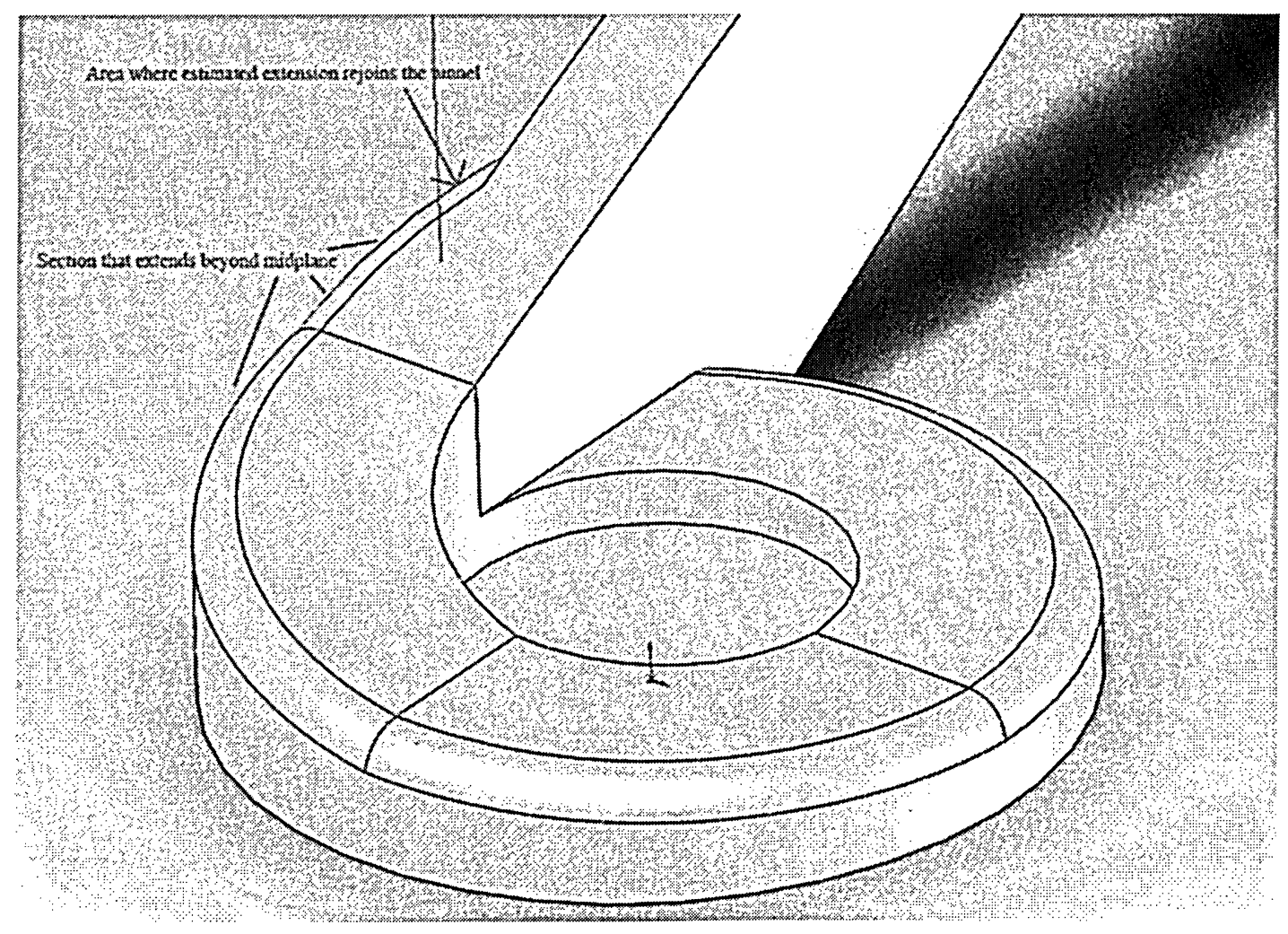

Fig. 16 Helical shape rejoining the tunnel

The overall shape and angle of the tunnel (with respect to the cutting pan) was governed by how the orientation of the system was defined earlier (1" inlet gap and tunnel fully raised). The width of the tunnel is half that of the tunnel used on the test rig because of the symmetry boundary. Use of different cutting pan heights in future models changes the solid so that the shape and angle of the tunnel will correspond with the specific situation.

Once the model was created, it was then exported as an IGES file. The IGES files were imported into GAMBIT but were still very raw, so some treatment was required. The IGES files are read into Gambit as a series of vertices, edges, and faces. Each face had its own set of edges and vertices with some edges overlapping. Some edges and vertices which existed in the exact same space with the same orientation but had different names and would create problems later and therefore needed to be connected. Connecting edges and vertices results in combining the overlapping edges and vertices together into a single new edge (or vertex) that would be part of all the faces (or edges) it was connected to. 
Another issue was that some edges and faces were very small; in later steps they would unnecessarily restrict the meshing process and cause problems. Therefore, it was necessary to merge the faces to form new, larger virtual faces. In Gambit there are two kinds of geometry: real and virtual. Real geometry comes from the original 3D model and is defined through equations that yield the desired shapes. Real geometry can undergo Boolean operations and simple modifications because the mathematics used to define the shapes can be combined or superimposed. Virtual geometry is different, however, because it is defined by distinctly mapped vertices and edges connected together. Virtual geometry cannot undergo Boolean operations due to the fact there are no mathematical definitions for them [4]. The only means to create higher virtual topology, or virtual volumes, is to define all the faces of the volume. All faces must have their edges connected, with no gaps between faces, or faces that cut the volume in half (i.e., define the same volume on both side of the face). Creating volumes with virtual geometry is a more complex process than using real geometry. Virtual geometry can be combined with real geometry; however, the resulting topology must be virtual and assembled by using a virtual geometry method.

Below is an overview of Gambit topology and geometry:

- Types of topology: vertex < edge < face < volume

(Edges are made of vertices, faces are made of edges, and volumes are made of faces)

- Combinations of geometry: real + real $=$ real (Boolean)

$$
\begin{aligned}
& \text { real }+ \text { real = virtual (merging geometry) } \\
& \text { real }+ \text { virtual }=\text { virtual } \\
& \text { virtual }+ \text { virtual }=\text { virtual }
\end{aligned}
$$

Once the models are cleaned up, it is possible to manipulate the resulting geometry so that simple shapes or holes can be added. The extra 1" gap needed for the inlet air was created at this step. Only the 1 " face was to be defined as the inlet and it is flush with the adjoining face. It is difficult to create individual faces that connect to each other smoothly in Solidworks because the software tends to merge them together. To create this 1 " inlet 
face in Gambit, the bottom face was translated 1" down and edges were added to connect the vertices. New faces were constructed out of these edges on the sides. The final $1^{\prime \prime}$ inlet gap is show in Fig. 17.

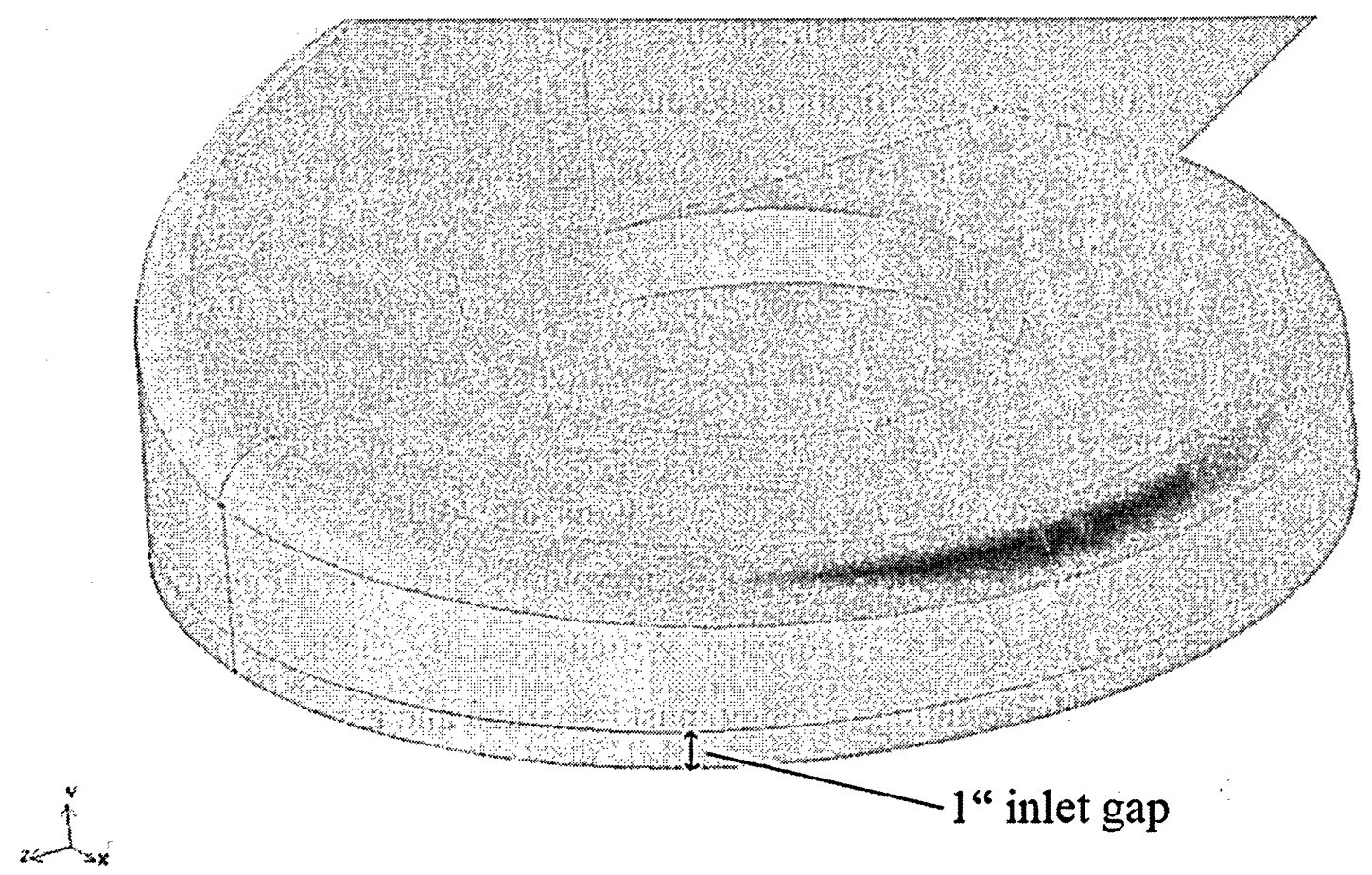

Fig. 17 Inlet gap around the base of the cutting pan

A similar technique is used later in the twin-blade models to add extra intake holes on the top in accordance with the original design.

It is possible to directly assign a velocity to a specific part, such as the blade. Large pressure gradients are created between the nodes on the moving part and the nodes in the adjacent space. This large gradient causes instability in the solution stage and prevents convergence. The instability was caused by the high degree of coupling between the momentum equations when the influence of a rotational or translational term is large and convection dominates the flow. The high velocity of the blades causes a large pressure gradient, which drives a flow away from the blades [5]. A scheme, called Multiple Reference Frame (MRF), can be used to remedy this problem. The MRF creates a local reference frame that has the same velocity as the moving components, or zero velocity 
relative to the moving blades. In the model, there are two reference frames, one rotating (the MRF) and one stationary (original). The MRF enhances the solution stability and improves the convergence. The MRF is approximate and valid only for steady-state applications. The MRF can be considered to provide a reasonable model of the timeaveraged flow for an application [5].

In order to use the MRF later in Fluent, definition of two separate fluid volumes is needed: a stationary volume and a rotating volume. The stationary volume begins as the total volume of the cutting pan and tunnel. This volume is created by forming a virtual volume from all virtual faces that encompass the volume area. The geometry of the stationary volume is shown in Fig. 18.

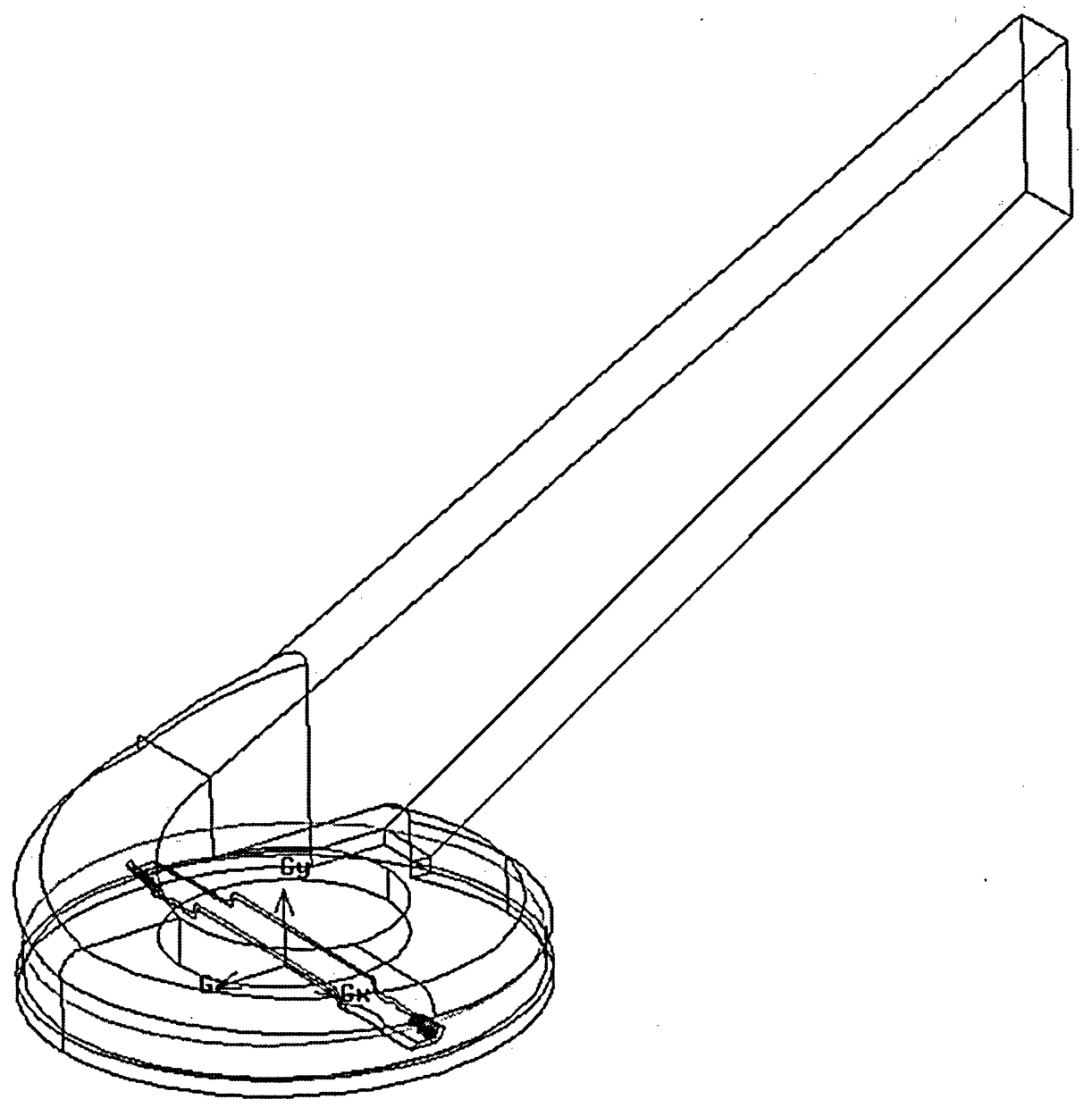

Fig. 18 Stationary volume with blade inside 
The blade model is the entity that is rotating and will need to be surrounded tightly by a rotating MRF volume and enclosed by the stationary volume. All nodes within the rotating volume will be close to the blade since the rotating volume tightly surrounds the blade. The boundary between the rotating volume and the stationary volume must be coupled together in order for the solver to work (i.e., they must share the same outer/inner faces). The rotating volume is created inside the stationary volume by creating a simple cylinder. The cylinder encloses the path that the blade will rotate within. The walls of the rotating volume come close to the edge of the blade but do not touch it. The walls of the three volumes are shown in Fig. 19.

At this point in the process, the rotating volume and the stationary volume overlap the same space. They must be separated from each other. To accomplish this, the rotating volume must be subtracted from the stationary volume. This process would be very easy using Boolean volume subtraction if both volumes were real; however, the stationary volume is virtual and Boolean functions cannot be used.

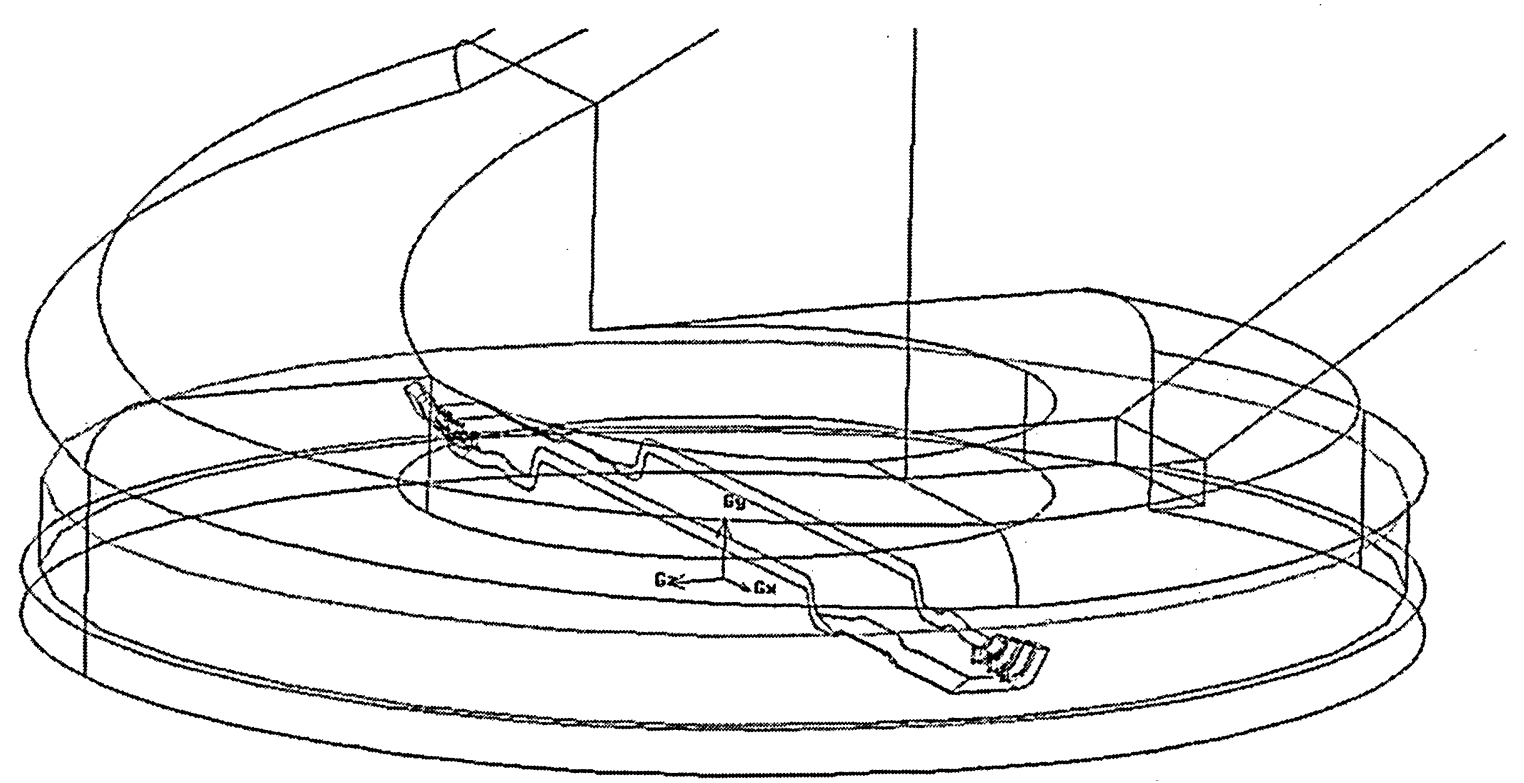

Fig. 19 Rotational MRF volume closely surrounding the blade 
In order to create a virtual volume from a set of faces, all faces must be connected to the others. The hollow core could not be created because the inner faces would not touch the outer faces. A solution, very similar to how casting is performed with a core, was developed to accomplish the task. The method involves creating a top-half volume by using the upper faces of the stationary volume and upper faces of the rotating volume cylinder (which acts as the core), and creating a lower-half of the volume using the lower faces of both the stationary volume and rotating volume. Extra faces are needed to complete the upper and lower half volumes. This requires that some edges be split so that the resulting vertices can be used to make orthogonal edges, and the new upper/lower boundary faces can be created. Fig. 20 shows the upper volume, lower volume, and faces between the two volumes.

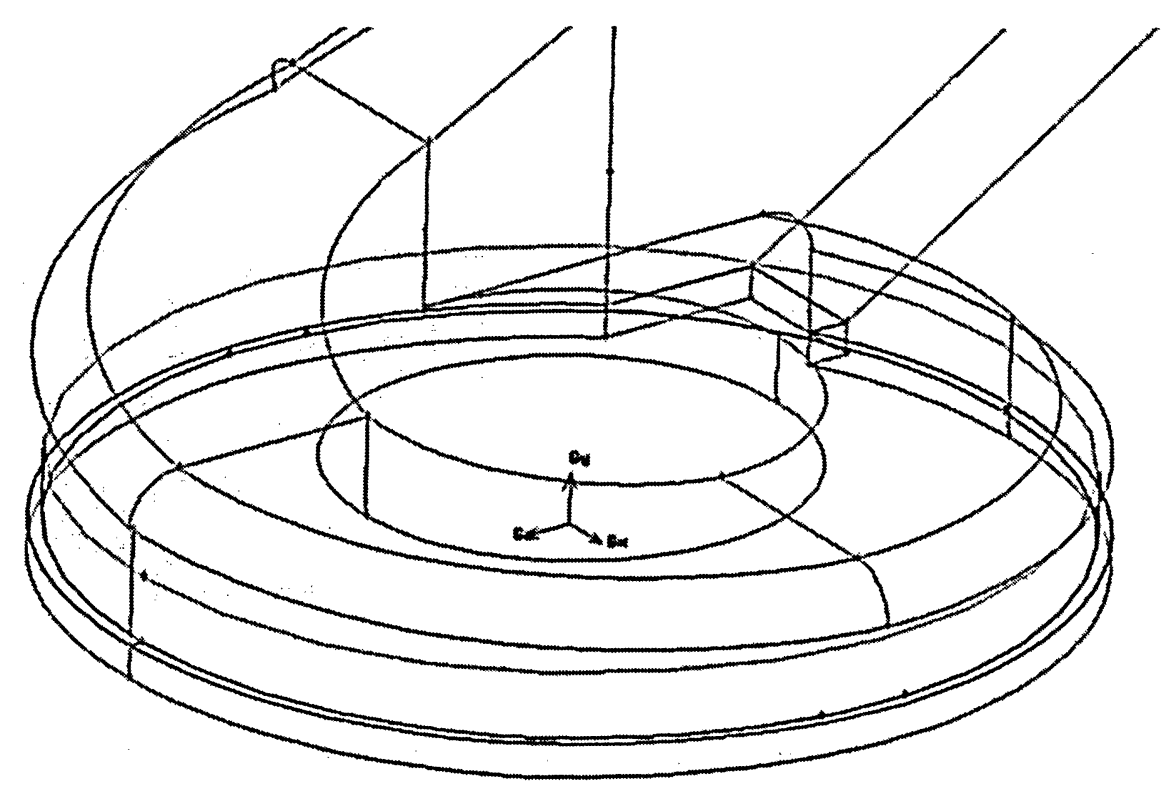

Fig. 20 Faces between the upper and lower volumes

Once the two virtual half-volumes are created, the two virtual volumes can be merged together to create one single volume with a hollow core at the centre. The faces between the two halves are removed from the final resulting volume. Note that the merge function is not the same as the Boolean operator functions. The resulting hollow volume becomes the new stationary space, which shares its inner faces with the rotating volume. 
The same technique is applied in order to remove the volume of the blade from the rotating volume. The result is three volumes that do not overlap in space and share the boundary faces with its neighbouring volume. The volumes are the stationary volume, rotating volume, and blade, as shown in Fig. 21.

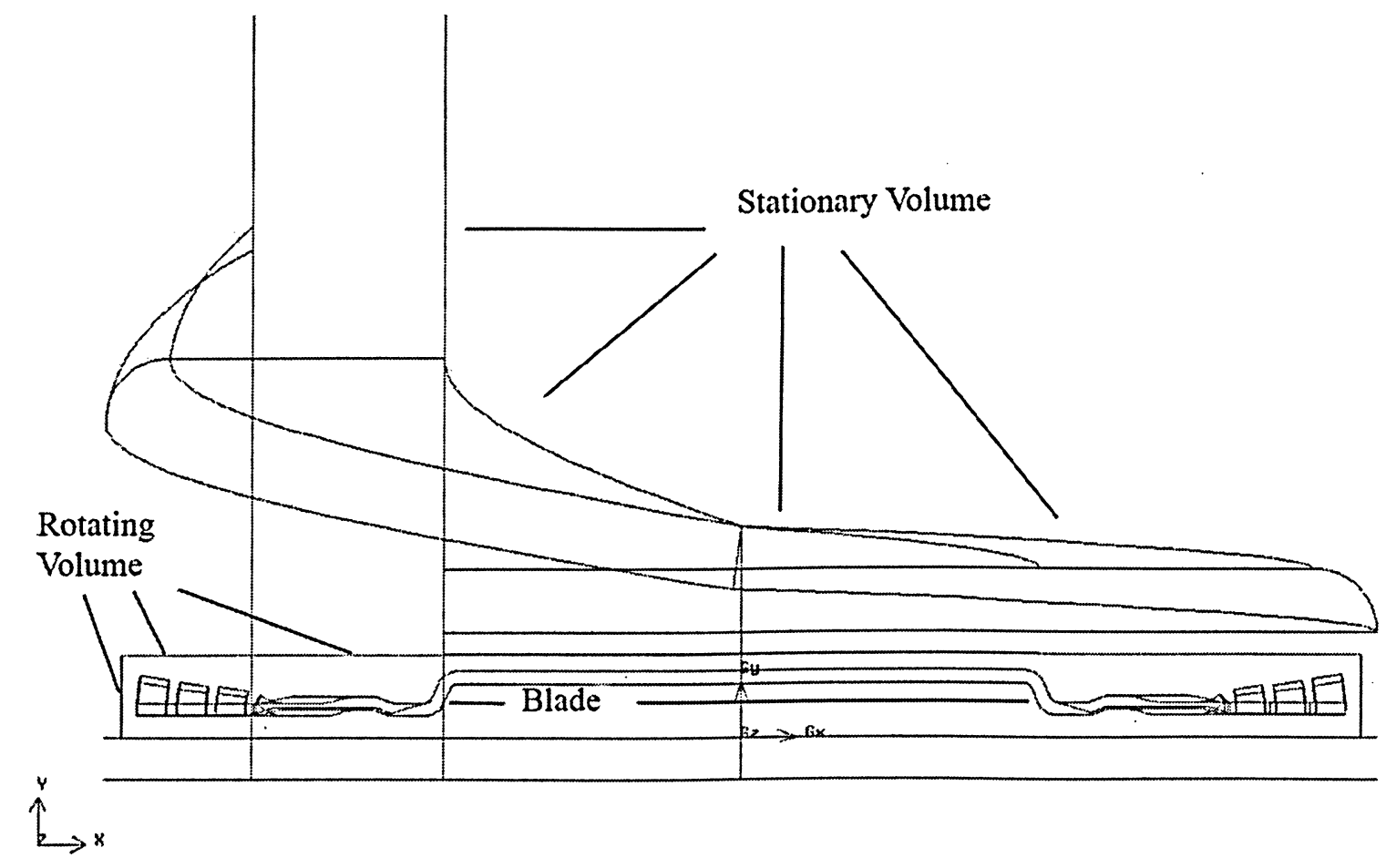

Fig. 21 The three volumes of the single blade model

With each of the volumes separately defined but coupled together, the volumes can be meshed so that a solution can be sought. Gambit has the ability to mesh a volume and its edges and faces. The shape used to connect the nodes in the mesh was tetrahedral (4sided pyramid). This was the recommended 3D shape by Gambit and was versatile enough to work within the complex geometry. Only the rotating and stationary volumes were meshed because they represent the regions in which the fluid can move through. Fluid cannot move through the blade. The outer faces of the blade are meshed because they are part of the rotating volume, but the internal volume of the blade is left unmeshed. The 3D meshing used in the CFD model can be seen in Fig. 22. 


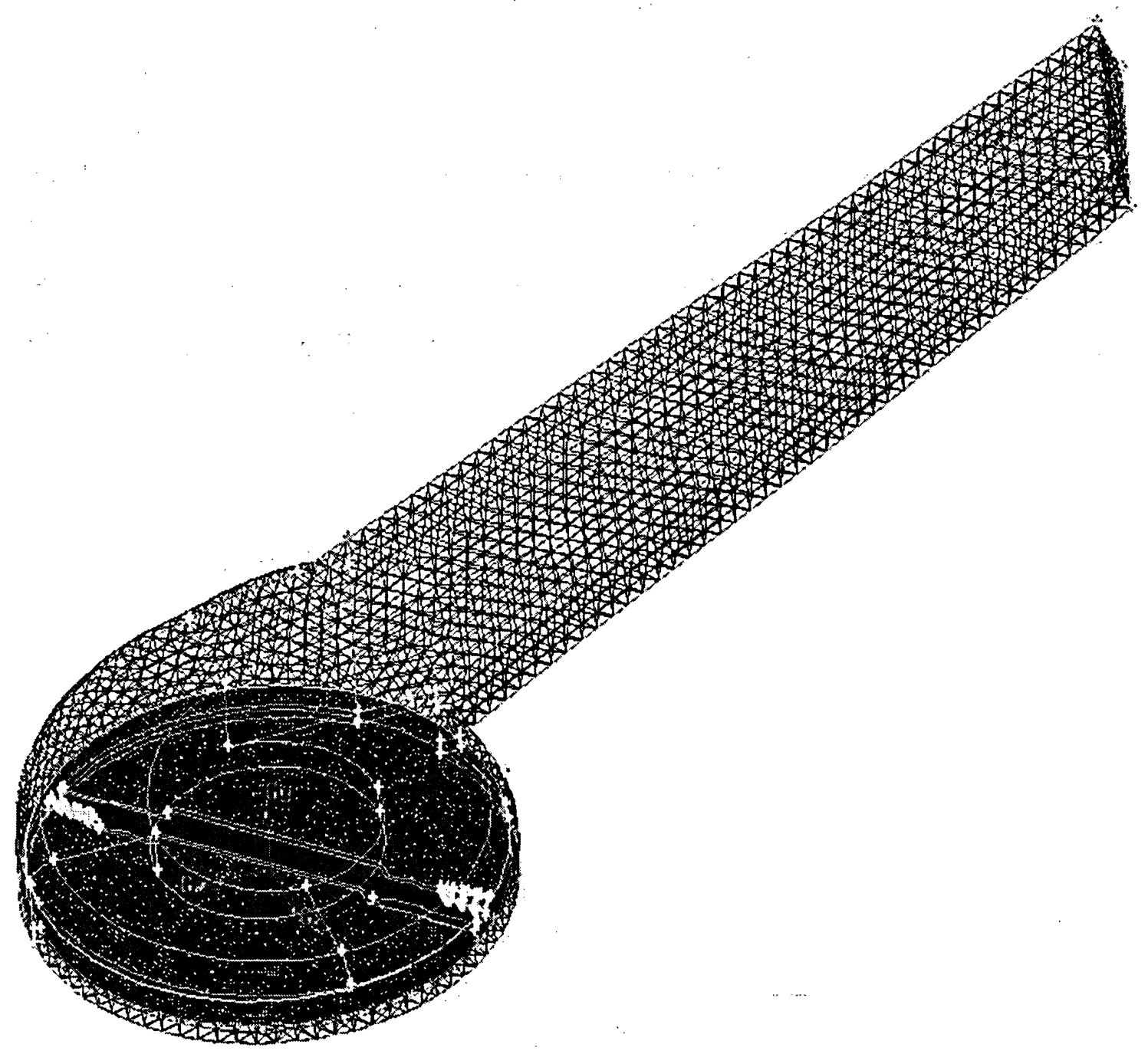

Fig. 22 Meshed single blade system

The spacing is another important part of the meshing process. Denser clusters of nodes result in more accurate solutions and a larger set of results; however, the more nodes there are in a mesh, the longer it will take the solver to return a converged solution. Considering the characteristics of the system, it was decided to have a dense cluster of nodes within the rotating volume where large gradients are expected $(1 \mathrm{~cm}$ spacing) and less dense mesh spacing in the stationary volume ( $3 \mathrm{~cm}$ spacing). A tight grouping of nodes is not necessary in the outer regions where flow is expected to be smooth. 
With the volumes meshed, the boundary conditions and fluid continuum can be defined. Fluent $5 / 6$ is selected as the solver type from the Gambit menu; this allowed for a set of boundary conditions specific to Fluent.

The inlet and outlet faces were defined as pressure boundaries. The symmetry wall was defined as a symmetry boundary condition. The faces of the blade were defined as a wall. Any faces that are not defined in Gambit are automatically assumed to be a wall. The blade faces were defined as a separate wall because rotation will be applied specifically to them. Fig. 23 shows the defined boundary conditions.

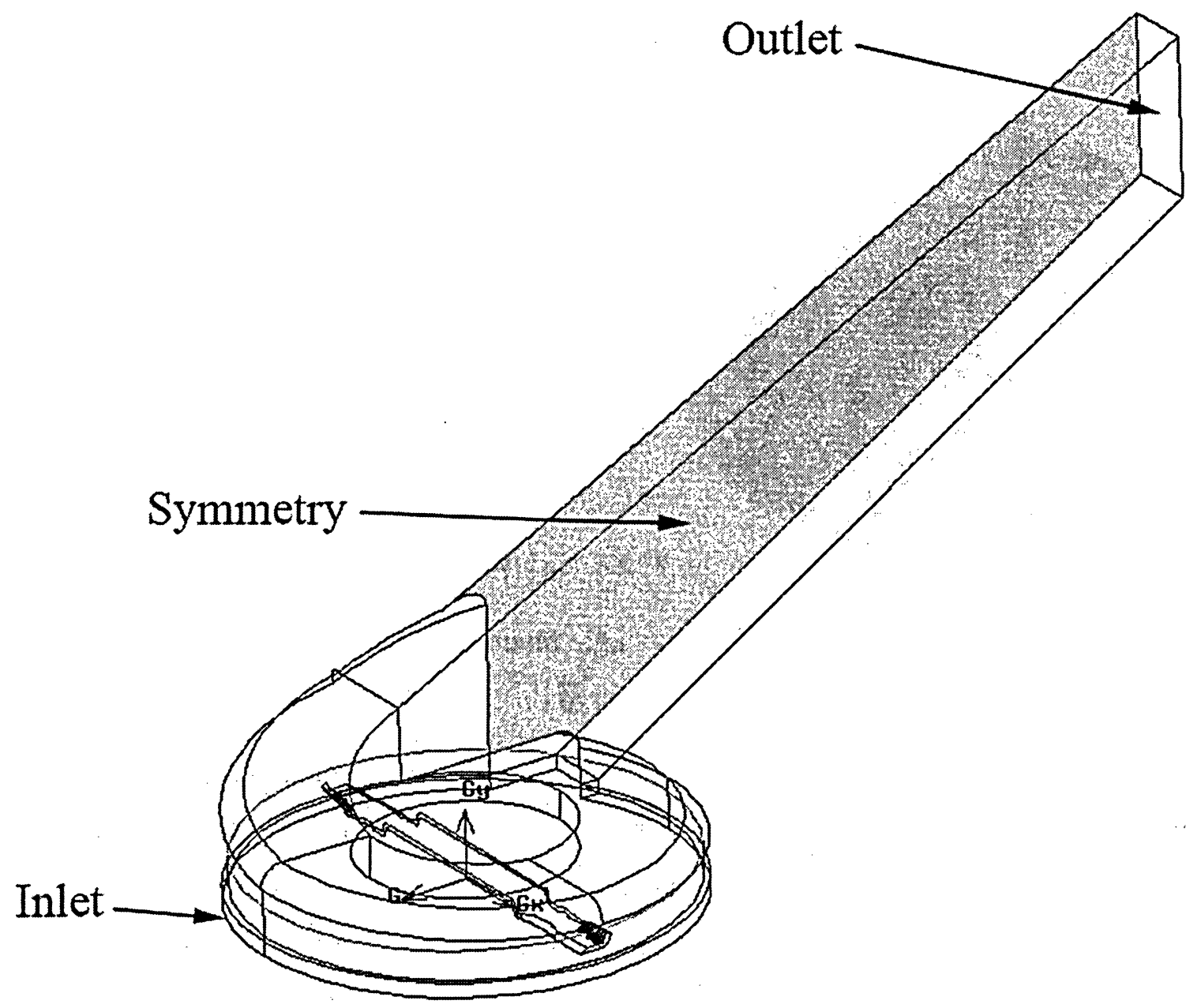

Fig. 23 Boundary conditions of single blade system 
The rotational and stationary volumes were each defined as a separate fluid. The blade faces were defined as walls.

The resulting volumes, mesh, and boundary conditions could now be exported as an .MSH file. The MSH file is read into Fluent. The nodes, walls, inlets, fluid spaces, etc., are kept intact.

There are many parameters that must be specified prior to the solution stage. The setup used in the cutting pan/tunnel/blade system is as follows:

- Solver: 3D, single precision, segregated, steady-state

- Energy: energy equation enabled

- Viscous: laminar flow

- Materials: air only

- Operation conditions: $101,325 \mathrm{~Pa}$, no gravity effects

- Boundary conditions: inlet, outlet $=0 \mathrm{~Pa}$ (gauge pressure)

- Set rotational volume to rotate at $270 \mathrm{rad} / \mathrm{s}$, blade to rotate at $0 \mathrm{rad} / \mathrm{s}$ relative to the rotational volume, Moving Reference Frame

- Momentum solution set to $2^{\text {nd }}$ order upwind

- Iterative solution begins at inlet nodes

- All residuals set to converge at 0.001

- Continuity residual convergence

- Serrated Blade

The solution time varies depending on the number of nodes, complexity of the defined parameters, and stability of the solution. Turbulent solutions tend to be more inconsistent; therefore, convergence may be delayed or not be reached at all as the results from each iteration fluctuate. Once the results have converged to an acceptable point, the final results can then be read or plotted through a variety of methods (e.g., vectors, contours, path lines, etc). 
The blade is oriented at a specific angle when the system is solved. The solution is an accurate representation of a snapshot of the steady-state solution when the blade is in that angular position. Obviously, the airflow through the system will be different when the blade is in different positions; therefore, four separate $3 \mathrm{D}$ models were created with the blade at $0^{\circ}, 45^{\circ}, 90^{\circ}$, and $135^{\circ}$ positions. Each system was solved separately with everything else the same. Due to the very high speed of the blade and flow, the results from the four individual solutions can be averaged and the resulting values would be more indicative of the real system.

When convergence is achieved, values of desired quantities can be taken from the computational model. Results were taken from two regions: one was at the base of the tunnel where the air exits the cutting pan, and the other was at the tunnel outlet. These results were compared to the results given in section 2.1.2. A sample picture of the velocity vectors through the tunnel is shown in Fig. 24.
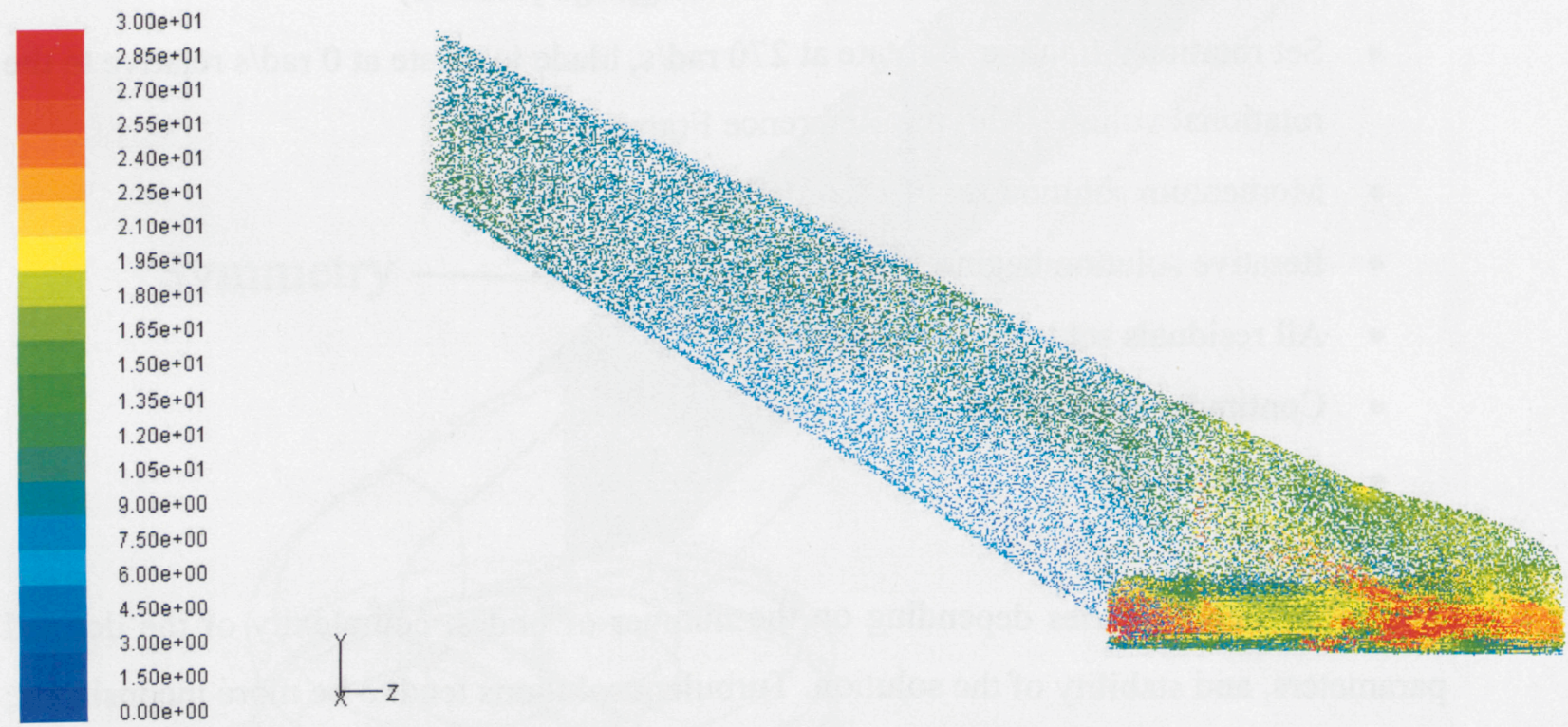

Fig. 24 Velocity vectors $(\mathrm{m} / \mathrm{s})$ of airflow inside the tunnel with blade oriented $90^{\circ}$ with respect to the tunnel

The flow velocity results at the symmetry wall were taken at the same locations as used in the test rig. There was a high reading $(5 \mathrm{~cm}$ from the top of the tunnel), a middle 
reading $(17.8 \mathrm{~cm}$ from the top of the tunnel), and a low reading $(28 \mathrm{~cm}$ from the top of the tunnel). The velocity vectors along the symmetry plane were recorded at the points listed above for blade angles of $0^{\circ}, 45^{\circ}, 90^{\circ}$, and $135^{\circ}$. Each setup was modeled and solved separately with the blade in different positions. The velocities of the flow seem to be very similar near the end of the tunnel for each of the different setups; however, the flows closer to the cutting pan at the bottom of the tunnel varied more with the orientation of the blade. The results of all the tests are tabulated in Table 7 and Table 8 .

Table 7 Tunnel Velocities of Single Blade Model with Symmetry

\begin{tabular}{|c|c|c|c|}
\hline $\begin{array}{l}\text { Blade } \\
\text { Angle }\end{array}$ & $\begin{array}{l}\text { Distance From } \\
\text { Top of Tunnel, } \\
\text { cm (inch) }\end{array}$ & $\begin{array}{l}\text { Tunnel Velocity } \\
\text { Near Blades, m/s } \\
\text { (fpm) }\end{array}$ & $\begin{array}{c}\text { Tunnel Velocity } \\
\text { at Outlet, m/s } \\
\text { (fpm) }\end{array}$ \\
\hline \multirow[t]{3}{*}{$0^{\circ}$} & $5.0(2)$ & $2(400)$ & $6(1200)$ \\
\hline & $17.8(7)$ & $10(2000)$ & $10(2000)$ \\
\hline & $28.0(11)$ & $7(1400)$ & $9(1800)$ \\
\hline \multirow[t]{3}{*}{$45^{\circ}$} & $5.0(2)$ & $12(2400)$ & $10(2000)$ \\
\hline & $17.8(7)$ & $4(800)$ & $10(2000)$ \\
\hline & $28.0(11)$ & $6(1200)$ & $11(2200)$ \\
\hline \multirow[t]{3}{*}{$90^{\circ}$} & $5.0(2)$ & $8(1600)$ & $10(2000)$ \\
\hline & $17.8(7)$ & $9(1800)$ & $11(2200)$ \\
\hline & $28.0(11)$ & $5(1000)$ & $12(2400)$ \\
\hline \multirow[t]{3}{*}{$135^{\circ}$} & $5.0(2)$ & $10(2000)$ & $8(1600)$ \\
\hline & $17.8(7)$ & $6(1200)$ & $10(2000)$ \\
\hline & $28.0(11)$ & $7(1400)$ & $11(2200)$ \\
\hline \multirow[t]{3}{*}{ Average } & $5.0(2)$ & $8(1600)$ & $8.5(1700)$ \\
\hline & $17.8(7)$ & $7.25(1400)$ & $10.25(2000)$ \\
\hline & $28.0(11)$ & $6.25(1200)$ & $10.75(2100)$ \\
\hline
\end{tabular}


Table 8 Average Tunnel Velocities of Single Blade Model with Errors

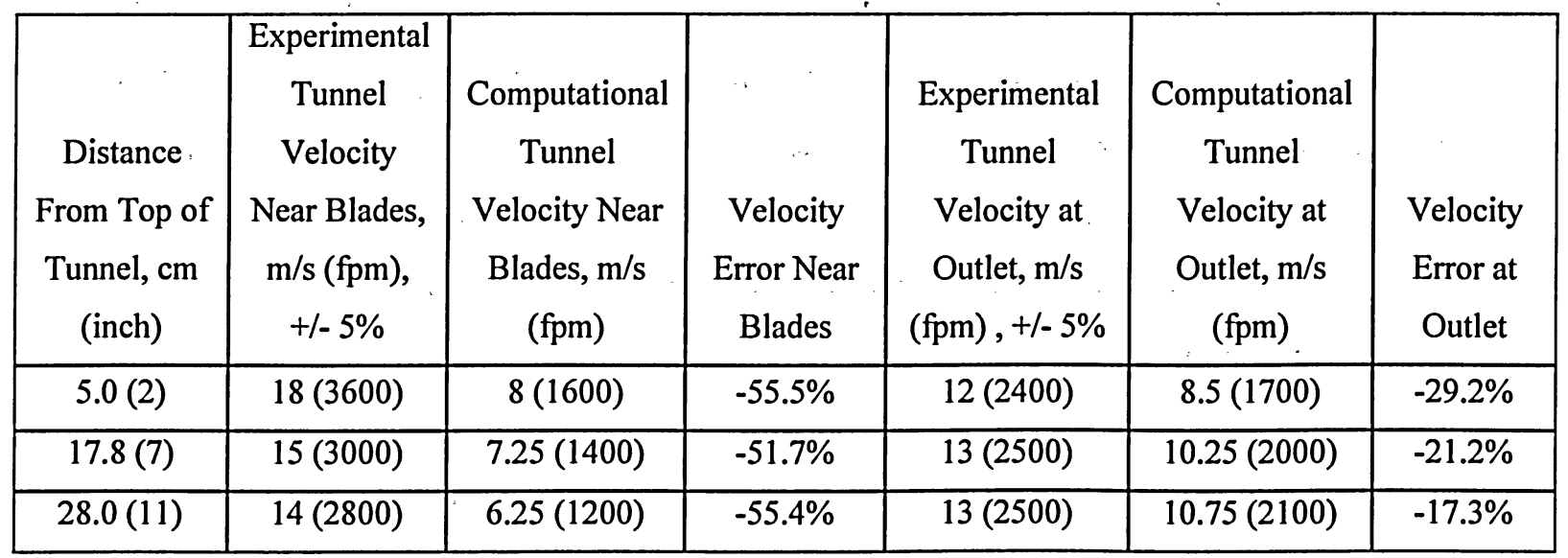

This section details the first attempt to model the complex cutting system. This model was laminar, used only one blade with a symmetry wall, and did not have the collector. Also missing from this model was the inlet holes on the top of the cutting chamber. Overall, the airflow in the simulation is lower than the experimental data. Some improvements made to the model are explored in section 2.2.3.

\subsubsection{Twin-Blade Cutting System Model with a Widened Cutting Pan}

This section deals with improved computational models of the cutting system having both blades modeled. Two cases were treated, one without the collector and the other with the collector. Altogether there are three separate models developed and discussed in this section. These models are:

1. Full cutting system and tunnel with collector, serrated cutting blades (turbulent flow)

2. Cutting system and tunnel without collector, serrated cutting blades (laminar flow)

3. Cutting system and tunnel without collector, paddle cutting blades (laminar flow)

The first model is used to investigate air velocity found within the cutting pan and collector. The airflow properties through the inlet gap at the base of the cutting pan, the inlet vents, and the collector's perforated vents are also examined. This model is also 
used to investigate the effects of closing one of the collector vents for better airflow inside the collector. Finally, the effect of different blade rotational speeds on the discharge flow at the end of the tunnel is examined.

The second and third models are used to compare the airflows generated by the serrated and paddle blades, respectively. These models do not contain the collector and are used to analyze the discharge velocity at the end of the tunnel only. Some convergence problems were encountered when trying to use the turbulence scheme in Fluent, especially for the paddle blade. As a result, laminar schemes were used in the computational models for the two different blades.

\subsubsection{Twin-Blade System Modeling Techniques}

This section discusses some of the methods and techniques used to set up and configure a comprehensive computational model for the twin-blade system including two counterrotating blades, cutting pan inlet vents, and the collector. In this comprehensive 3D model, the symmetry boundary conditions introduced for the simplification purposes are now removed. In order to simulate the flow generated by a pair of counter-rotating blades, the Moving Reference Frame (MRF) scheme is employed. Each blade is completely enveloped by a cylindrical volume that leaves a $1 \mathrm{~cm}$ gap between the edge of the blade and the cylinder. In the real machinery, the blade's rotating paths overlap slightly in order to ensure that there is no uncut grass strip. In the computer model, this would mean that the rotating volumes would overlap. This overlapping of rotating volumes cannot be modeled in Fluent because the overlapping prevents proper meshing of each individual volume. Consequently, the small overlapping of volumes swept by the rotating blades is ignored in the computational model. To accommodate this, the distance between the two shaft centerlines is increased by $10 \mathrm{~cm}$ in the computational model. Experimental results have confirmed that this modeling technique is acceptable. The $3 \mathrm{D}$ computational model is shown in Fig. 25. 
There are two sets of inlets in the model - the holes or air vents on top of the cutting pan and the gap between the bottom of the cutting pan and the ground, as shown in Fig. 26. The inlet holes are important in order for a sufficient amount of air to enter the system especially when the cutting pan is in the lowest position. There are seven equally spaced holes arranged in a circle on the top of either cutting pan. Each hole has an area of $16 \mathrm{~cm}^{2}$ $\left(2.5 \mathrm{in}^{2}\right)$. Both inlets are initially set to atmospheric pressure in the model so any flow through the holes is induced by the rotation of the blades.

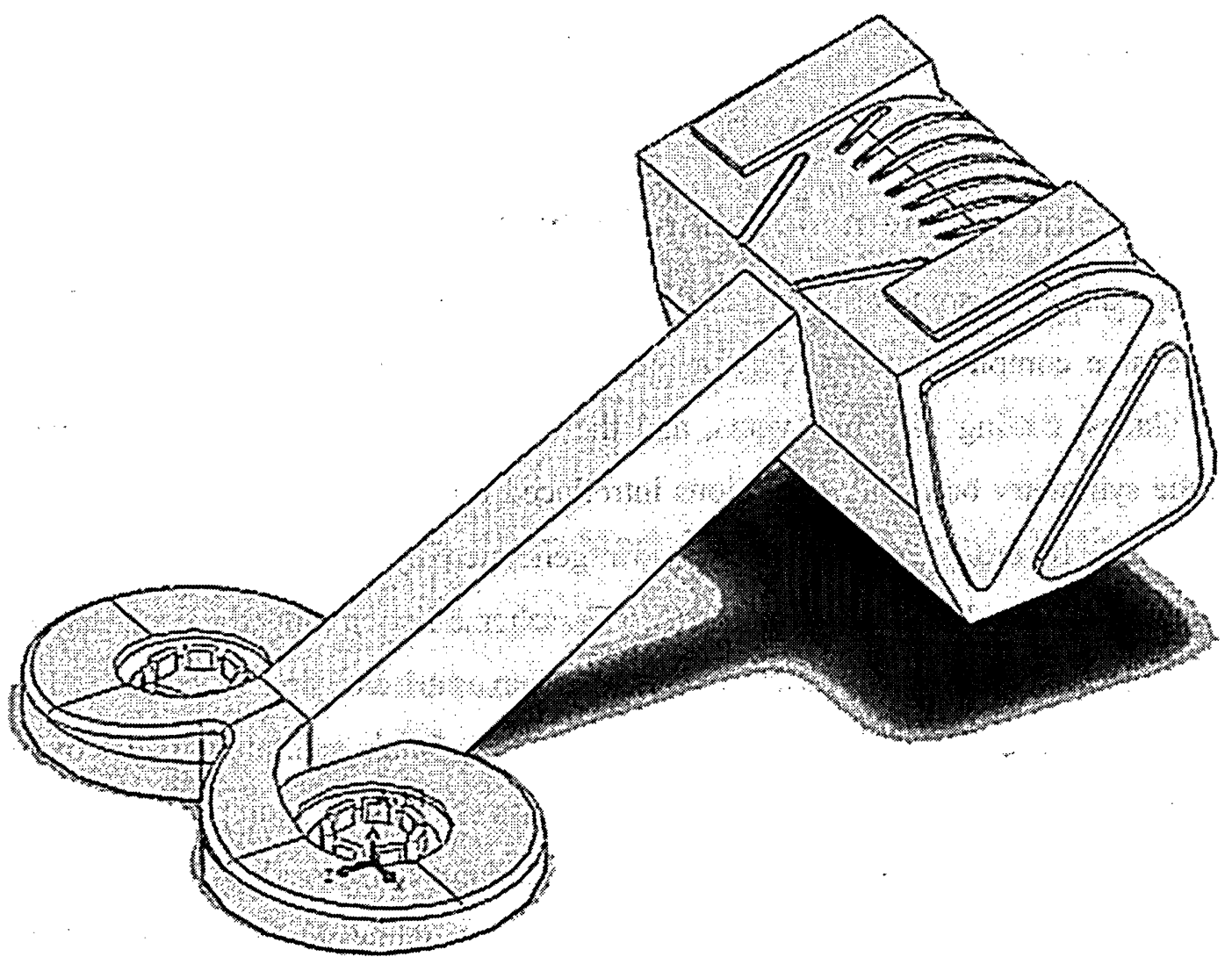

Fig. 25 Twin-blade cutting system overall geometry 


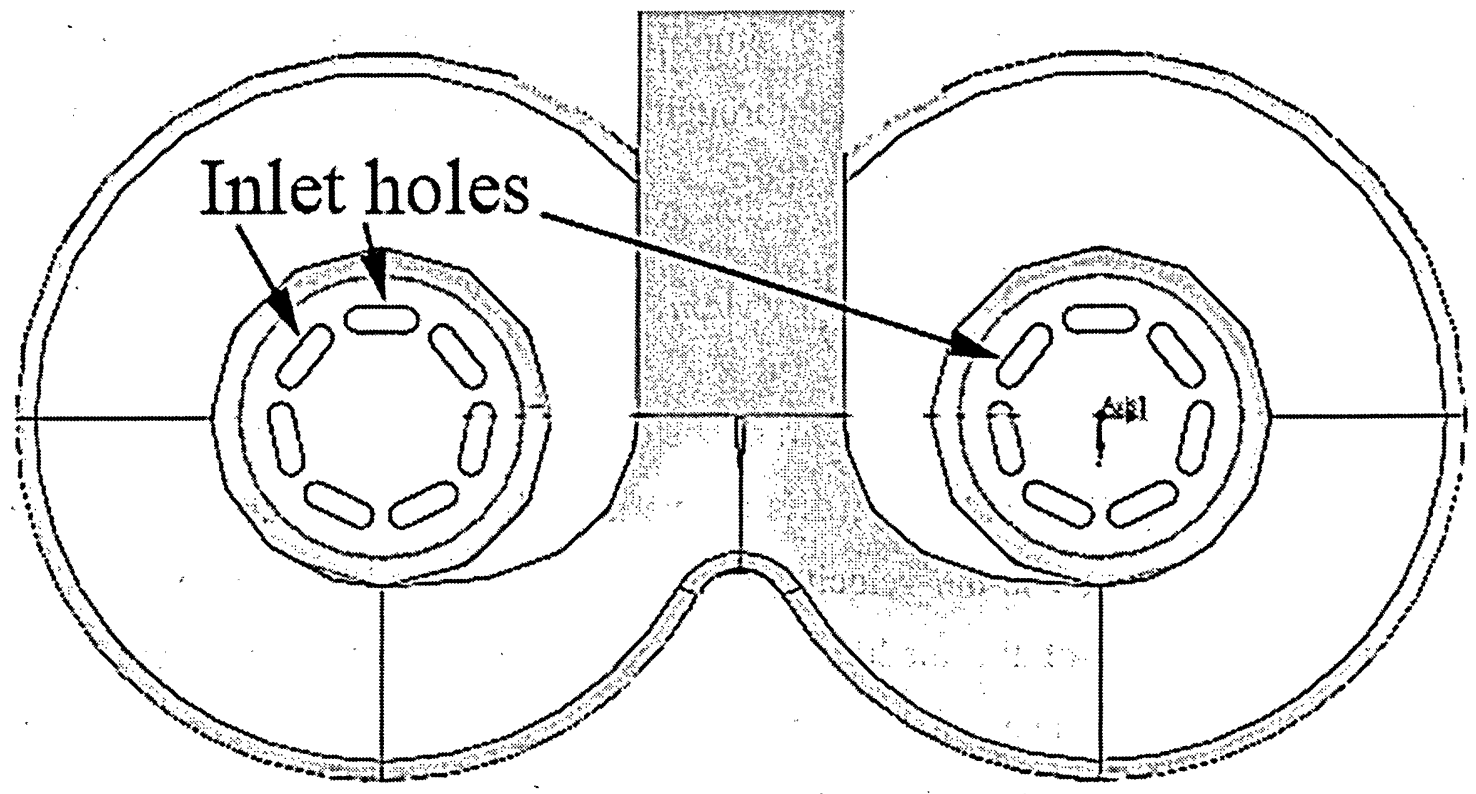

Fig. 26 Inlet vents on top of the twin-blade cutting pan

The collector shown in Fig. 8 is designed to retain clippings while allowing air to escape via vents or holes on the perforated collector surface. In Fluent, these outlet vents can be effectively modeled using the "Porous Jump" boundary condition, which is similar to a momentum sink. The porous jump reduces a certain amount of pressure from the flow that is a function of the velocity passing through the vent. The result is that the flow is allowed to pass through these vents in the direction locally normal to the outlet surface but loses its pressure as it moves past the vent. The vents protrude from the computational model of the collector because the 2-D surface between the protrusions and the collector must be defined as a porous jump. In Fluent, surfaces cannot be both a porous jump and a pressure outlet simultaneously. To model the outlet vents, the edges of the system are moved outward by a small amount. This allows the creation of a thin layer of air volume outside of the collector surfaces. These outer surfaces can then be defined as the pressure outlets and become part of the computational domain. The computational model of the collector is shown in Fig. 9. 
Porous jump conditions are essentially 1-D simplifications of a thin porous surface. It is often used when modeling pressure drops through screens of filters [5]. The pressure change through the porous jump is defined by:

$$
\Delta p=-\left(\frac{\mu}{\alpha} v+C_{2} \frac{1}{2} \rho v^{2}\right) \Delta m
$$

where $\mu$ is the laminar fluid viscosity; $\alpha$ is the permeability of the medium; $C_{2}$ is the pressure-jump coefficient; $v$ is the velocity normal to the porous face; $\rho$ is the density; and $\Delta m$ is the thickness of the medium. The negative sign denotes a pressure drop. According to the Fluent manual [5], when modeling a perforated plate, the permeability term can be ignored. Only the inertial loss term in Eq. 2.1 needs to be included. In this case, $C_{2}$, is defined by:

$$
C_{2}=\left(\frac{1}{C^{2}}\right) \frac{\left(\frac{A_{p}}{A_{f}}\right)^{2}-1}{t}
$$

where $C$ is an empirical coefficient; $A_{p}$ is the plate area including both solid and holes; $A_{f}$ is the total area of the holes; and $t$ is the plate thickness. The value of $C$ is 0.98 if $D / t>$ 1.6 (hole diameter to thickness ratio) [5].

For the collector, $A_{p} / A_{f}=3.1, D=5 \mathrm{~mm}, t=1.59 \mathrm{~mm}$, the value of $\mathrm{C}_{2}$ is $5626 \mathrm{~m}^{-1}$.

\subsubsection{Computational Schemes Used in the Twin-Blade Model Using Collector with Normal Vents}

The computational scheme used in this model is as follows:

- Solver: 3D, single precision, segregated, steady-state

- Energy: energy equation enabled 
- Viscous: $\mathrm{k}-\varepsilon$ turbulence model, realizable, standard wall functions

- Materials: air only

- Operation conditions: $101325 \mathrm{~Pa}$, no gravity effects

- Boundary conditions: inlet, outlet $=0 \mathrm{~Pa}$ (gauge pressure), vents used $\mathrm{C}_{2}=5626$ $\mathrm{m}^{-1}$ and $\Delta \mathrm{m}=1.59 \times 10^{-3} \mathrm{~m}$.

- Set rotational volume of each blade to rotate at $270 \mathrm{rad} / \mathrm{s}$ (blades rotate in opposite direction), blades to rotate at $0 \mathrm{rad} / \mathrm{s}$ relative to the respective rotational volume, Moving Reference Frame

- Momentum solution set to $2^{\text {nd }}$ order upwind

- Iterative solution begins at inlet nodes

- All residuals set to converge at 0.001

- Continuity residual convergence

- Serrated Blades

\subsubsection{Airflow through Inlets in Twin-Blade Model}

Fig. 27 shows the velocities of airflow through both the inlet holes and inlet gap. Initial inspection shows that the inlet holes have speeds ranging from $16.1 \mathrm{~m} / \mathrm{s}$ to $25.0 \mathrm{~m} / \mathrm{s}$ and that all velocities are pointed straight down towards the blades. This downward velocity is expected because the holes are positioned on the top of the cutting pan. 

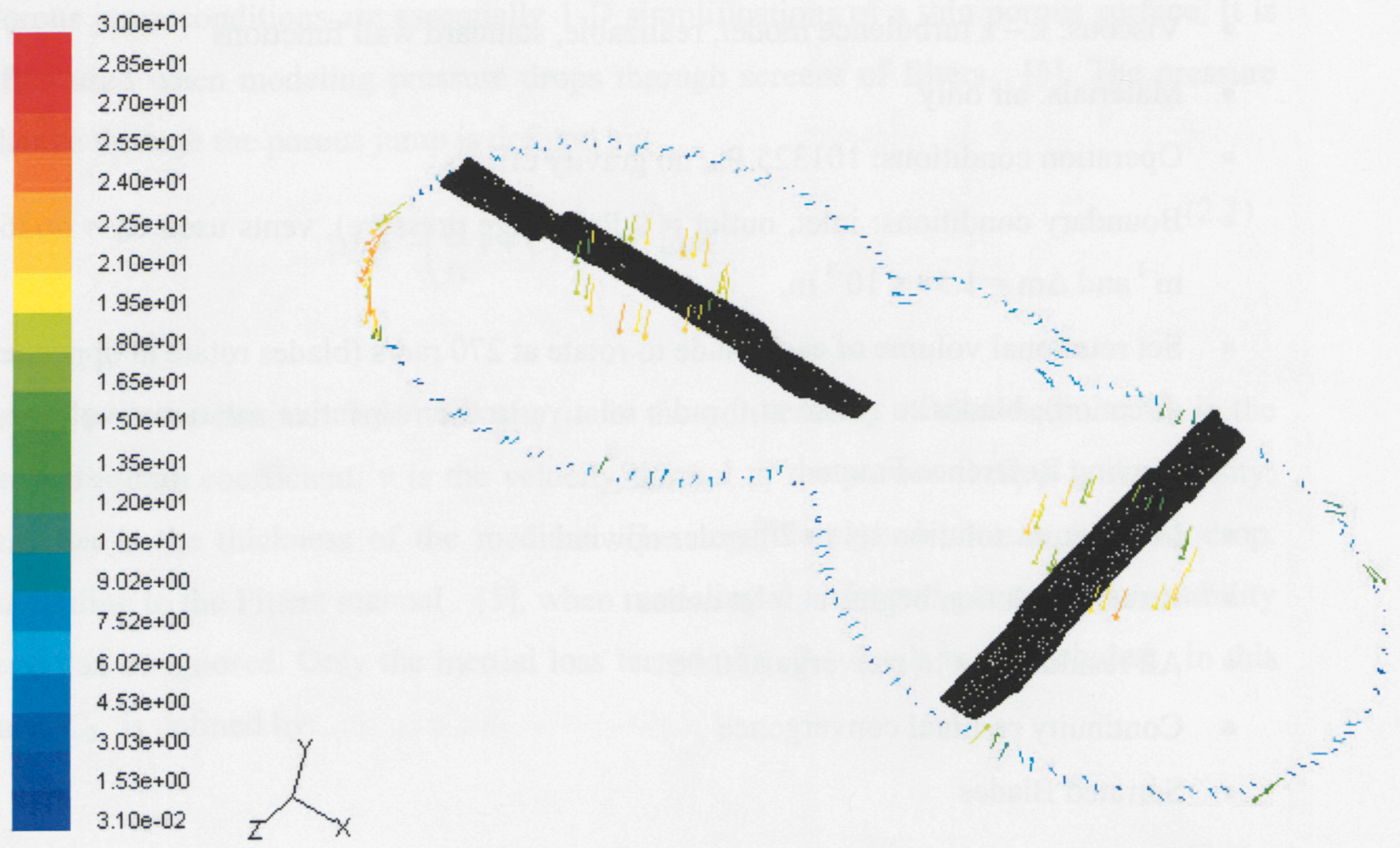

Fig. 27 Velocity vectors $(\mathrm{m} / \mathrm{s})$ through inlet boundaries

The airflow through the inlet gap appears to fluctuate depending on the position of the blade. Areas of the inlet gaps near the blade have velocities approaching $17.7 \mathrm{~m} / \mathrm{s}$, whereas areas of the gap far from either blade have velocities as low as $1.61 \mathrm{~m} / \mathrm{s}$ or no flow at all.

The inlet holes have $0.376 \mathrm{~kg} / \mathrm{s}$ of air moving through them with an area of $17.9 \times 10^{-3} \mathrm{~m}^{2}$ while the inlet gap has $0.371 \mathrm{~kg} / \mathrm{s}$ and an area of $109.8 \times 10^{-3} \mathrm{~m}^{2}$. The inlet holes have approximately the same mass flow rate with a sixth of the area; therefore, the average air velocity through the inlet holes is six times greater than the average velocity through the inlet gap. 


\subsubsection{Airflow inside the Cutting Pan}

Fig. 28 shows the airflow inside the cutting pan. The airflow mainly circulates along with the blade motion through $270^{\circ}$ of rotation until it reaches the central hub of the cutting pan where the air is propelled into the tunnel. The air moves fastest in regions closest to the outside edge of the cutting pan, and is slower closer towards the centre. There is a near-zero velocity at the centre of each blade. The air enters into the cutting pan from the inlet holes, flows outwards rapidly, and joins the main stream at the outer edge of cutting pan.
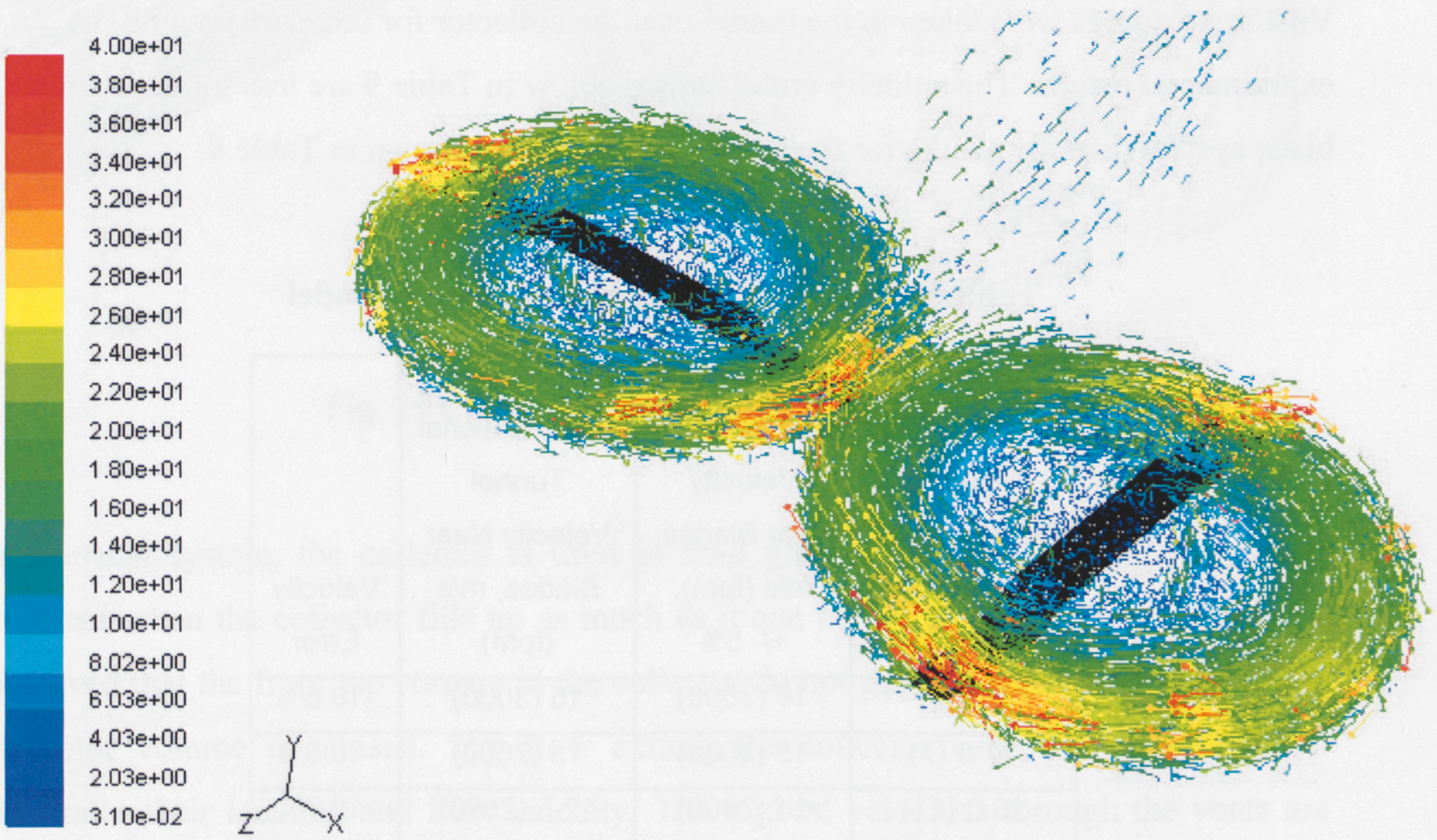

Fig. 28 Velocity vectors $(\mathrm{m} / \mathrm{s})$ inside cutting pan

The highest velocities are found directly in front of the cutting blades and directly behind and under the cutting blades. The high velocities range from $26 \mathrm{~m} / \mathrm{s}$ in regions near the blade, to $90 \mathrm{~m} / \mathrm{s}$ or higher on nodes adjacent to the blades. The high velocity regions in front of the cutting blades can be attributed to air flowing from high pressure regions 
(about $+5000 \mathrm{~Pa}$ ) formed immediately in front of the rotating blade surface to regions of lower pressure.

The high velocity of airflow behind the blades is due to the air near atmospheric pressure rushing into the vacuum pressure regions immediately following the blade surface $(-3000$ $\mathrm{Pa}$ ). The high-speed rotation of the blade causes a vacuum and creates the low pressure regions trailing the moving blades.

\subsubsection{Airflow through Tunnel in Twin-Blade Model}

Velocity readings were taken in the tunnel near the collector for comparison with the experimental results. The velocity errors shown below in Table 9 are less for the twinblade system than the results for the single-bladed system shown in Table 8.

Table 9 Tunnel Velocities of Twin-Blade Model

\begin{tabular}{|c|c|c|c|}
\hline $\begin{array}{c}\text { Distance } \\
\text { From Top of } \\
\text { Tunnel, cm } \\
\text { (inch) }\end{array}$ & $\begin{array}{c}\text { Experimental } \\
\text { Tunnel } \\
\text { Velocity } \\
\text { Near Blades, } \\
\text { m/s (fpm), } \\
+/-5 \%\end{array}$ & $\begin{array}{l}\text { Computational } \\
\text { Tunnel } \\
\text { Velocity Near } \\
\text { Blades, m/s } \\
\text { (fpm) }\end{array}$ & $\begin{array}{c}\text { Velocity } \\
\text { Error }\end{array}$ \\
\hline $5.0(2)$ & $18(3600)$ & $15(3000)$ & $-18.9 \%$ \\
\hline$\overline{17.8(}$ & 15( & $13(2600)$ & $-13.3 \%$ \\
\hline 28.0 & (7) & $12.5(2500)$ & $-10.7 \%$ \\
\hline
\end{tabular}

\subsubsection{Airflow inside Collector and Through Outlet Vents in Twin-Blade Model}

The outlet vents are located along several surfaces on the collector as illustrated in Fig. 9. The air velocity around the inside surface of the collector is shown in Fig. 29. The velocity ranges from $11 \mathrm{~m} / \mathrm{s}$ at the top and back vent regions to about $1 \mathrm{~m} / \mathrm{s}$ in regions near the bottom and at the front of the collector. 


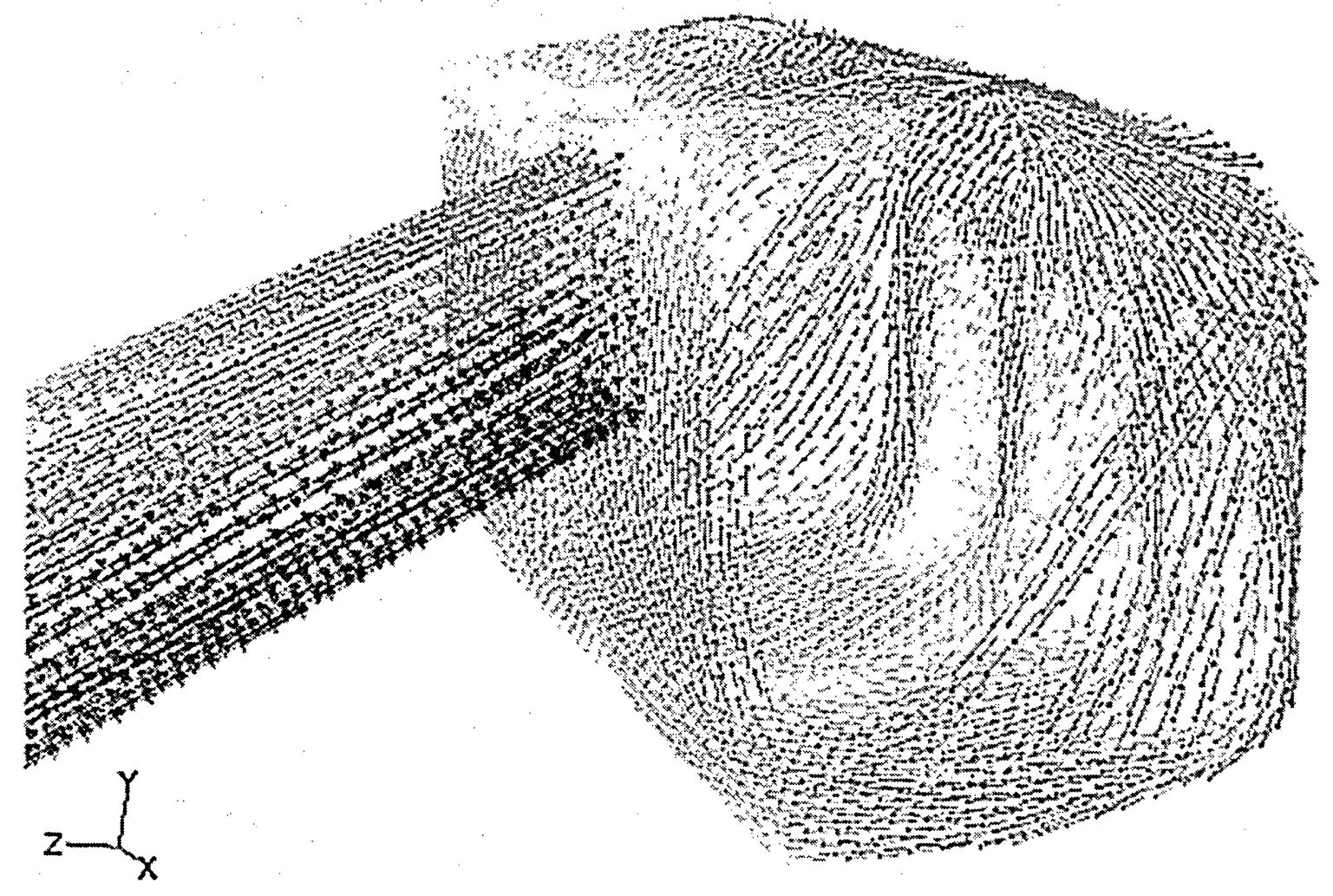

Fig. 29 Collector airflow with all vents open

In the real system, the collector is used to hold grass clippings. The system is most efficient when the collector fills up as much as it can before being emptied. It has been observed that the front top corners in the collector do not get filled and about $20 \%$ of the collector volume is unused. The flow exiting the collector vents shown in Fig. 30 illustrates their location and flow velocity. The highest velocities through the vents are about $6 \mathrm{~m} / \mathrm{s}$. For some vents, there is no airflow at all. 


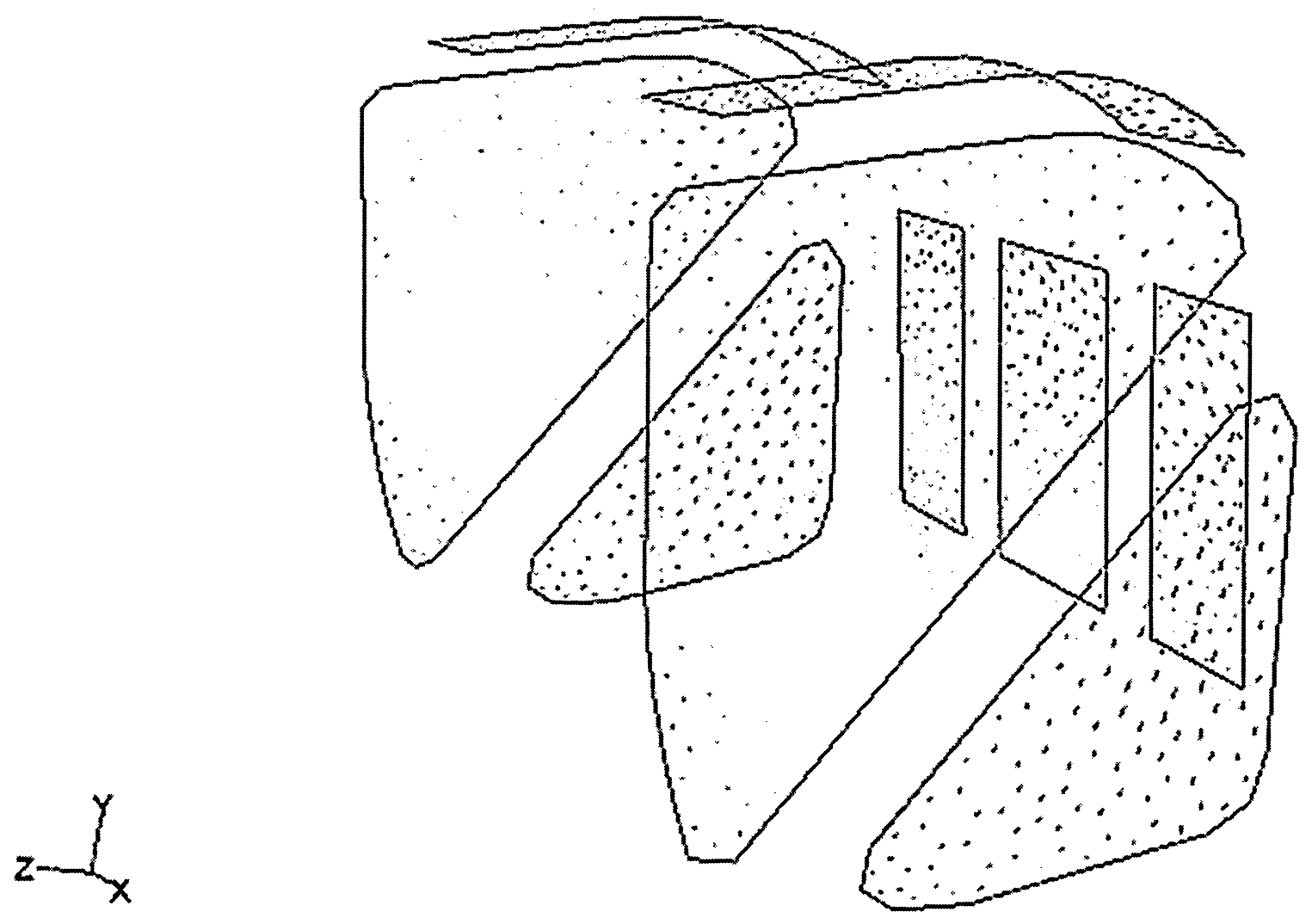

Fig. 30 Collector vent airflow with all vents open

The velocity results for positions in Fig. 9, obtained from the computational model, are given in Table 10.

Fig. 31 shows a side view of the airflow coming from the tunnel and impacting the toprear of the collector. The air continues around the collector edge in a clockwise manner, with the velocity of the air decreasing as the air travels further around the collector. 
Table 10 Velocities through Collector Vents (All Vents Open)

\begin{tabular}{|c|c|c|c|}
\hline $\begin{array}{c}\text { Collector } \\
\text { Vent } \\
\text { Position }\end{array}$ & $\begin{array}{c}\text { Experimental } \\
\text { Vent Velocity, } \\
\mathrm{m} / \mathrm{s}(\mathrm{fpm}),+/- \\
5 \%\end{array}$ & $\begin{array}{c}\text { Computational } \\
\text { Vent Velocity, } \\
\mathrm{m} / \mathrm{s}(\mathrm{fpm})\end{array}$ & $\begin{array}{c}\text { Velocity } \\
\text { Error }\end{array}$ \\
\hline $1 \mathrm{a}$ & $5(1000)$ & $5.5(1100)$ & $10.0 \%$ \\
\hline $1 \mathrm{~b}$ & $<2.5(<500)$ & $2.5(500)$ & $\mathrm{n} / \mathrm{a}$ \\
\hline $1 \mathrm{c}$ & $<2.5(<500)$ & $1.5(300)$ & $\mathrm{n} / \mathrm{a}$ \\
\hline $2 \mathrm{a}$ & $6.5(1300)$ & $6.75(1350)$ & $3.8 \%$ \\
\hline $2 \mathrm{~b}$ & $5(1000)$ & $2.25(450)$ & $55.0 \%$ \\
\hline $2 \mathrm{c}$ & $4.5(900)$ & $1(200)$ & $77.0 \%$ \\
\hline $3 \mathrm{a}$ & $4(800)$ & $4(800)$ & $0.0 \%$ \\
\hline $3 \mathrm{~b}$ & $<2.5(<500)$ & $1.5(300)$ & $\mathrm{n} / \mathrm{a}$ \\
\hline $3 \mathrm{c}$ & $<2.5(<500)$ & $1.5(300)$ & $\mathrm{n} / \mathrm{a}$ \\
\hline $3 \mathrm{~d}$ & $<2.5(<500)$ & $0.75(150)$ & $\mathrm{n} / \mathrm{a}$ \\
\hline $4 \mathrm{a}$ & $6(1200)$ & $6(1200)$ & $0.0 \%$ \\
\hline $4 \mathrm{~b}$ & $5(1000)$ & $6.5(1300)$ & $30.0 \%$ \\
\hline $4 \mathrm{c}$ & $<2.5(<500)$ & $2.5(500)$ & $\mathrm{n} / \mathrm{a}$ \\
\hline $4 \mathrm{~d}$ & $<2.5(<500)$ & $4(800)$ & $\mathrm{n} / \mathrm{a}$ \\
\hline
\end{tabular}




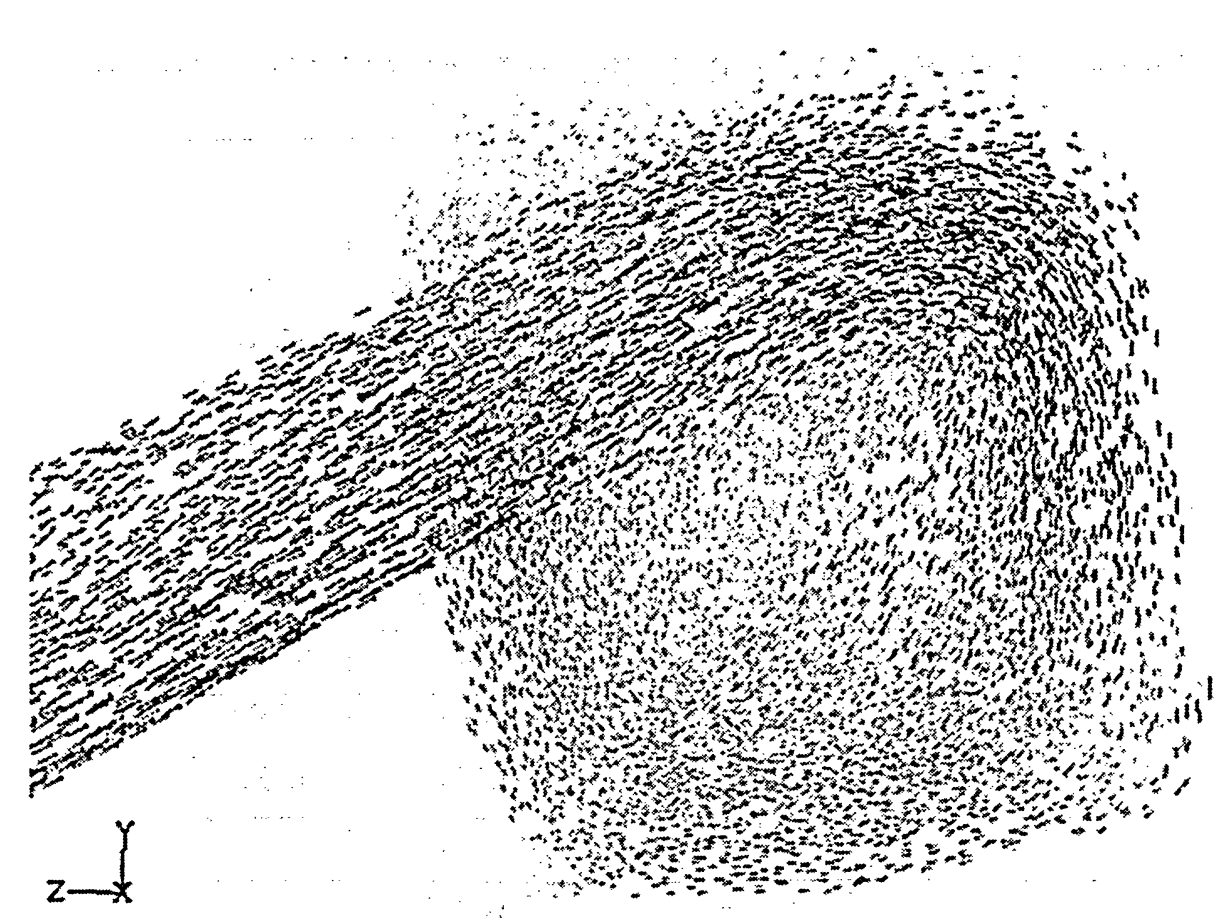

Fig. 31 Side view of air entering the collector (all vents open)

Fig. 32 shows a top view perspective of the air entering the collector and being spread out along the width of the collector. This spreading of the airflow is in part due to the guides mounted internally in the collector. These guides are present on the top of collector's inner surface and are seen on the top of the collector in Fig. 10. 


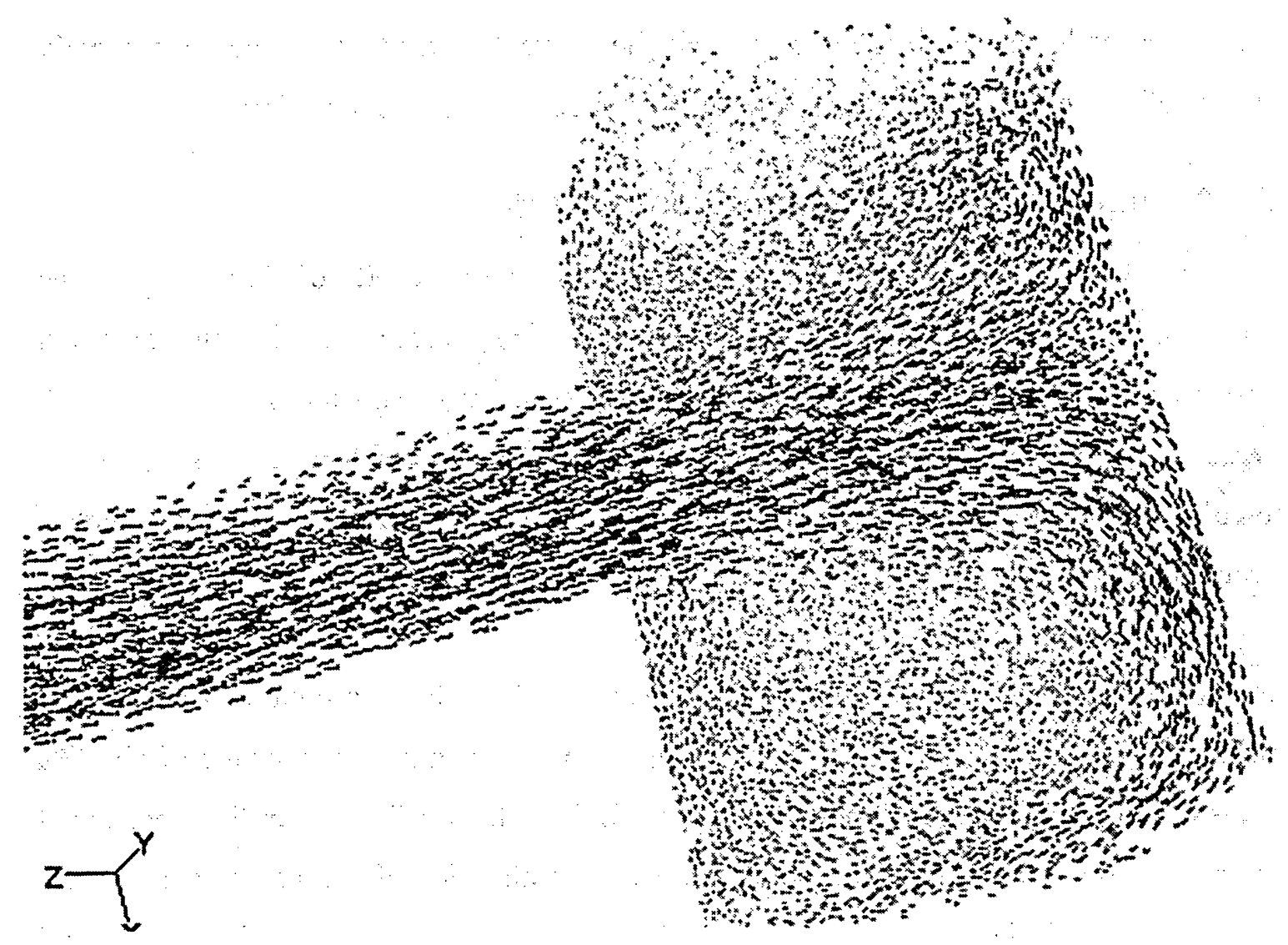

Fig. 32 Top view of air entering the collector (all vents open)

The simulation results show that the air is partially recirculating inside the collector. This would be beneficial for maximizing filling capacity if air moves everywhere throughout the collector. However, the velocity of airflow appears to diminish quite substantially before it can complete one rotation. This means that the majority of airflow is leaving the collector as the bulk of the stream contacts the rear vents. Air that does not initially escape through the top of the rear vents has a good chance of escaping through another vent section as it moves towards the bottom of the collector. Airflow that gets directed to the extreme sides of the collector may not come close to the rear vents, but will get exhausted very quickly through the side vents (which cover most of the side collector walls). The air enters the collector at a very fast speed and possesses a large amount of kinetic energy and momentum. This kinetic energy is lost as the air escapes early through the vents, not leaving enough kinetic energy in the flow to circulate around to the top- 
front of the collector. A solution is to limit the amount of air that escapes in the early portions of the recirculation, which is described in detail in the next section.

\subsubsection{Twin-Blade Model with a Closed Vent}

In this section, the rear centre vent is closed off and the results of doing so will be examined. The rear centre vent is shown in Fig. 10. The expectation of closing a rear vent is that more of the airflow will be able to move past the rear vents and not lose as much kinetic energy, thus enabling more air to flow through the upper front corner regions of the collector. This will in turn reduce the stagnation regions near the top two corners of the collector.

Closing the rear centre vent can be easily simulated in the computational model by changing the porous jump condition to a simple wall, preventing the passage of air. The results of closing the vent are shown in Fig. 33. Indeed, the air flows over the closed vent region and continues around the collector. Air at both sides of the center vent is still exhausted through the side rear collectors. The airflow moves past the closed vent and continues around the base of the collector with higher speeds when compared to those obtained with the center vent open (Fig. 29). The front collector wall below the tunnel has a greater upward velocity as a result of closing the vent. This shows that allowing more air past the rear vents promotes a greater amount of recirculation, although only a small increase is observed in this case in the centre region. A small increase in airflow was also observed in the front top corners of the collector. The velocities through various points in the collector with the closed vent are shown in Table 11. 


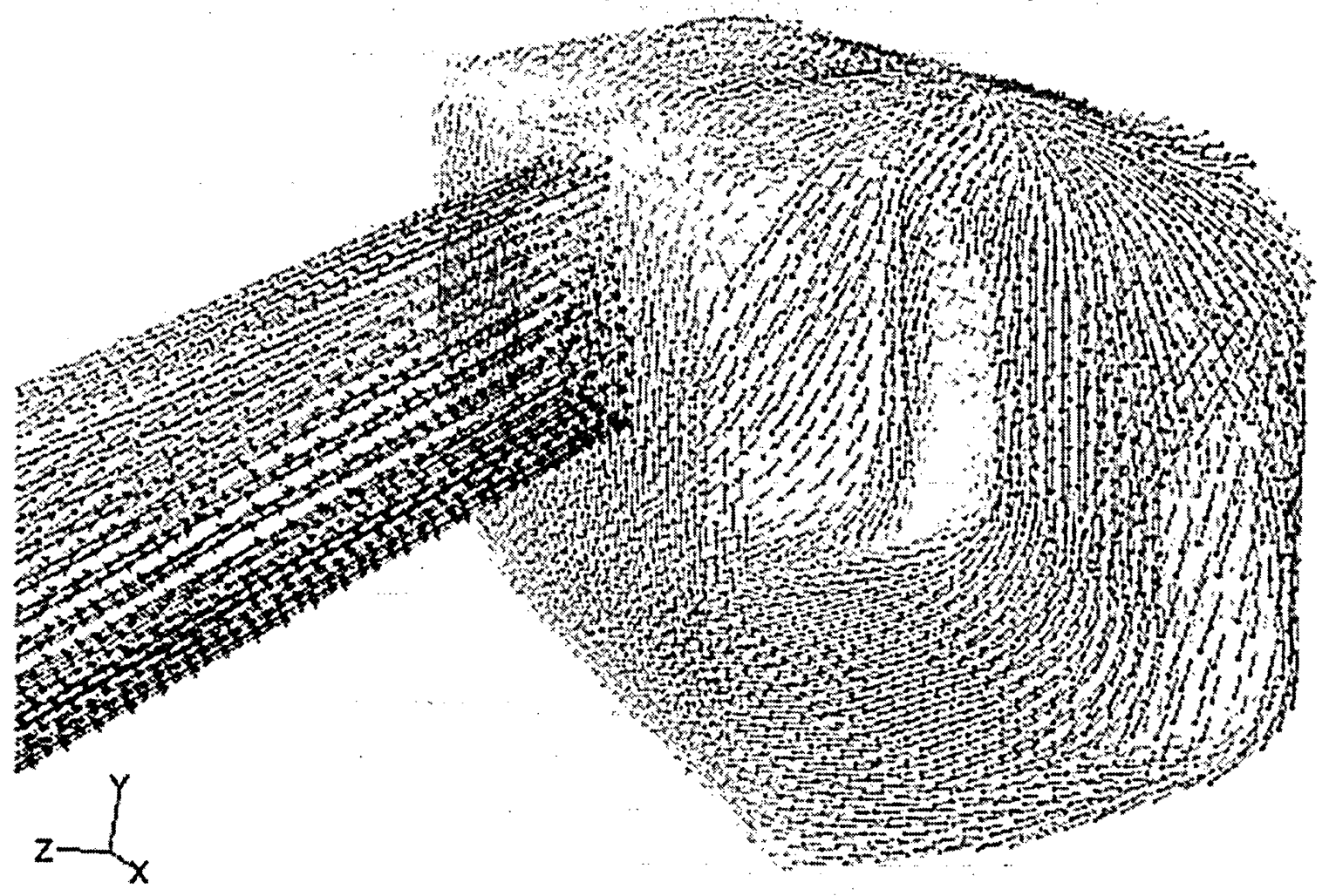

Fig. 33 Collector airflow with centre rear vent closed

\subsubsection{Results of the Twin-Blade Model with Varying Rotational Speed}

Under harsh cutting conditions, it is likely that the motor cannot provide enough power to maintain the designed $270 \mathrm{rad} / \mathrm{s}$ rotational speed to achieve a linear tip speed of 19000 $\mathrm{fpm}$. A reduction in the blade rotational speed affects the quality of cut and collection capacity. In the twin-blade computational model, the rotational speed of the blades was varied between $270 \mathrm{rad} / \mathrm{s}$ and $197 \mathrm{rad} / \mathrm{s}$ (19000 fpm to $14000 \mathrm{fpm})$. The maximum and minimum discharge velocities were taken from the end of the tunnel, before the air flows into the collector. The results are tabulated in Table 12. 
Table 11 Velocities through Collector Vents with Centre Vent Closed

\begin{tabular}{|c|c|c|c|}
\hline $\begin{array}{c}\text { Collector } \\
\text { Vent } \\
\text { Position }\end{array}$ & $\begin{array}{c}\text { Experimental } \\
\text { Velocity, } \mathrm{m} / \mathrm{s} \\
(\mathrm{fpm}),+/-5 \%\end{array}$ & $\begin{array}{c}\text { Computational } \\
\text { Velocity, } \\
\mathrm{m} / \mathrm{s}(\mathrm{fpm})\end{array}$ & $\begin{array}{c}\text { Velocity } \\
\text { Error }\end{array}$ \\
\hline $1 \mathrm{a}$ & $5(1000)$ & $5(1000)$ & $0.0 \%$ \\
\hline $1 \mathrm{~b}$ & $<2.5(<500)$ & $2.3(460)$ & $\mathrm{n} / \mathrm{a}$ \\
\hline $1 \mathrm{c}$ & $<2.5(<500)$ & $1.5(300)$ & $\mathrm{n} / \mathrm{a}$ \\
\hline $2 \mathrm{a}$ & Closed & Closed & Closed \\
\hline $2 \mathrm{~b}$ & Closed & Closed & Closed \\
\hline $2 \mathrm{c}$ & Closed & Closed & Closed \\
\hline $3 \mathrm{a}$ & $5(1000)$ & $4(800)$ & $-20.0 \%$ \\
\hline $3 \mathrm{~b}$ & $<2.5(<500)$ & $2(400)$ & $\mathrm{n} / \mathrm{a}$ \\
\hline $3 \mathrm{c}$ & $<2.5(<500)$ & $1(200)$ & $\mathrm{n} / \mathrm{a}$ \\
\hline $3 \mathrm{~d}$ & $<2.5(<500)$ & $0.5(100)$ & $\mathrm{n} / \mathrm{a}$ \\
\hline $4 \mathrm{a}$ & $6(1200)$ & $5.5(1100)$ & $-8.3 \%$ \\
\hline $4 \mathrm{~b}$ & $4.5(900)$ & $6(1200)$ & $33.0 \%$ \\
\hline $4 \mathrm{c}$ & $<2.5(<500)$ & $3(600)$ & $\mathrm{n} / \mathrm{a}$ \\
\hline $4 \mathrm{~d}$ & $<2.5(<500)$ & $5(1000)$ & $\mathrm{n} / \mathrm{a}$ \\
\hline
\end{tabular}

Table 12 Angular Speed Variation Results

\begin{tabular}{|c|c|c|c|c|}
\hline $\begin{array}{c}\text { Blade Tip } \\
\text { Speed } \\
(\text { fpm })\end{array}$ & $\begin{array}{l}\text { Angular } \\
\text { Speed } \\
(\mathrm{rad} / \mathrm{s})\end{array}$ & $\begin{array}{l}\text { Maximum } \\
\text { Discharge } \\
\text { Velocity, } \\
\mathrm{m} / \mathrm{s} \text { (fpm) }\end{array}$ & $\begin{array}{c}\text { Minimum } \\
\text { Discharge } \\
\text { Velocity, } \\
\mathrm{m} / \mathrm{s} \text { (fpm) }\end{array}$ & $\begin{array}{c}\text { Total Mass } \\
\text { flow Rate } \\
\text { through } \\
\text { Collector } \\
\text { Vents } \\
(\mathrm{Kg} / \mathrm{s})\end{array}$ \\
\hline 19000 & 270 & $11.3(2260)$ & $7(1400)$ & 0.747 \\
\hline 18000 & 253 & $10.5(2100$ & $7(1400)$ & 0.728 \\
\hline 17000 & 239 & $9.8(1960)$ & $6.8(1360)$ & 0.701 \\
\hline 16000 & 225 & $9(1800)$ & $6.8(1360)$ & 0.672 \\
\hline 15000 & 211 & $8.3(1660)$ & $6(1200)$ & 0.64 \\
\hline 14000 & 197 & $7.5(1500)$ & $6(1200)$ & 0.608 \\
\hline
\end{tabular}




\subsubsection{Results of the Twin-Blade Model without collector for Blade Comparison}

The model used in this section consists of the cutting pan and tunnel without the collector in order to test the outlet velocity of the tunnel. There are two types of blades that numerical testing has been performed on, they are called serrated (Fig. 2) and paddle (Fig. 3). This model uses a laminar flow scheme to compare the discharge velocities between each blade. The turbulence scheme was not used because of the convergence problems experienced with the paddle blade. Below is the solution scheme:

- Solver: 3D, single precision, segregated, steady-state

- Energy: energy equation enabled

- Viscous: laminar, standard wall functions

- Materials: air only

- Operation conditions: $101325 \mathrm{~Pa}$, no gravity effects

- Boundary conditions: inlet, outlet $=0 \mathrm{~Pa}$ (gauge pressure)

- Set rotational volume of each blade to rotate at $270 \mathrm{rad} / \mathrm{s}$ (blades rotate in opposite direction), blades to rotate at $0 \mathrm{rad} / \mathrm{s}$ relative to the respective rotational volume, Moving Reference Frame

- Momentum solution set to $2^{\text {nd }}$ order upwind

- Iterative solution begins at inlet nodes

- All residuals set to converge at 0.001

- Continuity residual convergence

- Both serrated and paddle blades

Fig. 34 illustrates the velocity generated in the tunnel from the serrated blades. The velocities at the end of the tunnel range from 3 to $14 \mathrm{~m} / \mathrm{s}$, with an average velocity of 10 $\mathrm{m} / \mathrm{s}$. 


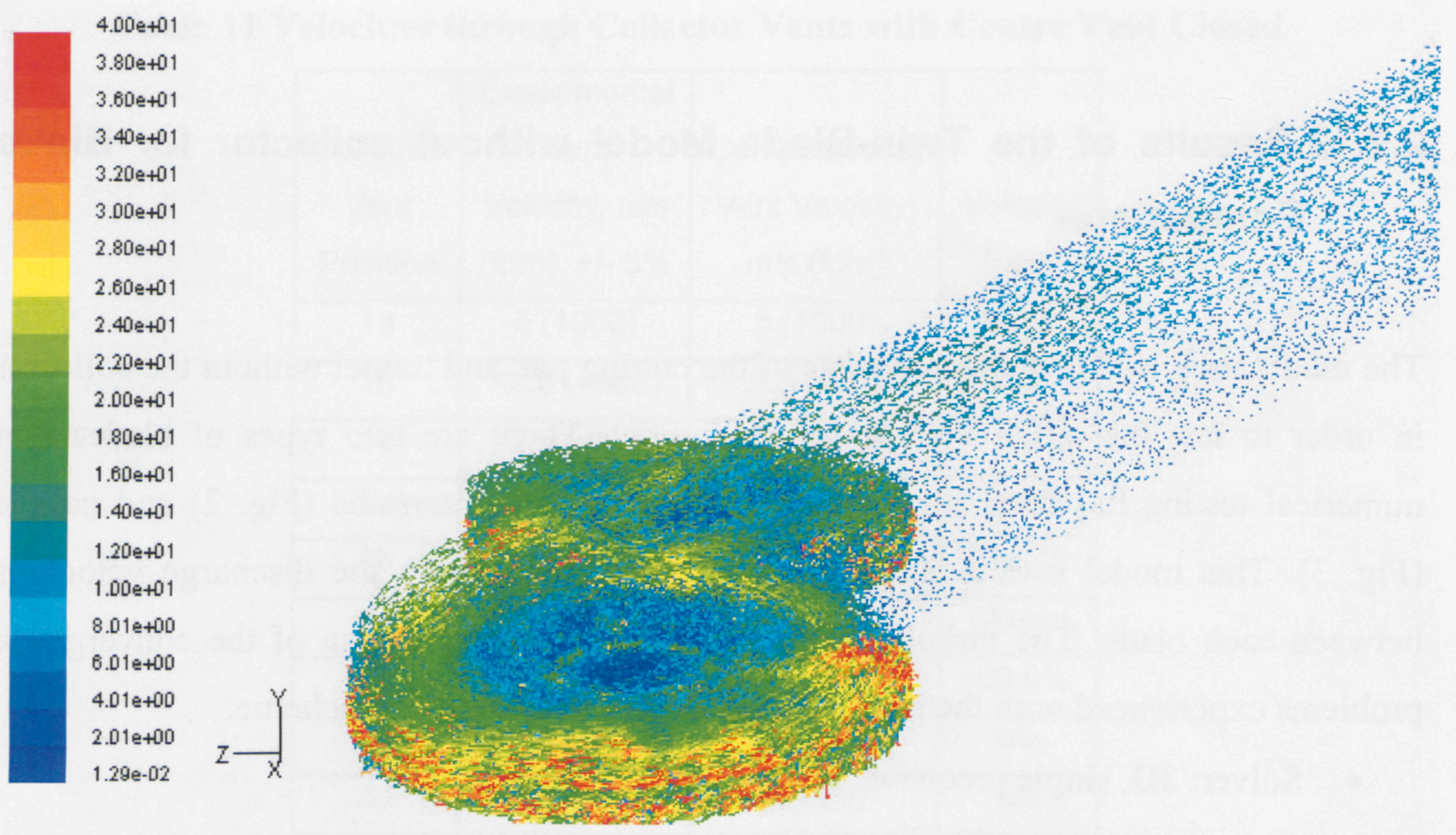

Fig. 34 Velocity vectors $(\mathrm{m} / \mathrm{s})$ through tunnel using serrated blade

The airflow generated by the paddle blades is seen in Fig. 35. The velocity range at the end of the tunnel in this model is 6 to $24 \mathrm{~m} / \mathrm{s}$, with an average velocity of $16 \mathrm{~m} / \mathrm{s}$.

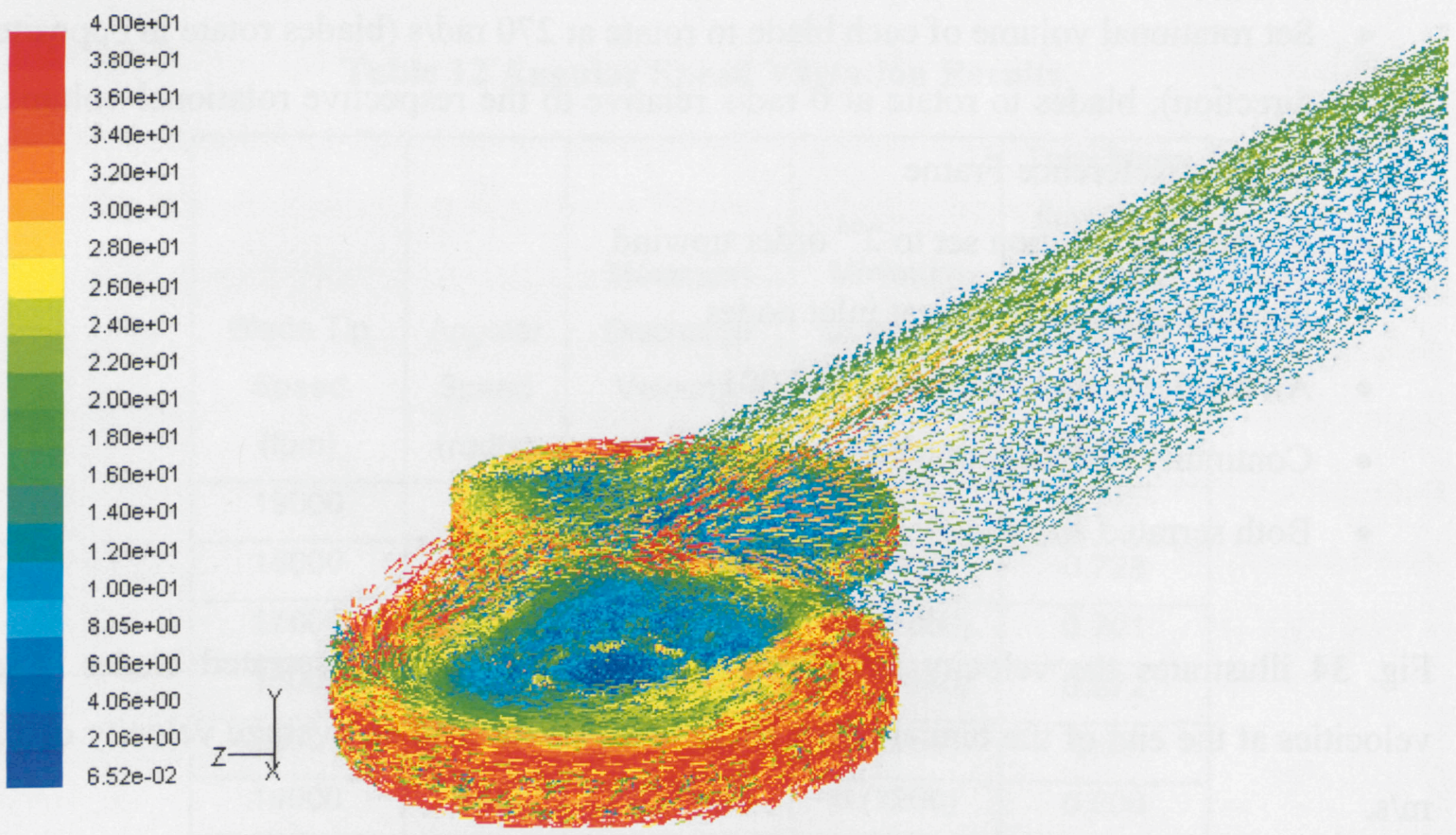

Fig. 35 Velocity vectors $(\mathrm{m} / \mathrm{s})$ through tunnel using paddle blade 
The serrated blades compact the clippings better than the paddle blades, but lack the discharge velocity that the paddle blades have. The numerical results successfully demonstrate this observation. Paddle blades produce a higher discharge velocity in all respects. As a result, air entering the collector possesses higher kinetic energy. These models show that different rotating blade shapes create different outflow velocities. It is shown later in the 2-D analysis that while the paddle does produce more airflow, it also consumes more power.

\subsection{Three-Dimensional Computational Flow Results: Comparison and Discussion}

The error between the test-rig measurements and the one-blade symmetry model results is about $55 \%$ for the region close to the blade, and about $25 \%$ for the region at the end of the tunnel. The error is very large near the blades, which means that the technique of using symmetry was not adequate in simulating the counter-rotational blade flow field and interference effects.

The error between the test rig measurements and the twin-blade model is about $14 \%$. The slightly widened cutting pan solution appeared to be a better method for simulating the airflow in the lawn care system. The direction of the velocity in all cases was the same between experiment and computational model. With all vents open, the error between the results was low (10\%) for most of the points. The exceptions to this were points $2 \mathrm{~b}$ and $2 \mathrm{c}$ (lower, rear, centre vent) where the computational results are $55 \%$ and $77 \%$ less than experimental data. This suggests that the porous jump vents on the computational model allow air to escape too easily at the top of the vent. With the centre vent closed, the results were even better. The error was low for most points; the exception is that the computed velocity at point $4 \mathrm{~b}$ is $33 \%$ higher than the experimental data. Even with errors, the direction of the air escaping the collector was the same between the experiments and the computer models. It is noted that positions with low velocity readings from the experiment were also low on the model, even though the error could not be calculated 
due to the lack of reliable experimental value. The manometer simply cannot measure velocity less than $2.5 \mathrm{~m} / \mathrm{s}$ in magnitude.

When the rotational speed of the cutting blades is reduced, the corresponding outlet mass flow rate is also reduced. The rotational speed was reduced, in steps, by about $36 \%$, which saw a reduction in mass flow rate of $23 \%$. The smaller reduction in mass flow rate could mean that the blades are inefficient at the speed they are rotating. The issue here is that $19000 \mathrm{fpm}$ is an industry standard for achieving quality of cut. 


\section{Chapter 3: Two-Dimensional Blade Flow Analysis}

\subsection{Introduction of Two-Dimensional Blade Flow}

The focus of this chapter is to analyze conventional blade shapes in terms of mass flow and power consumption. Results from the 2D simulations are used to provide guidance for blade design in the industry. Design of blades by conducting series of threedimensional analyses is computationally expensive and time consuming. Earlier 3-D studies showed that while 3-D simulations were possible, it was a very lengthy process that would prevent series of sensitivity studies. The idea for saving simulation time is to develop a reliable 2-D model for quick blade analysis and design. This chapter focuses on the airflow induced by a single blade although the actual cutting system has two blades. The intent is to find the optimal blade shape for airflow and power consumption.

The lawn care blades are surrounded by a molded cutting pan liner that is formed to the path of the blades and helps to better direct air through the tunnel and into the collector. The molded liner has shape properties that resemble both axial and centrifugal fan housings by directing air in both axial and radial directions (Fig. 36).

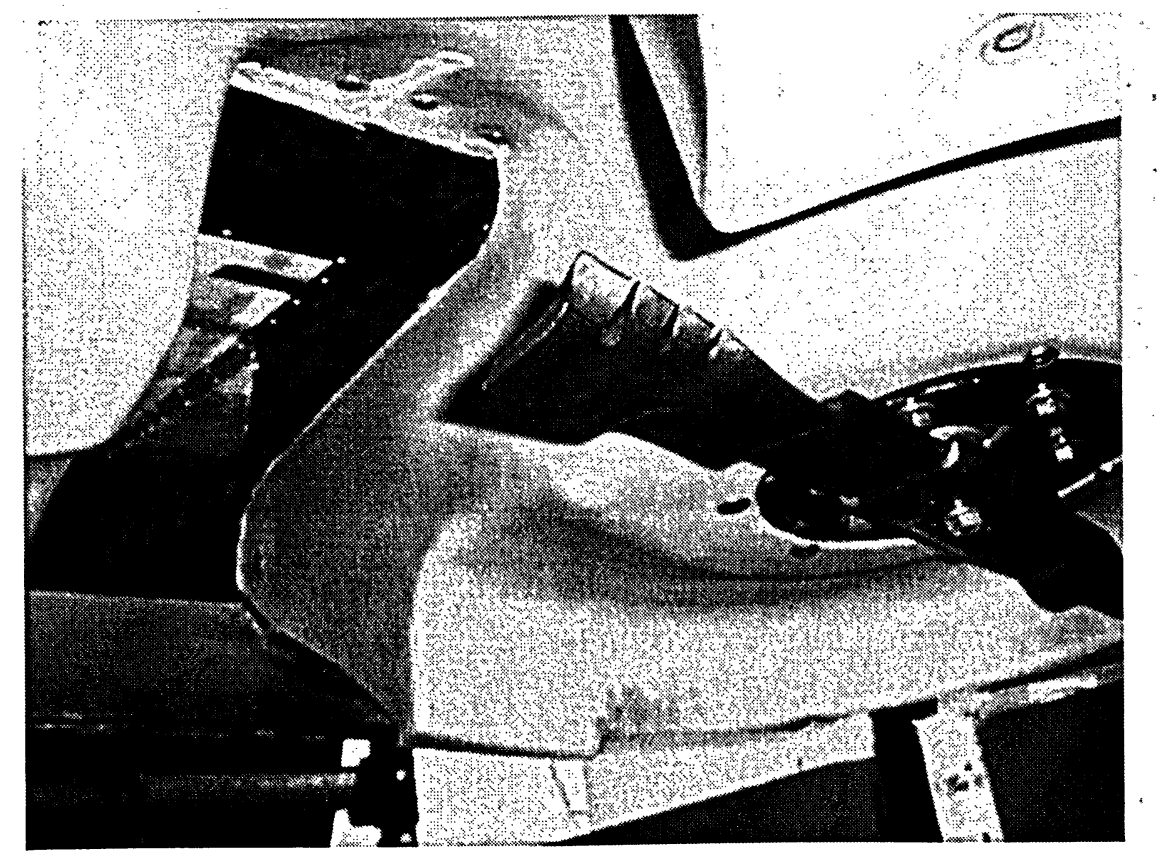

Fig. 36 Conventional blade 1 inside cutting pan 
The end of a cutting blade is responsible for the grass cutting and generation of sufficient airflow in the axial and circumferential directions. The airflow in the radial direction is small. For this reason, the system could be modeled as a tube-axial problem due to the low number of vanes ( 2 only) or vane-axial fan [6] due to the high nominal linear speed of $96.5 \mathrm{~m} / \mathrm{s}(19,000 \mathrm{ft} / \mathrm{min})$ at the tip. Under normal cutting, the blades rotate at $269 \mathrm{rad} / \mathrm{s}$ $(2569 \mathrm{rpm})$. The axial and circumferential airflows are determined by the effective 2-D shape of the blade near the end at a constant radius as shown in Fig. 37. The sharp leading edge of the blade is responsible for cutting grass while the raised trailing edge generates the upward airflow. A common method used to model 2-D axial fans is by transforming the endless rotational path of the blades into a finite, linear path as seen in many 2-D axial compressor cascade analyses [7] - [12].

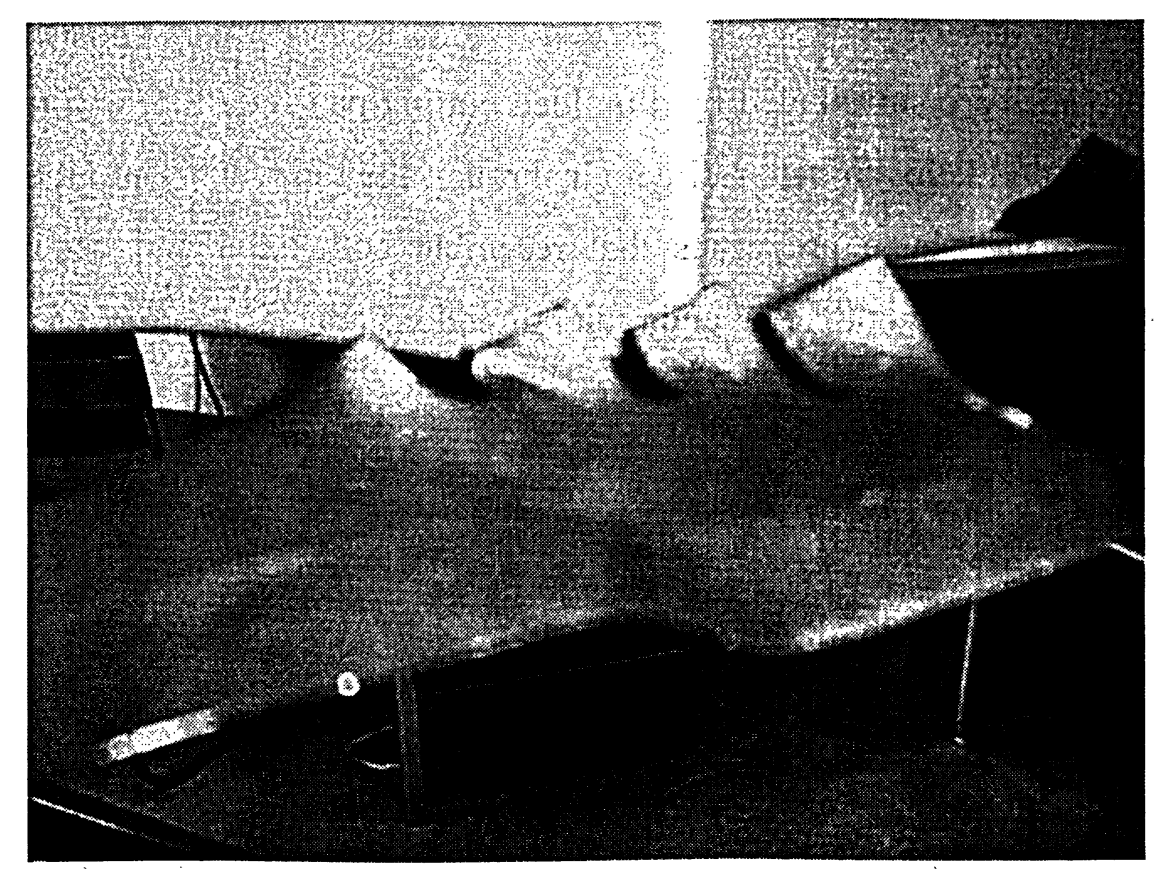

Fig. 37 Conventional blade 1 with raised trailing fins and sharp cutting edge

\subsection{Validation of Two-Dimensional Model}

The solution technique used in this chapter is based on 2-D axial fan/compressor analysis. The 2-D flow generated by lawn care blades is difficult to validate because existing 2-D 
results for lawn care blades do not exist. The technique will be validated by applying it to a CDA-43 compressor blade cascade with known experimental values.

\subsubsection{Two-Dimensional Validation Model set-up}

The experiment and model both use a 10-blade cascade, where the rotating path has been transformed into a linear path. A MRF is used in the subdomain containing the blades, and an adjacent stationary frame is present. The MRF moves at $20 \mathrm{~m} / \mathrm{s}$ to the left. The left, bottom, and right boundaries are set as pressure inlets; the top boundary is set as a pressure outlet. All boundaries are set to $0 \mathrm{~Pa}$ gauge pressure. The model can be seen in Fig. 38.

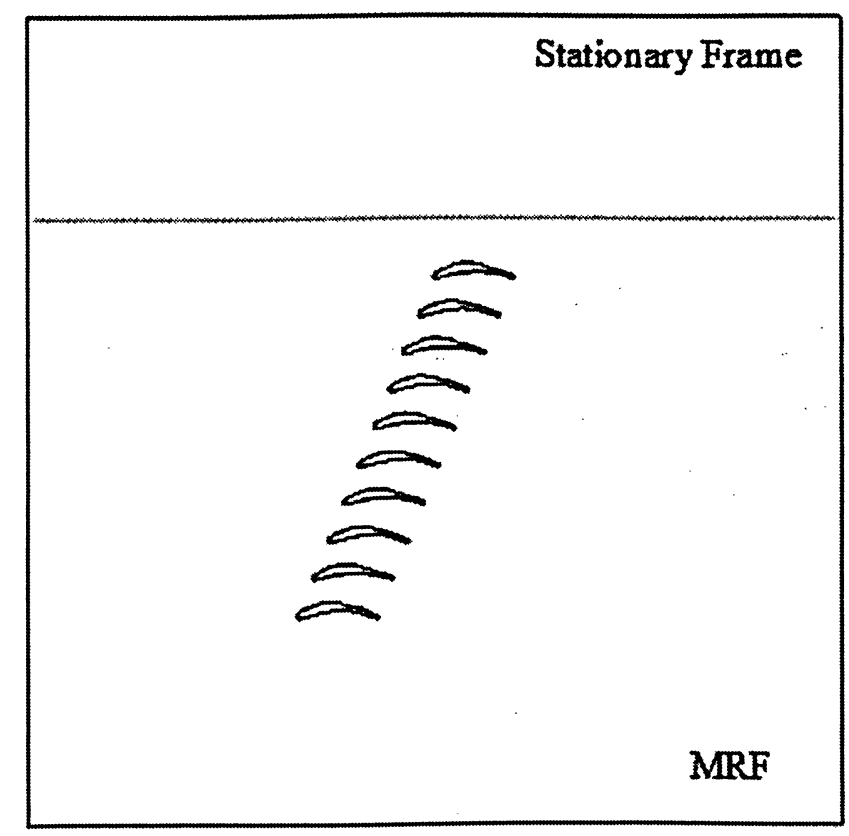

Fig. 38 Cascade of CDA-43 compressor blades

The blade edges were meshed with an interval size of $3 \mathrm{~mm}$, double-sided grading of 1.112. A boundary layer mesh was created on all blades with a first row height of 0.3 $\mathrm{mm}$, and 4 rows with a growth rate of 1.2. The MRF and stationary faces were meshed with an unstructured tri-pave mesh of interval length of $100 \mathrm{~mm}$. 
The solver is set-up as 2-D, time-steady, segregated, and implicit. The energy equation is not used. A standard k- $\varepsilon$ turbulence model is used with default constant values of $C_{\mu}=$ $0.09, C_{1 \varepsilon}=1.44, C_{2 \varepsilon}=1.92, \sigma_{\varepsilon}=1.3, \sigma_{\mathrm{K}}=1.0$. The properties of air were a constant density of $1.225 \mathrm{~kg} / \mathrm{m}^{3}$ (incompressible) and a constant viscosity of $1.789 \mathrm{E}-05 \mathrm{~kg} / \mathrm{m}-\mathrm{s}$. Operating pressure was $101.325 \mathrm{kPa}$. The no-slip condition is used on all surfaces.

Two sets of results were found for angles of attack equal to $0^{\circ}$ and $22^{\circ}$. The results of the model are shown in Fig. 39 and Fig. 40. The pressure coefficient is determined on the surface of the $5^{\text {th }}$ blade from the bottom of the cascade. The experimental values were obtained from [13]. SS is the suction surface, PS is the pressure surface.

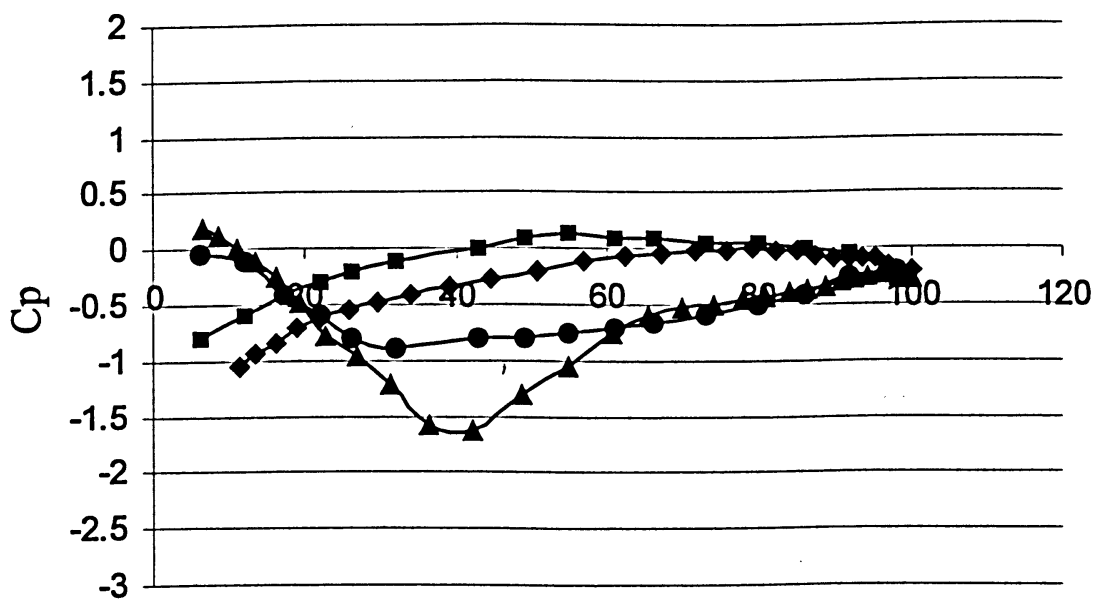

$\rightarrow-\operatorname{Exp}$. SS

$\rightarrow-$ Exp.PS

$\rightarrow$ Comp. SS

$\rightarrow$ Comp. PS

Chord \%

Fig. 39 CDA 43 surface pressure (Angle of Attack $=0^{\circ}$ ) 


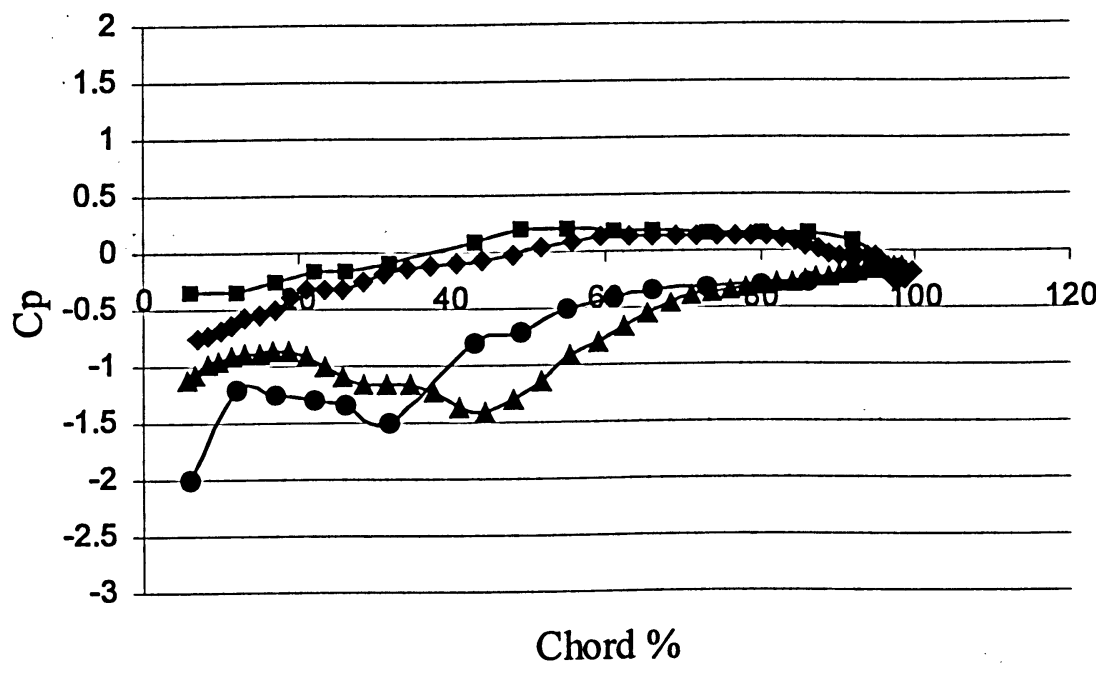

$\rightarrow-$ Exp. SS

$\rightarrow-$ Exp. PS

$\rightarrow$ Comp. SS

$\rightarrow$ Comp. PS

Fig. 40 CDA 43 surface pressure (angle of attack $=22^{\circ}$ )

The surface pressures generally matched well along the blade surfaces. The largest discrepancy was at the $40 \%$ chord position with an angle of attack of $0^{\circ}$.

\subsection{Two-Dimensional Computational Model}

The standard GP-T blade for the 54" cutting/collection system is $0.721 \mathrm{~m}$ long. The blade cross-section changes along the blade length. The blade shape near either tip is critical and has a length of about $8 \mathrm{~cm}$. The inner portion of the blade is not significant in terms of grass cutting and airflow generation." However, as an integral part of the blade, the inner portion is responsible for transmitting power from the hub to the tips. In the 2-D model, the cross section is taken $4 \mathrm{~cm}$ from the tip of the blade in order to attain a profile in the middle of the scoop. At this location, the cross section of the blade has a linear speed of $86.5 \mathrm{~m} / \mathrm{s}(17,000 \mathrm{ft} / \mathrm{min})$. The transformed linear shape of the cutting pan housing can be seen in Fig. 41. The edges of the cutting pan (bottom and sides) in

Fig. 41 are set as inlets. The edges at the end of the raised tunnels are the outlets. 


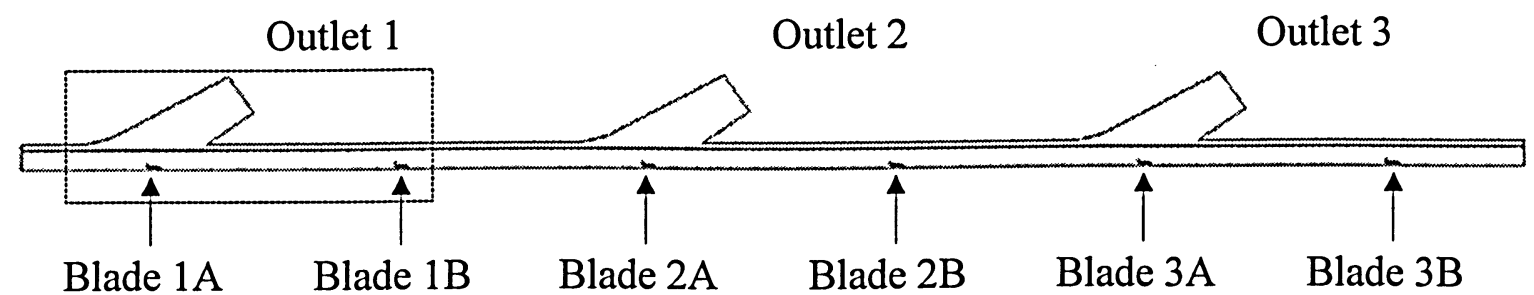

(a) Complete 2-D model

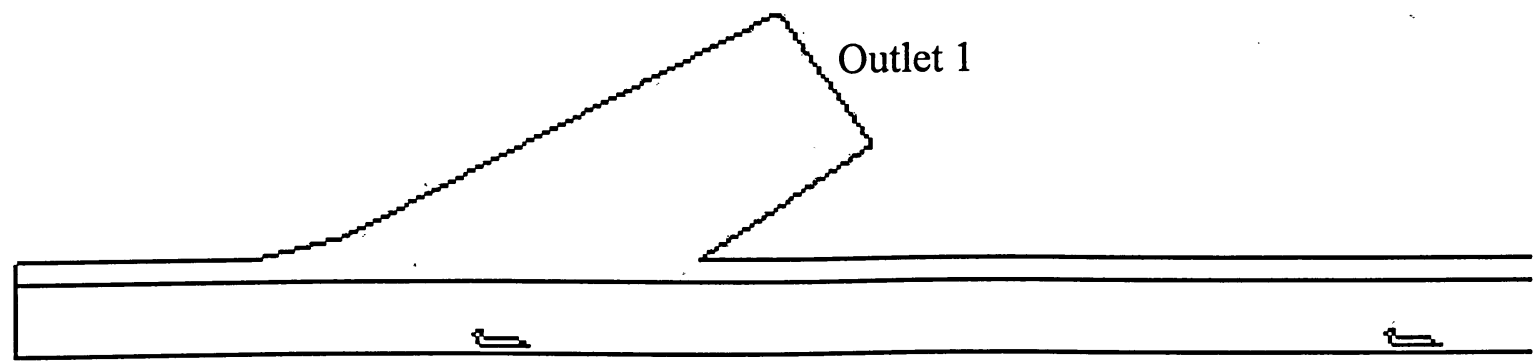

(b) Detailed view

Fig. 41 Linearly transformed cutting pan housing

The linear cutting pan model is $6.1 \mathrm{~m}$ long and is capable of simulating airflow for the first three complete turns of the blade. Since the cutting blade has a cutting edge on each end, the individual blade profiles have a linear spacing of half of the circumference of the rotational blade path. For an effective diameter of $0.641 \mathrm{~m}$, the blade path is then 2.014 $\mathrm{m}$. The entire model includes six blade profiles and three tunnel outlets. The outlets are raised $30^{\circ}$, which is representative of a lawn care system tunnel $35 \mathrm{~cm}$ in length and 18 $\mathrm{cm}$ in height. The actual tunnel is $1.6 \mathrm{~m}$ long and connects the cutting pan to the collector where the clippings are stored. The height of the horizontal cutting pan area used was 11 $\mathrm{cm}$. This height varies between $1 \mathrm{~cm}$ and $15 \mathrm{~cm}$ to allow flexibility in cutting heights. In this model, the actual tunnel and collector are not included because the focus is on the blade profile design and power consumption. 
It is necessary to include several blade configurations in the model because the flow needs to develop as it passes from one blade to the next. Usually six to ten configurations are sufficient for the flow to be fully developed in a 2-D compressor cascade [14]. The 2-D model shown in Fig. 41 has a blade spacing of $1.007 \mathrm{~m}$ and a blade length of 0.065 $\mathrm{m}$, with a blade spacing to length ratio of 15 . The interference effects from one blade to another can be considered negligible when the blade spacing to length ratio is equal to or greater than three in conventional axial-bladed systems [1]. In many axial flow systems, the top edge is open so that air can flow directly through. However, the lawnmower system has a wall on the top edge, which prevents the passage of air. The closeness of a wall to the blades may induce more severe interference effects. As a result, six blade configurations were used in the model.

In all cases studied in this chapter, the blades are positioned such that the trailing edge of every other blade coincides with the midpoint of a tunnel outlet. It is understood that the instantaneous steady-state flow field surrounding the blades varies as they move through the cutting pan; however, this position was picked as the common position in which all the blade profiles are analyzed. Since the actual blades have two scoop profiles per blade, results obtained in a 2-D model must use the combined effect of two adjacent blade profiles.

\subsubsection{Two-Dimensional Boundary Conditions}

All inlet and outlet surfaces are set to have zero gauge pressure. These surfaces are exposed to the atmosphere and the pressure values on these edges remain at zero gauge pressure in all models. The velocity through the edge nodes can change, but it will not affect the zero gauge pressure. Since the inlet and outlet surface pressures are equal, there is no back-pressure load on the system for a steady-state solution In real tests, the pressures at the inlet and outlet deviate from atmospheric conditions, but it is difficult to apply a specific pressure at the 2-D edges since they cannot be found directly from test rig measurement. A test was conducted to see whether the gap between the bottom of the blade and the inlet surface provided enough computational space to allow the pressure to 
deviate from atmospheric conditions. Two cases shown in Fig. 42 were examined. The first case has a gap of $1 \mathrm{~cm}$ between all the blades and the inlet, the second case has a gap of $15 \mathrm{~cm}$. The results are tabulated in Table 13 .

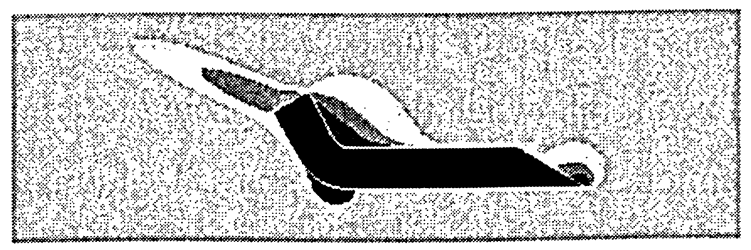

(a)

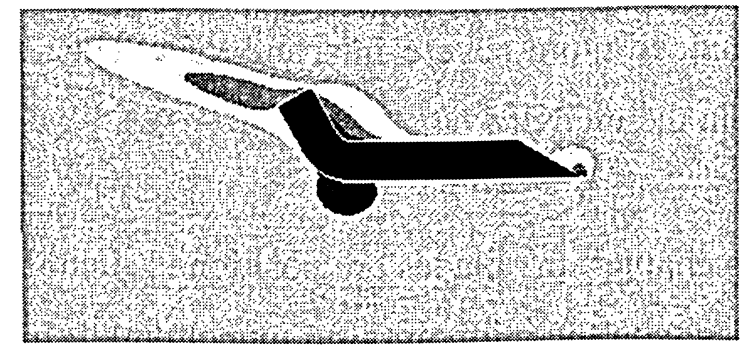

(b)

Fig. 42 Total pressure contours around blade with inlet gaps of (a) $1 \mathrm{~cm}$ (b) $15 \mathrm{~cm}$

Table 13 Effects of Inlet Gaps on Airflow

\begin{tabular}{|c|c|c|}
\hline Gaps $(\mathrm{cm})$ & Drag force $(\mathrm{N})$ & $\begin{array}{l}\text { Mass Flow } \\
\text { Rate }(\mathrm{kg} / \mathrm{s})\end{array}$ \\
\hline 1 & 180 & 6.99 \\
\hline 15 & 158 & 6.97 \\
\hline
\end{tabular}

The mass flow rates for the two cases are the same. The drag force acting on the blades for the $1 \mathrm{~cm}$ case is larger than that for the $15 \mathrm{~cm}$ case. The pressure regions surrounding the blade are the same in both cases. The extra computational domain with the $15 \mathrm{~cm}$ gap allows for a smaller pressure gradient under the blade; however, much of the extra space is not needed and only adds to the size of the model. In this study, the lower $1 \mathrm{~cm}$ gap is used in optimal blade designs. 
The initial model exhibited some numerical instability when the velocity boundary condition was applied directly to the blades. This was most likely caused by the high degree coupling between the two momentum equations when the influence of a rotational or translational term is large [5]. The Multiple Reference Frame (MRF) can be used to remedy this problem. The MRF zone must be a straight rectangular shape for a translational path. In the final model, MRF zone begins $2.5 \mathrm{~cm}$ below the top of the cutting pan ceiling and goes to the base inlet surface, Fig. 4.

For the solver boundary conditions, the bottom zone was set as a MRF with a translational velocity of $86.5 \mathrm{~m} / \mathrm{s}$ to the right. All of the blade surfaces have their adjacent cell zones as the MRF; therefore, in momentum options, the blade walls are defined as "Moving Wall", "Relative to Adjacent Cell Zone" with a translational speed of $0 \mathrm{~m} / \mathrm{s}$ to the right. The zero speed is relative to the MRF which moves at $86.5 \mathrm{~m} / \mathrm{s}$.

\subsubsection{Two-Dimensional Grid Analysis}

Meshing begins on the edges of each blade with a spacing of $1 \mathrm{~mm}$. A boundary layer mesh was created with 4 rows. The first row is $0.5 \mathrm{~mm}$ from the surface and uses a growth rate of 1.2. The MRF area and upper area were meshed with a Tri-Pave scheme with a $5 \mathrm{~mm}$ interval size (Fig. 43). Similar techniques were used to create the other meshes, and are tabulated in Table 14. 


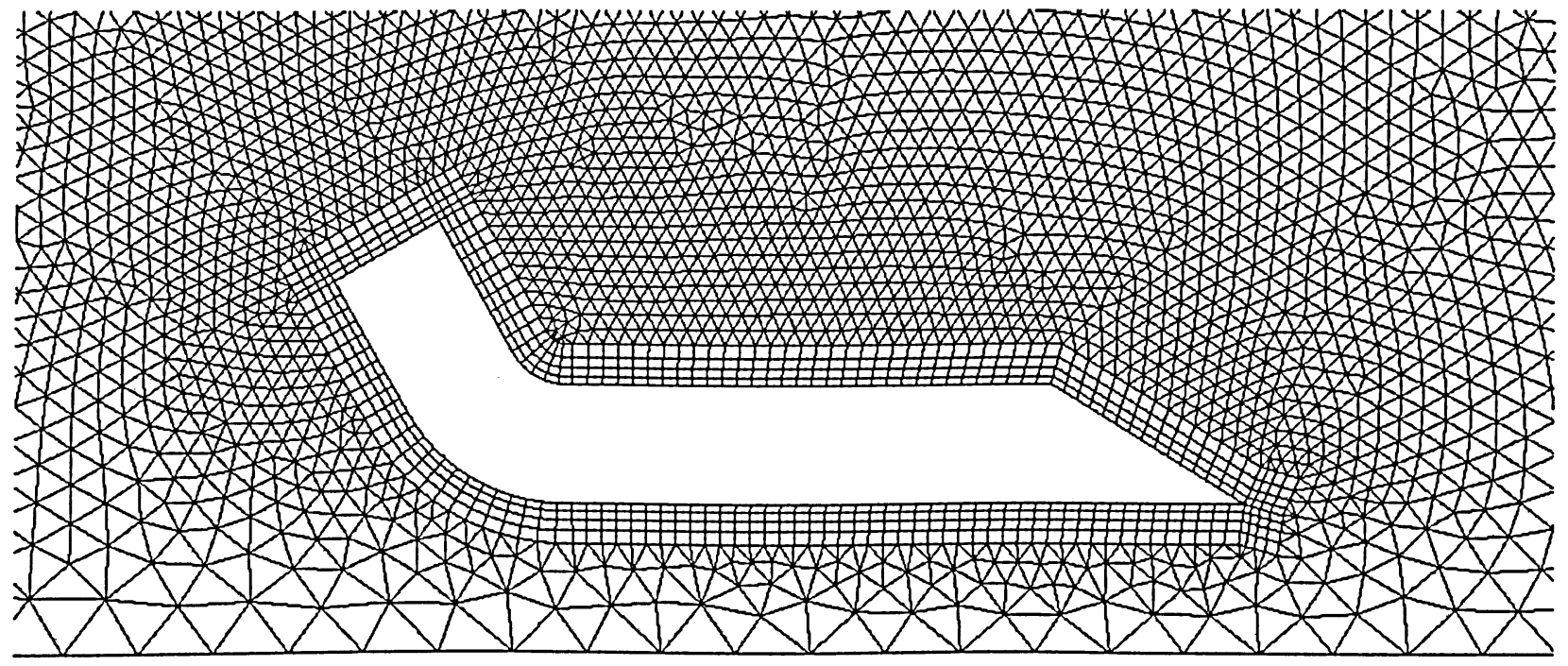

Fig. 43 Medium mesh around blade profile

Table 14 Grid Analysis Parameters

\begin{tabular}{|c|c|c|c|c|c|c|}
\hline & $\begin{array}{r}\text { Boundary La } \\
\text { Parame }\end{array}$ & $\begin{array}{l}\text { er Mesh } \\
\text { rs }\end{array}$ & Tri- & & & \\
\hline Meshes & $\begin{array}{c}\text { Edge } \\
\text { interval size } \\
{[\mathrm{mm}]}\end{array}$ & $\begin{array}{c}\text { First } \\
\text { row } \\
\text { height } \\
{[\mathrm{mm}]}\end{array}$ & $\begin{array}{c}\text { Pave } \\
\text { Interval } \\
\text { size } \\
{[\mathrm{mm}]}\end{array}$ & $\begin{array}{c}\text { Number } \\
\text { of } \\
\text { Elements }\end{array}$ & $\begin{array}{c}\text { Drag Force } \\
\qquad \mathrm{N}]\end{array}$ & $\begin{array}{l}\text { Mass Flow } \\
\text { Rate }[\mathrm{kg} / \mathrm{s}]\end{array}$ \\
\hline Coarse & 2 & 1 & 10 & 32,263 & 7.13 & 0.558 \\
\hline Medium & 1 & 0.5 & 5 & 125,910 & 7.22 & 0.562 \\
\hline Fine & 0.5 & 0.25 & 2.5 & 478,724 & 7.27 & 0.550 \\
\hline
\end{tabular}

Table 14 shows that the results are the same for all mesh sizes. The medium sized mesh parameters were used in all tests to achieve a balance of computational time and detail in flow field diagrams.

\subsubsection{2-Dimensional Solution Parameters}

The solver is set as 2-D, time-steady, segregated, and implicit. The energy equation is not used in the system as temperature rise is not a concern. A standard $k-\varepsilon$ turbulence model 
is used with default constant values of $C_{\mu}=0.09, C_{1 \varepsilon}=1.44, C_{2 \varepsilon}=1.92, \sigma_{\varepsilon}=1.3, \sigma_{\mathrm{\kappa}}=$ 1.0. These values were determined from experiments with air and water and have been found to work well for wall-bounded flows [5]. The properties of air were a constant density of $1.225 \mathrm{~kg} / \mathrm{m}^{3}$ (incompressible) and a constant viscosity of $1.789 \mathrm{E}-05 \mathrm{~kg} / \mathrm{m}-\mathrm{s}$. Operating pressure was $101.325 \mathrm{kPa}$ and gravity was set to $-9.8 \mathrm{~m} / \mathrm{s}^{2}$, downwards. The no-slip condition is used on all surfaces.

\subsection{Blade Profile Shapes:}

Thirteen blade profiles were analyzed in total. Fig. 44 shows two blade profiles that have been used in the industry. Each profile is $8 \mathrm{~mm}$ thick and has a $30^{\circ}$ cutting tip. The chord lengths of conventional profiles 1 and 2 are $6.2 \mathrm{~cm}$ and $9.5 \mathrm{~cm}$, respectively.

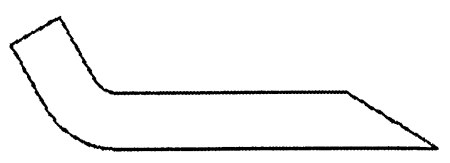

(a)

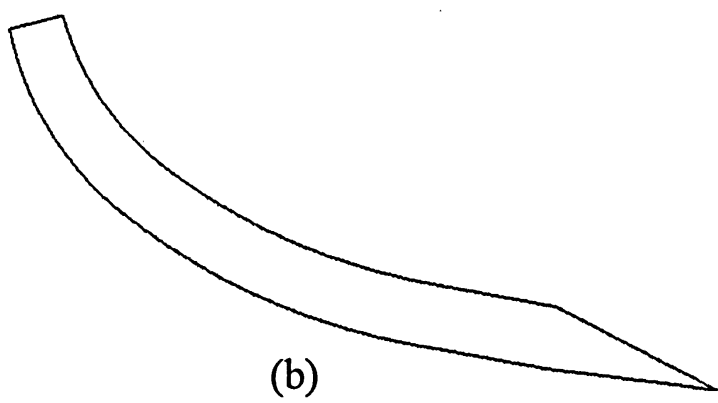

Fig. 44 Two blade profiles currently used in industry

New blade profiles were created based on conventional profile 1 , which has a $2.2 \mathrm{~cm}$ tail at $60^{\circ}$. The features of the tail that were altered are the shape, the angle, and the length. Variations of the tail are shown in Fig. 45, Fig. 46, and Fig. 47. Fig. 45a has a $75^{\circ}$ bottom tail edge, Fig. $45 \mathrm{c}$ has a $30^{\circ}$ top tail edge, and the remaining edges are unchanged at $60^{\circ}$. The profile in Fig. $46 \mathrm{a}$ has an extended tail length of $4.4 \mathrm{~cm}$. The profile in Fig. $46 \mathrm{c}$ has a tail length of $1.1 \mathrm{~cm}$. Fig. $47 \mathrm{a}$ has a $75^{\circ}$ tail angle. Fig. $47 \mathrm{c}$ has a $30^{\circ}$ tail angle. 


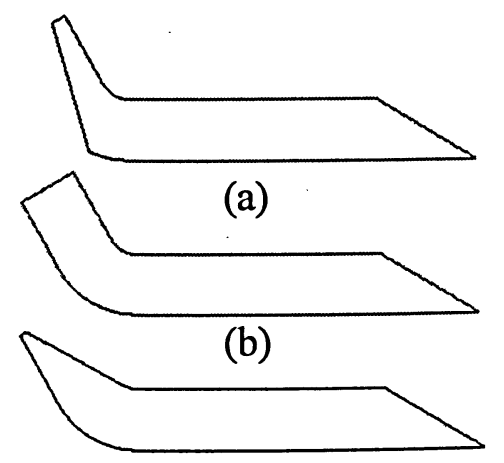

(c)

Fig. 45 Tail shape modifications: (a) ground rear, (b) the first conventional profile, and (c) ground front

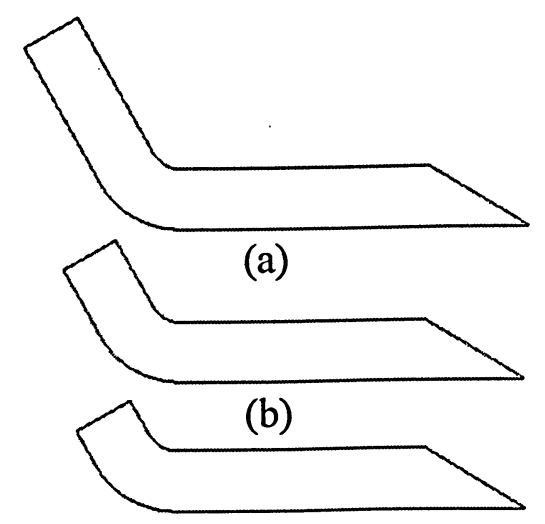

(c)

Fig. 46 Tail length modifications, (a) extended length, (b) the first conventional profile, (c) decreased length 

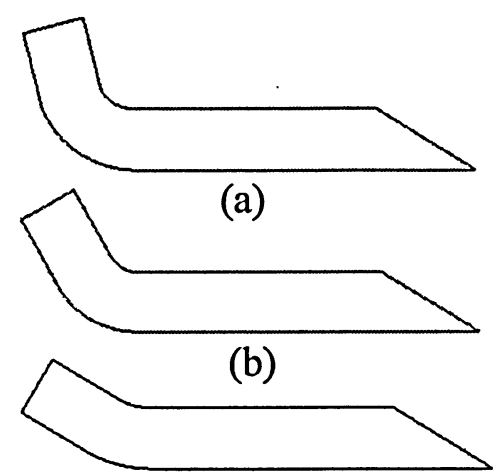

(c)

Fig. 47 Tail angle modifications: (a) extended, $75^{\circ}$, (b) the first conventional profile, $60^{\circ}$, (c) reduced, $30^{\circ}$

Conventional blade shapes have a raised tail near the back. Typical aerofoil shapes have camber lines that are either circular or parabolic from front to back [14]. The new aerofoil shapes under consideration will have the curve initiated more towards the front and maintain a maximum thickness of $8 \mathrm{~mm}$. The maximum height of the profile is 4.75 $\mathrm{cm}$, which is the same as that of the second conventional profile.

Four aerofoil shapes were examined (Fig. 48). The first aerofoil blade has a $30^{\circ}$ tail of 4 $\mathrm{cm}$ in length, ground down to a sharp point. The chord length is $6.2 \mathrm{~cm}$. The second aerofoil profile has a shorter tail, $3 \mathrm{~cm}$ in length. The third aerofoil has a $20^{\circ}$ tail of $3 \mathrm{~cm}$ in length. The final aerofoil profile has a tail angle of $20^{\circ}$ and an extended length of $6 \mathrm{~cm}$. 


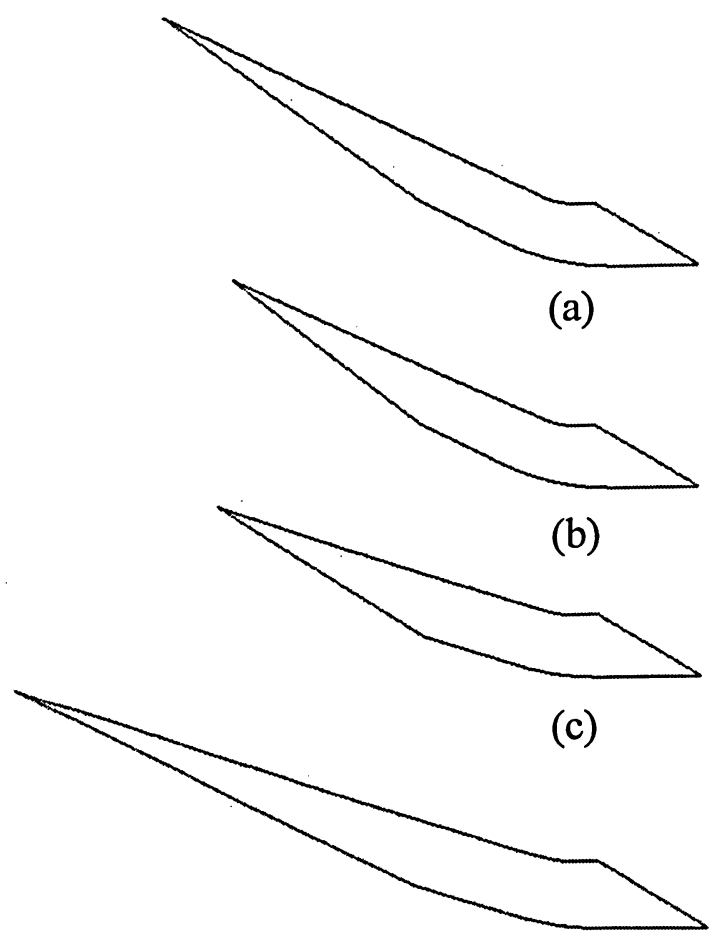

(d)

Fig. 48 Aerofoil shapes: (a) initial aerofoil, (b) decreased tail length, (c) decreased tail angle, (d) increased tail length

\subsection{2-D Computational Results}

The computed quantities include the mass flow rate at outlet 3 shown in Fig. 41, and the drag force on each blade profile. The power consumption was determined by multiplying the drag force by the arm of $0.321 \mathrm{~cm}$. The blades spin at $269 \mathrm{rad} / \mathrm{s}(2570 \mathrm{rpm})$ in opposite directions. The right-most column in Table 15 through Table 19 shows the ratio of mass flow rate to power. It is expected that more efficient blades produce high ratios of the mass flow to power consumption.

In the 2-D numerical simulations, the results are per unit depth into the $3^{\text {rd }}$ dimension. For example, a 2-D mass flow rate result of $7.03 \mathrm{~kg} / \mathrm{s}$ actually represents $7.03(\mathrm{~kg} / \mathrm{s}) /($ per meter depth). The depth in our system is $8 \mathrm{~cm}$. The $8 \mathrm{~cm}$ depth comes from $4 \mathrm{~cm}$ on either side of the blade profile since it was taken mid-way. A $7.03 \mathrm{~kg} / \mathrm{s}$ in $2-\mathrm{D}$ would 
represent $0.56 \mathrm{~kg} / \mathrm{s}$ mass flow rate in these systems. Results listed for force and mass flow rate have been multiplied by the $0.08 \mathrm{~m}$ depth.

Table 15 Results for Conventional Blades

\begin{tabular}{|c|c|l|l|c|}
\hline Profiles & $\begin{array}{l}\text { Mass Flow } \\
\text { Rate }[\mathrm{kg} / \mathrm{s}]\end{array}$ & $\begin{array}{l}\text { Drag } \\
\text { Force }[\mathrm{N}]\end{array}$ & $\begin{array}{l}\text { Power } \\
{[\mathrm{kW}]}\end{array}$ & $\begin{array}{l}\text { Efficiency Ratio } \\
{[(\mathrm{kg} / \mathrm{s}) / \mathrm{kW}]} \\
\cdot\end{array}$ \\
\hline Fig. 44a & 0.56 & 7.23 & 1.25 & 0.45 \\
\hline Fig. 44b & 0.71 & 14.29 & 2.46 & 0.29 \\
\hline
\end{tabular}

Table 16 Tail Shape Modification Results

\begin{tabular}{|c|c|c|c|l|}
\hline & $\begin{array}{l}\text { Mass Flow } \\
\text { Rate [kg/s] }\end{array}$ & $\begin{array}{l}\text { Drag } \\
\text { Force }[\mathrm{N}]\end{array}$ & $\begin{array}{l}\text { Power } \\
{[\mathrm{kW}]}\end{array}$ & $\begin{array}{l}\text { Efficiency } \\
\text { Ratio } \\
{[(\mathrm{kg} / \mathrm{s}) / \mathrm{kW}]}\end{array}$ \\
\hline Fig. 45a & 0.50 & 6.11 & 1.05 & 0.48 \\
\hline Fig. 45b & 0.56 & 7.23 & 1.25 & 0.45 \\
\hline Fig. 45c & 0.44 & 4.31 & 0.75 & 0.59 \\
\hline
\end{tabular}

Table 17 Tail Length Modification Results

\begin{tabular}{|c|l|c|c|l|}
\hline & $\begin{array}{l}\text { Mass } \\
\text { Flow Rate } \\
{[\mathrm{kg} / \mathrm{s}]}\end{array}$ & $\begin{array}{l}\text { Drag } \\
\text { Force }[\mathrm{N}]\end{array}$ & $\begin{array}{l}\text { Power } \\
{[\mathrm{kW}]}\end{array}$ & $\begin{array}{l}\text { Efficiency } \\
\text { Ratio } \\
{[(\mathrm{kg} / \mathrm{s}) / \mathrm{kW}]}\end{array}$ \\
\hline Fig. 46a & 0.63 & 9.85 & 1.70 & 0.37 \\
\hline Fig. 46b & 0.56 & 7.23 & 1.25 & 0.45 \\
\hline Fig. 46c & 0.45 & 4.96 & 0.86 & 0.52 \\
\hline
\end{tabular}




\section{Table 18 Tail Angle Modification Results}

\begin{tabular}{|l|l|l|l|l|}
\hline Profiles & $\begin{array}{l}\text { Mass } \\
\text { Flow Rate } \\
{[\mathrm{kg} / \mathrm{s}]}\end{array}$ & $\begin{array}{l}\text { Drag } \\
\text { Force }[\mathrm{N}]\end{array}$ & $\begin{array}{l}\text { Power } \\
{[\mathrm{kW}]}\end{array}$ & $\begin{array}{l}\text { Efficiency Ratio } \\
{[(\mathrm{kg} / \mathrm{s}) / \mathrm{kW}]}\end{array}$ \\
\hline Fig. 47a & 0.57 & 7.67 & 1.32 & 0.43 \\
\hline Fig. 47b & 0.56 & 7.23 & 1.25 & 0.45 \\
\hline Fig. 47c & 0.40 & 3.94 & 0.68 & 0.59 \\
\hline
\end{tabular}

Table 19 Aerofoil Shape Results

\begin{tabular}{|c|l|c|c|c|}
\hline Profiles & $\begin{array}{l}\text { Mass } \\
\text { Flow Rate } \\
{[\mathrm{kg} / \mathrm{s}]}\end{array}$ & $\begin{array}{l}\text { Drag } \\
\text { Force }[\mathrm{N}]\end{array}$ & $\begin{array}{l}\text { Power } \\
{[\mathrm{kW}]}\end{array}$ & $\begin{array}{l}\text { Efficiency Ratio } \\
{[(\mathrm{kg} / \mathrm{s}) / \mathrm{kW}]}\end{array}$ \\
\hline Fig. 48a & 0.59 & 7.94 & 1.37 & 0.43 \\
\hline Fig. 48b & 0.57 & 7.08 & 1.22 & 0.47 \\
\hline Fig. 48c & 0.50 & 5.14 & 0.89 & 0.56 \\
\hline Fig. 48d & 0.51 & 5.67 & 0.98 & 0.52 \\
\hline
\end{tabular}

\subsection{Discussion on Two-Dimensional Computational Flow}

Analysis of the conventional blades showed that the paddle blade profile produced a mass flow of $0.71 \mathrm{~kg} / \mathrm{s}$, which is $27 \%$ higher than the serrated blade profile. The paddle blade profile consumes about $3.3 \mathrm{hp}$, which is $94 \%$ higher than the serrated blade profile. This translates to a lower efficiency ratio of $0.22(\mathrm{~kg} / \mathrm{s}) / \mathrm{hp}$ for the paddle blade compared to 0.34 for the serrated blade. It is known from the testing of the actual lawn care system that the paddle blade consumes a great deal of power, but the serrated blade does not. This is in agreement with the numerical results. It is also observed in the real system that the airflow speed generated by the paddle blade (profile 2) is much higher compared to the serrated blade (profile 1) and is beneficial for tunnel clog prevention and clipping compaction. The trend is also found in the computational results. 
Grinding the rear edge on the blade profiles decreased both the mass flow and the power consumption. Grinding the top edge had the effect of a large reduction in power consumption and had a significant increase in efficiency.

Increasing the tail length had the effect of increasing both mass flow rate and power consumption. Decreasing the tail length caused both to decrease.

Increasing the angle of the tail caused a slight increase in both mass flow rate and power consumption. Decreasing the tail angle caused a decrease in mass flow and almost cut the power consumption in half, resulting in a relatively large efficiency. Generally, the most efficient profiles had the lowest top surface tail angle.

The position of the blades inside the cutting pan in the numerical model will affect the results. This study uses only one position, which is the same for all blade profiles. A series of positions for the profiles could result in a more thorough analysis; however, it would significantly increase the work required to analyze many profiles. The scope of this study was to mainly compare different 2-D profiles under the same conditions.

GP-Turfcare had concerns over the aerofoil shaped blade profiles. These profiles have thin, tapered tails and these sections often get worn very quickly on real blades due to the sand-blasting affect that the high speed clippings and debris have on the blades. Unless the material along the trailing edge of the blades are somehow be hardened, the thin trailing edge may be worn away prematurely and lessen the life and effectiveness of the blade. 


\section{Chapter 4: Vibration Analysis}

\subsection{Introduction}

Real world and laboratory tests of the lawn care unit both demonstrated that a great deal of noise is generated during operations. The level of noise is such that it exceeds some strict decibel level requirements. In real world testing, the combustion engine would significantly contribute to the overall sound level; in the lab testing, a quieter electric motor was used instead. This study will use vibration analysis to find out if the natural frequency of the blades is close to the forcing frequency, which would cause excessive blade vibration. A combination of experimental and computational analysis was done. The blades spin at $2570 \mathrm{rpm}$, or $42.8 \mathrm{~Hz}$. The blades have a raised edge on each side of the blade, which would create a forcing frequency of $85.6 \mathrm{~Hz}$, double the shaft speed.

\subsection{Experimental Set-up}

To find the static natural frequency of the blade, it was supported normally in the cutting pan on the test rig. It was struck with an impact hammer and the resulting frequencies were found with a data acquisition system and the frequency domain was displayed on a computer. The data acquisition system consisted of an accelerometer mounted to the tip of a blade, which had its analog signal converted to digital, then routed into a computer . where it was processed. The software used to display the frequency domain was Visual Designer.

The forcing frequency on the blades is low; therefore, only the first few bending modes will be investigated. It is verified later in the computational section that the first mode is bending. The accelerometer is mounted to record bending modes, not twisting or other modes, Fig. 49. 


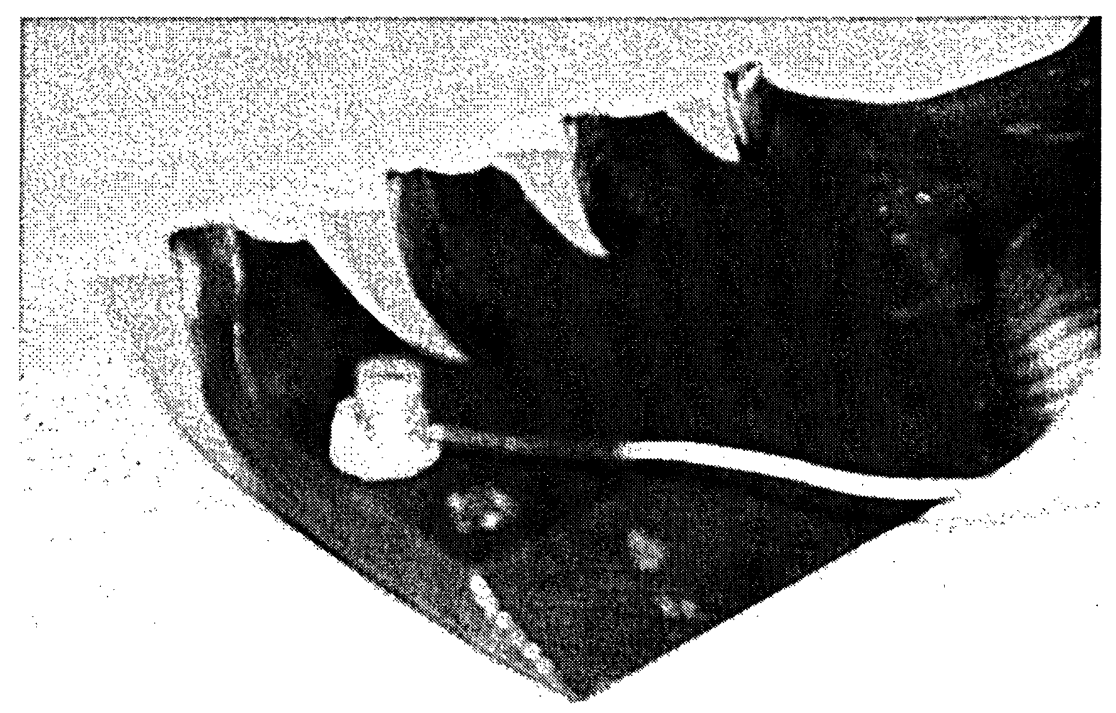

Fig. 49 Accelerometer mounted on serrated blade

The mounting of the blade onto the lawnmower is done via a clamping system where the blade is set between a round shaft with a T-shaped flange (Fig. 50) and a bottom plate (Fig. 51). The blade is securely fit between the 2 pieces by a bolt in the middle which has threads that tighten in the opposite direction as the blade rotation. This will ensure that a tight fit is kept and that the blade will not come off during normal operations. In the theoretical mounting, the plate is flush with the blade and no gaps are present. The dimensions of the T-shaped flange are $4.5 \mathrm{~cm}$ by $9.8 \mathrm{~cm}$. 


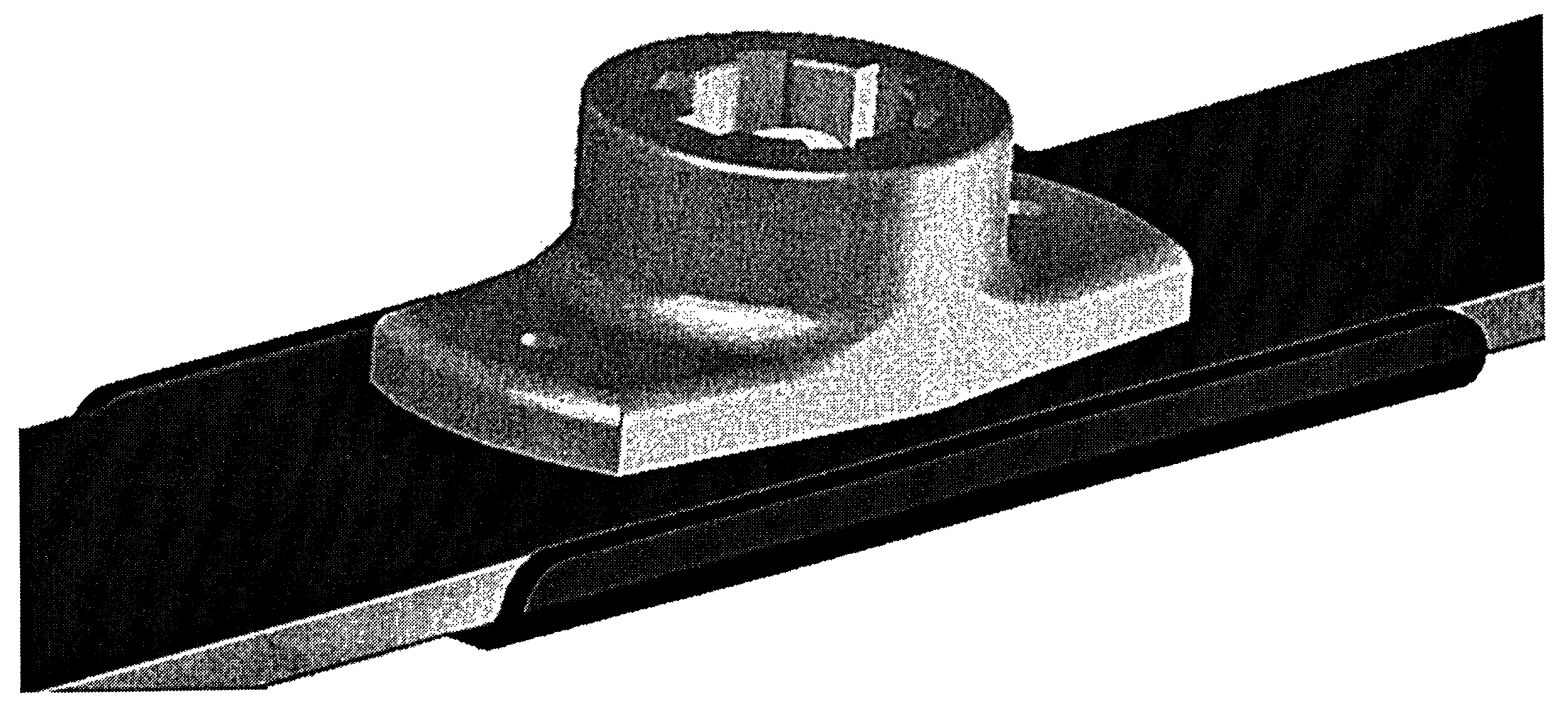

Fig. 50 Computer model of T-shaped flange clamping the top of the blade

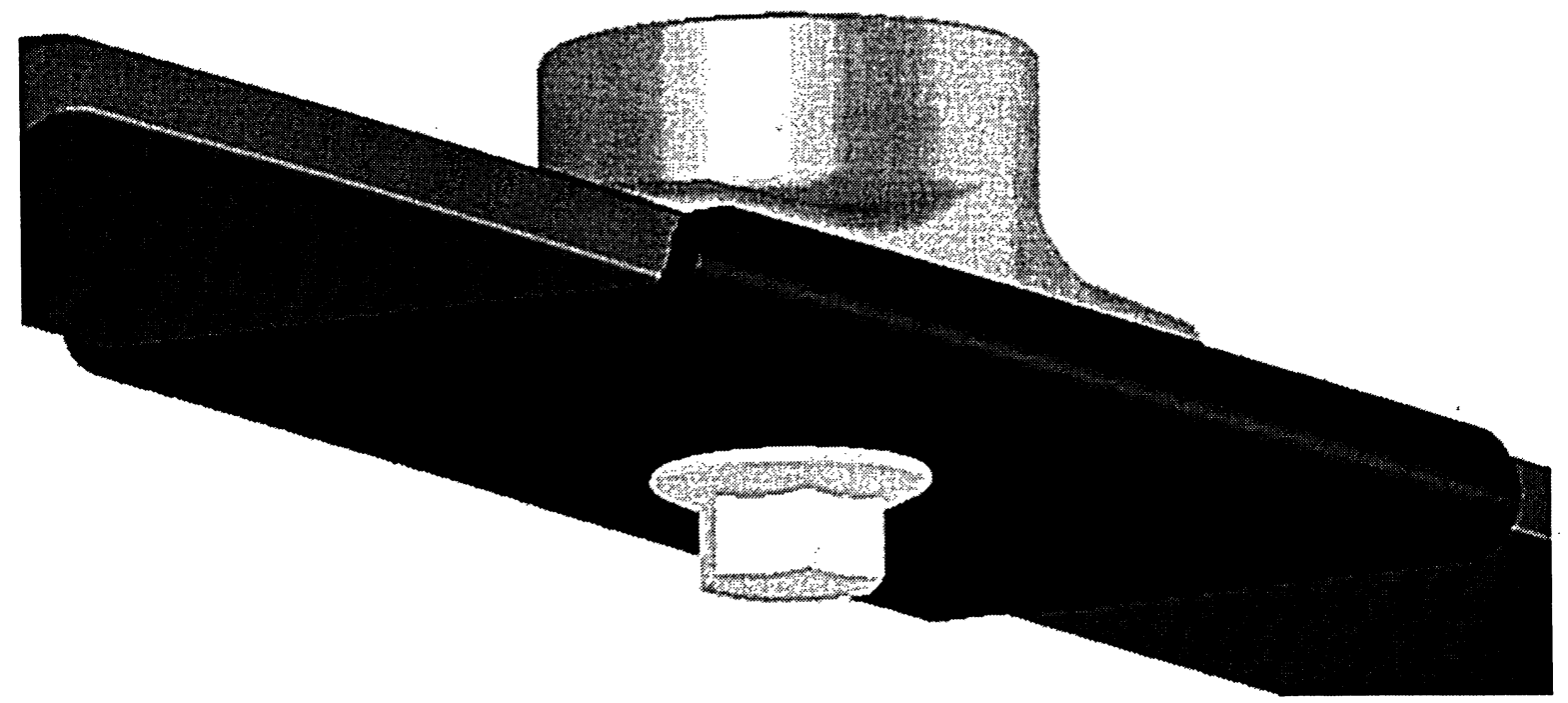

Fig. 51 Computer model of bottom plate and bolt clamping the bottom of the blade

The actual mounting of the blade produces a small gap between the blade and the bottom plate, Fig. 52. This is due to the high bolt tightness, which ensures a tight fit in the areas around the bolt, but a bending effect further away. 


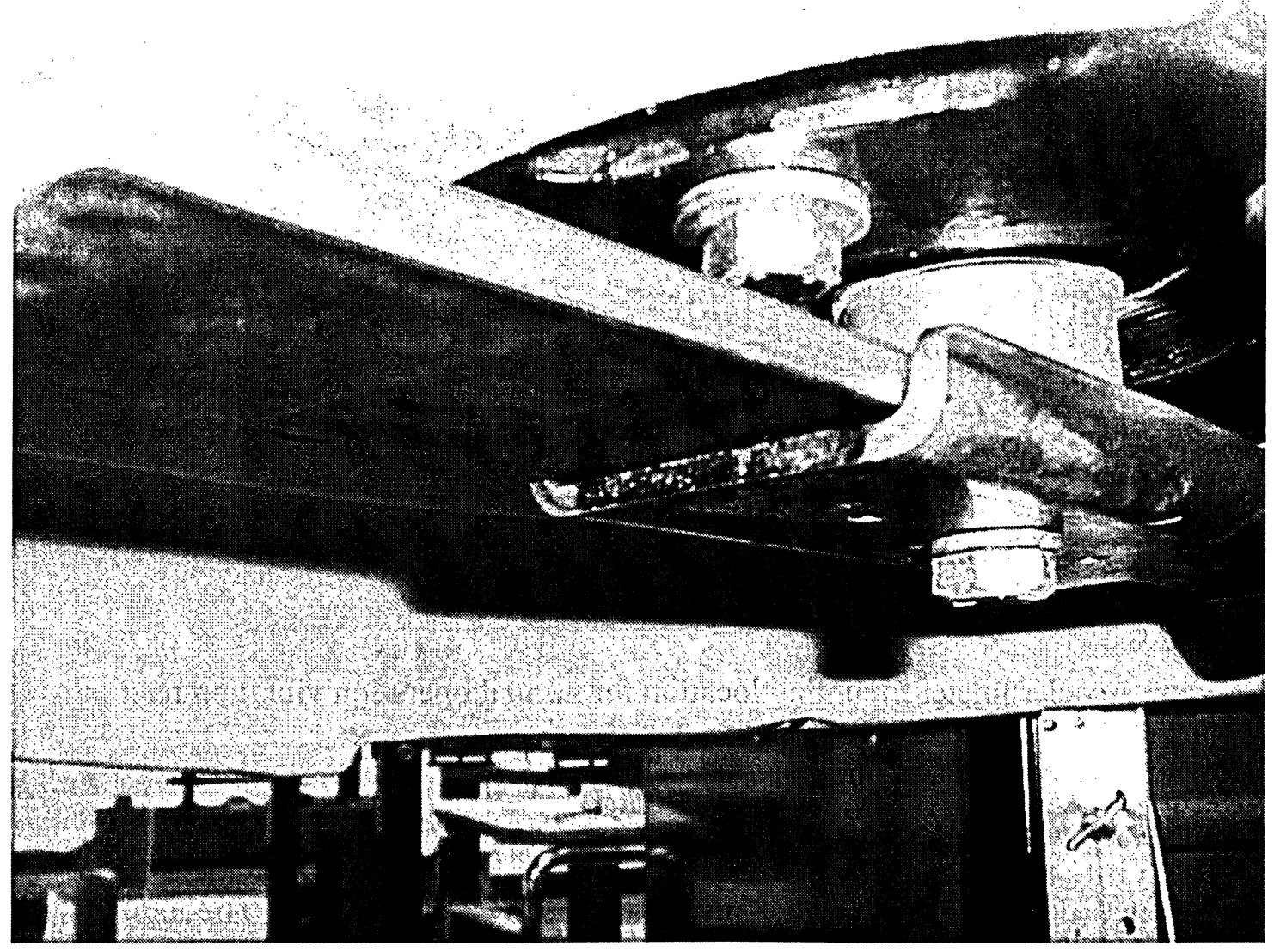

Fig. 52 Blade mounted to the bottom plate with gap between them

The accelerometer was also mounted to the top of the tunnel, near the cutting pan, and data was collected while the system was running. The location is shown in Fig. 53. This data will be used to determine which frequencies the system is vibrating at during normal operation. 


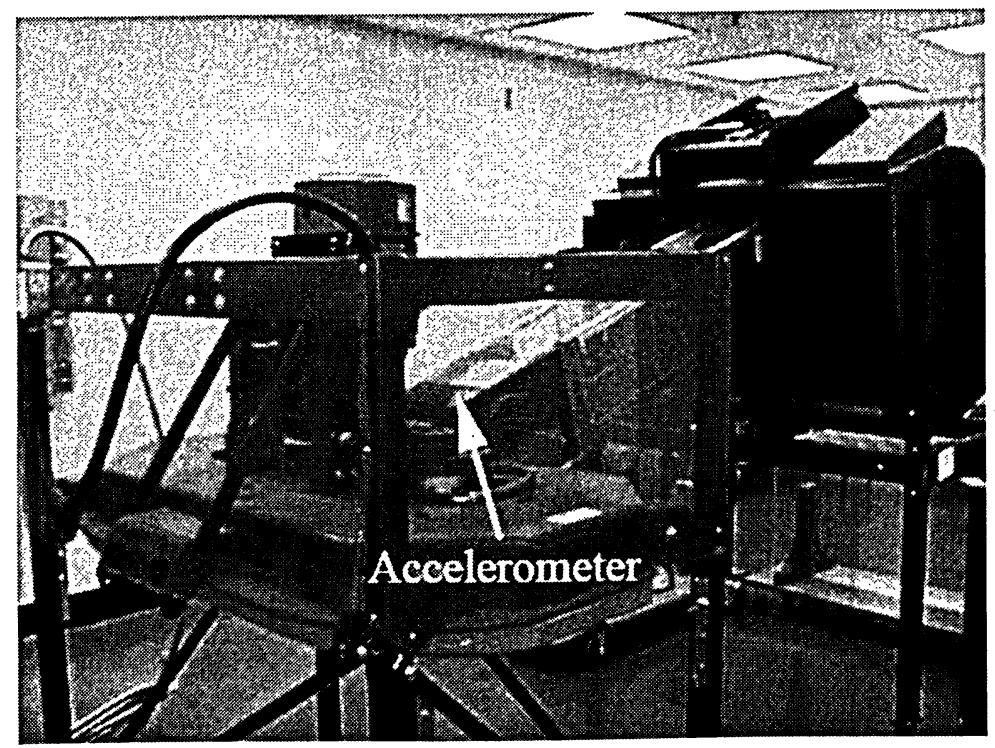

Fig. 53 Accelerometer mounting location for normal operation vibration reading

\subsection{Experimental Results}

The frequency domain of the blade response is shown in Fig. 54. The first natural frequency corresponding to the first flexural or bending mode of blade vibration is $68 \mathrm{~Hz}$ and is clearly shown in the zoomed image of Fig. 55.The second bending mode is much higher at about $380 \mathrm{~Hz}$.

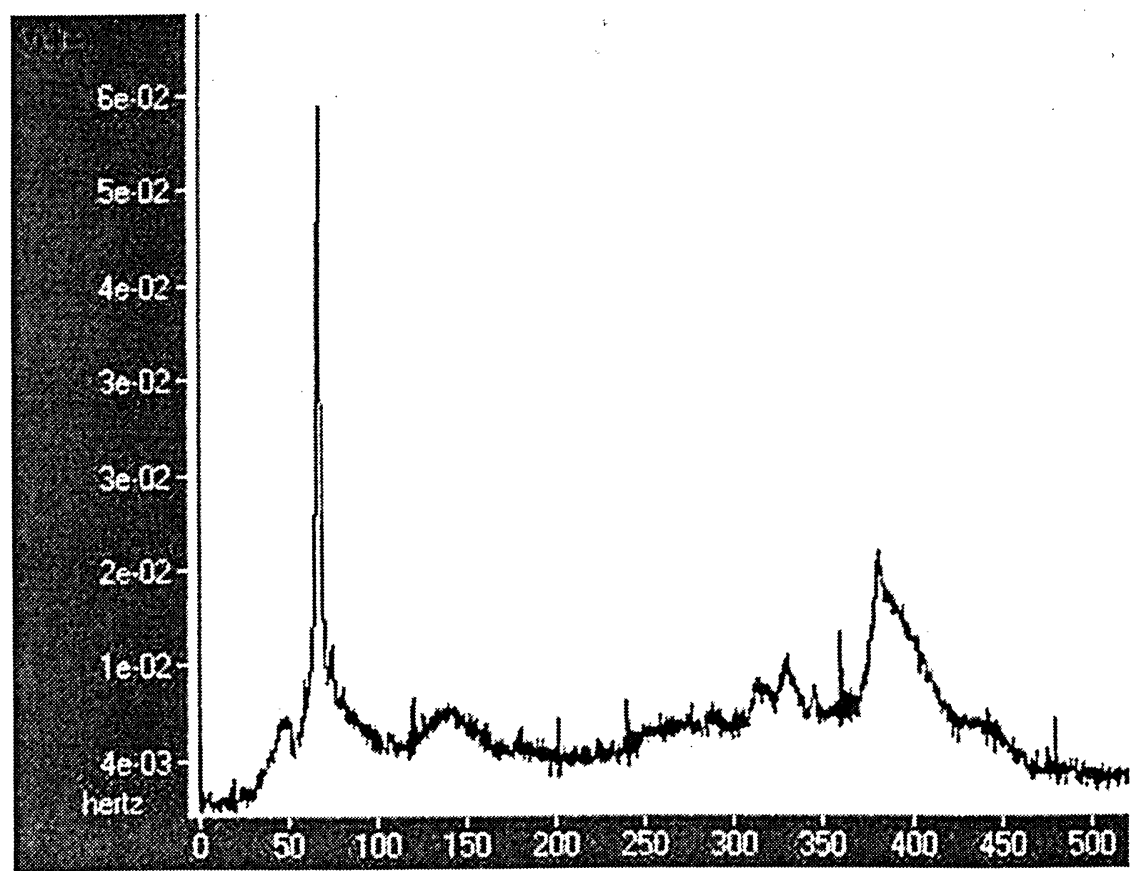

Fig. 54 Fourier transform of the blade tip free flexural vibration 


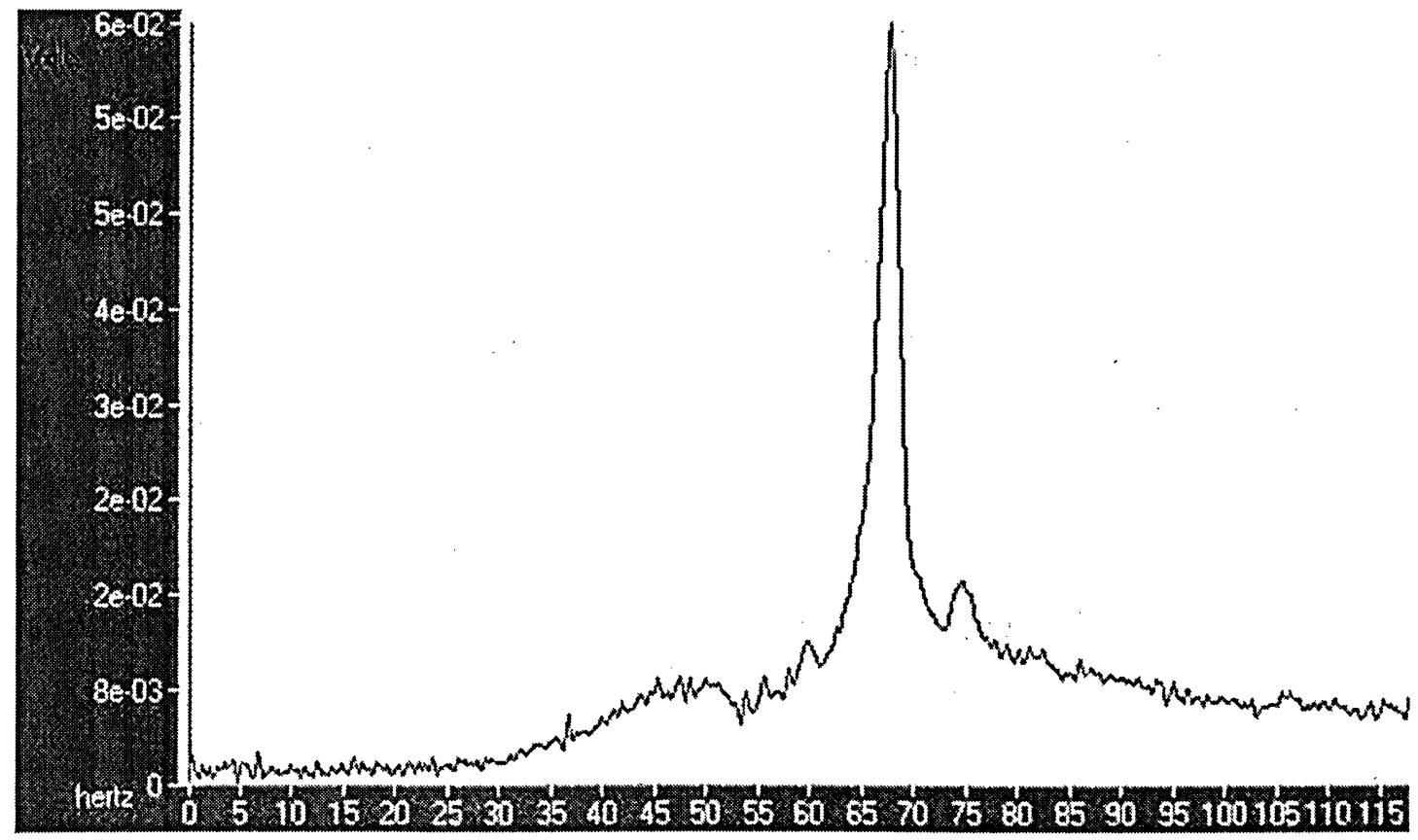

Fig. 55 Detailed view of spectrum in the vicinity of the first peak

The recorded vibration data for the accelerometer mounted to the test rig is shown in Fig. 56 . The largest peaks are observed at approximately $44 \mathrm{~Hz}, 88 \mathrm{~Hz}$, and $176 \mathrm{~Hz}$.

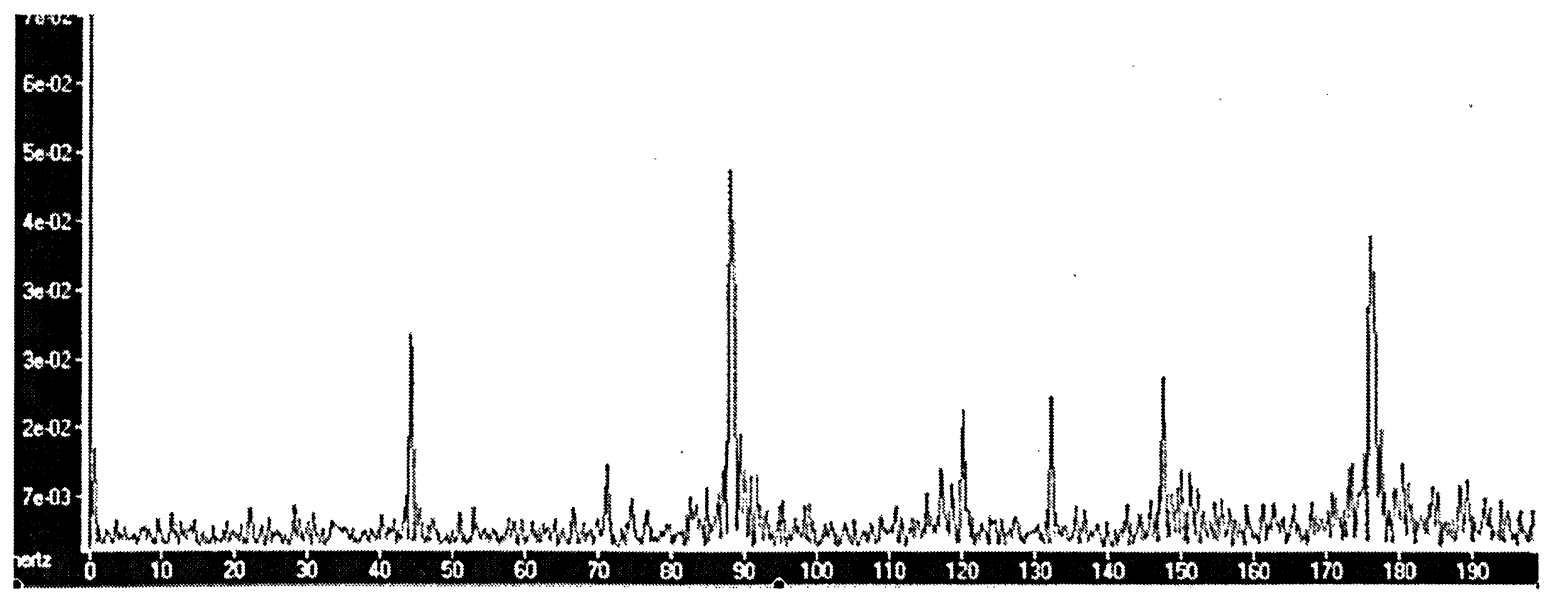

Fig. 56 Fourier transform of test rig vibration data 


\subsection{Computational Set-up}

GP-Turfcare had provided a 3D model of the serrated-style blade which was used in the computational analysis. Modal and harmonic analyses were done on the modeled blade using ANSYS.

The material model of the blade was defined as structural, linear, elastic, and isotropic. Young's modulus was set as $207 \mathrm{GPa}$, Poisson's ratio was 0.3, and density was 7700 $\mathrm{kg} / \mathrm{m}^{3}$. The blade was meshed using the SOLID92 element which is a $3-\mathrm{D}, 10$-node tetrahedral structural solid which is well suited to model irregular shapes. The blade was meshed using a SmartSize level of 10 (coarse) and is seen in Fig. 57. The meshed blade has 9068 elements with 18747 nodes. Each node has three degrees of freedom, UX, UY, and UZ.

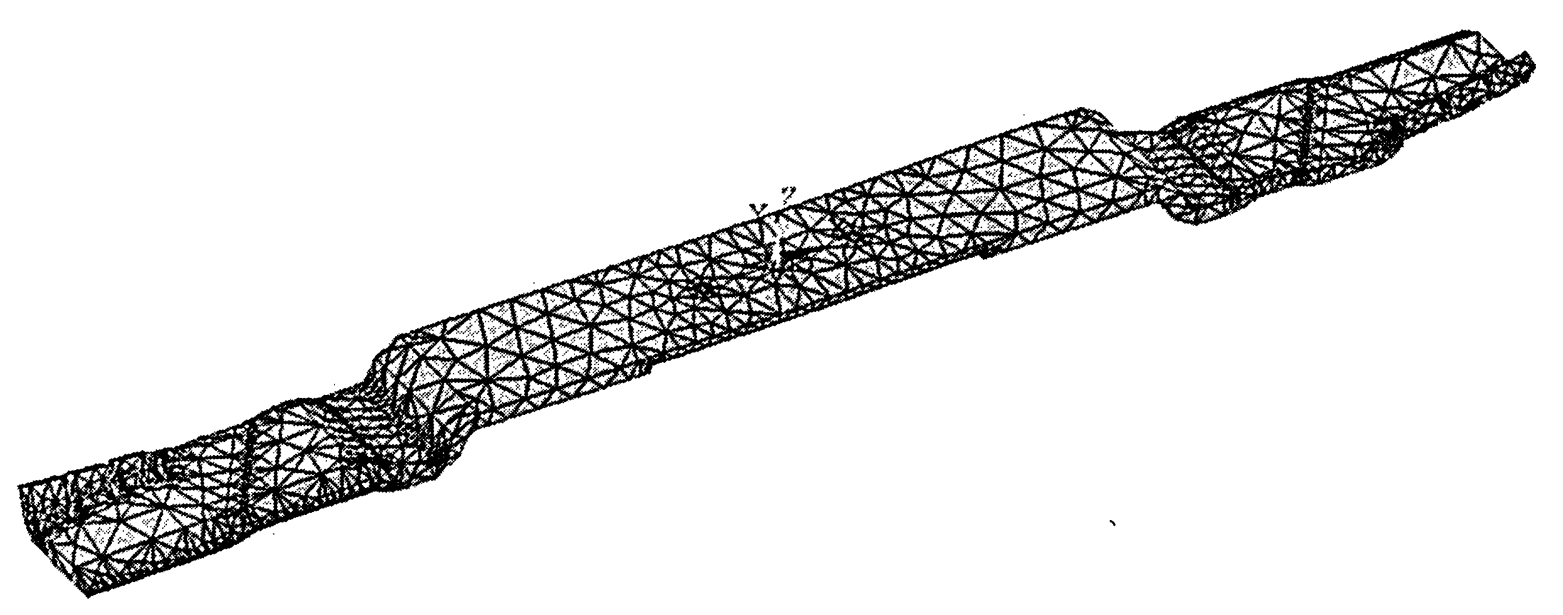

Fig. 57 Meshed blade in ANSYS

In the actual system, the bottom plate is supposed to be in contact with a large area on the bottom; however, investigations on the experimental set-up revealed that the bottom plate does not make full contact with the blade. Displacement DOFs were constrained in all directions (UX, UY, UZ) in the region of the T-shaped clamp on the top and bottom surfaces of the blade, Fig. 58. The middle plane of the blade and areas away from the Tshaped flange were not constrained because they would not make contact with the clamping pieces. 


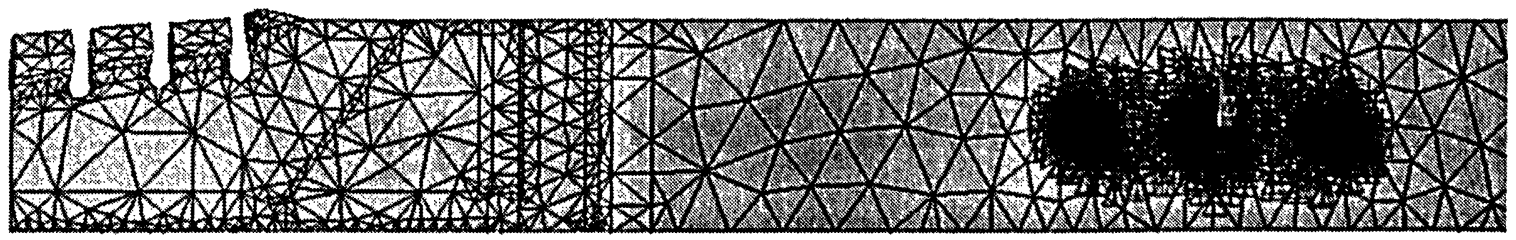

Fig. 58 DOF constraints on blade (constraint symbols are in black)

In the modal analysis options, a Block Lanczos extraction method was used to extract the first 10 modes of the blade. The lumped mass approximation was not used, and mode shapes were normalized to the mass matrix.

The harmonic analysis options were set to a full solution method and do not use the lumped mass approximation. A frontal equation solver was used. A force was applied at a node $4 \mathrm{~cm}$ from the tip of the blade in the vertical direction. This force represents the vertical lift forces on the blades as they rotate. The amplitude of the force was $+/-2.2 \mathrm{~N}$, which was the amplitude of lift force found in earlier 2-D computational models. In that model, the average lift force was $-16.7 \mathrm{~N}$ (downward); however, ANSYS only uses applied forces that are centered on $0 \mathrm{~N}$ in harmonic analyses. It is assumed that the 16.7 $\mathrm{N}$ average downward force does not significantly affect the deformation of the blade enough to make an impact on the response because the maximum tip deflection is only about $3 \mathrm{~mm}$. The force is applied $4 \mathrm{~cm}$ from the edge to match the conditions in the 2-D analysis. Two harmonic analyses were run; the first ranged from $0 \mathrm{~Hz}$ to $450 \mathrm{~Hz}$ in $10 \mathrm{~Hz}$ increments, the second went from $60 \mathrm{~Hz}$ to $80 \mathrm{~Hz}$ in $1 \mathrm{~Hz}$ increments. The damping ratio used for steel was $\zeta=0.005$.

After the computer model has been validated by comparing the results of the static natural frequencies of the blade at rest, the dynamic frequencies are found on the computational model. The dynamic natural frequencies are found by first performing a static analysis to determine stress distribution through the blade caused by a rotational speed of $269 \mathrm{rad} / \mathrm{s}$. Then the subsequent modal analysis included stress-stiffening effects as well as spin-softening effects. 


\subsection{Modal Analysis Results of Static Frequencies}

The first two static frequencies were bending at $69.76 \mathrm{~Hz}$ and $70.38 \mathrm{~Hz}$ (Fig. 59 and Fig. $60)$. These frequencies were the vertical bending modes of the left and right sides of the blade. They are approximately equal due to the symmetry on either side of the axis of rotation. This is the case with the rest of the modes where mode shapes 3 and 4 are the same mode, 5 and 6 are the same mode, etc. The $3^{\text {rd }}$ and $4^{\text {th }}$ frequencies were $379.44 \mathrm{~Hz}$ and $380.03 \mathrm{~Hz}$ (Fig. 61 and Fig. 62), which were side-to-side (horizontal) bending. The $5^{\text {th }}$ and $6^{\text {th }}$ frequencies were $396.83 \mathrm{~Hz}$ and $399.77 \mathrm{~Hz}$ (Fig. 63 and Fig. 64), and were the second-order vertical bending modes (the same type of bending mode as frequencies 1 and 2). The $7^{\text {th }}$ and $8^{\text {th }}$ frequencies $666.38 \mathrm{~Hz}$ and $666.46 \mathrm{~Hz}$ (Fig. 65 and Fig. 66), and were twisting modes. The final frequencies, 9 and 10, were third-order bending modes of 1023.7 Hz and 1030.7 Hz (Fig. 67 and Fig. 68).

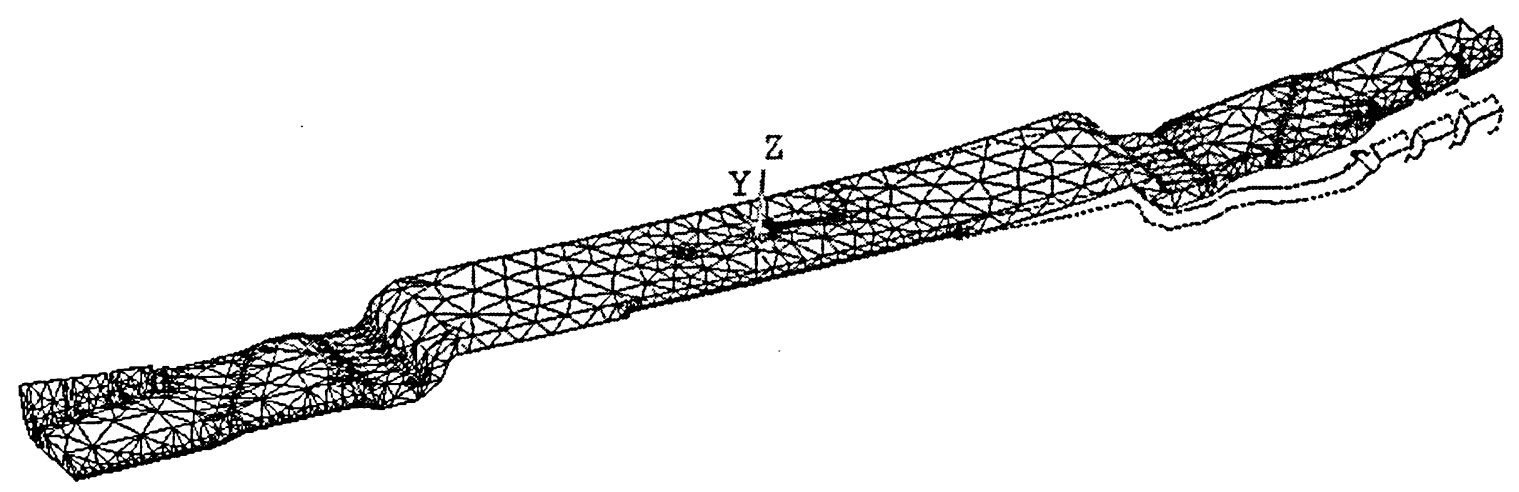

Fig. 59 Mode shape $1,69.76 \mathrm{~Hz}$

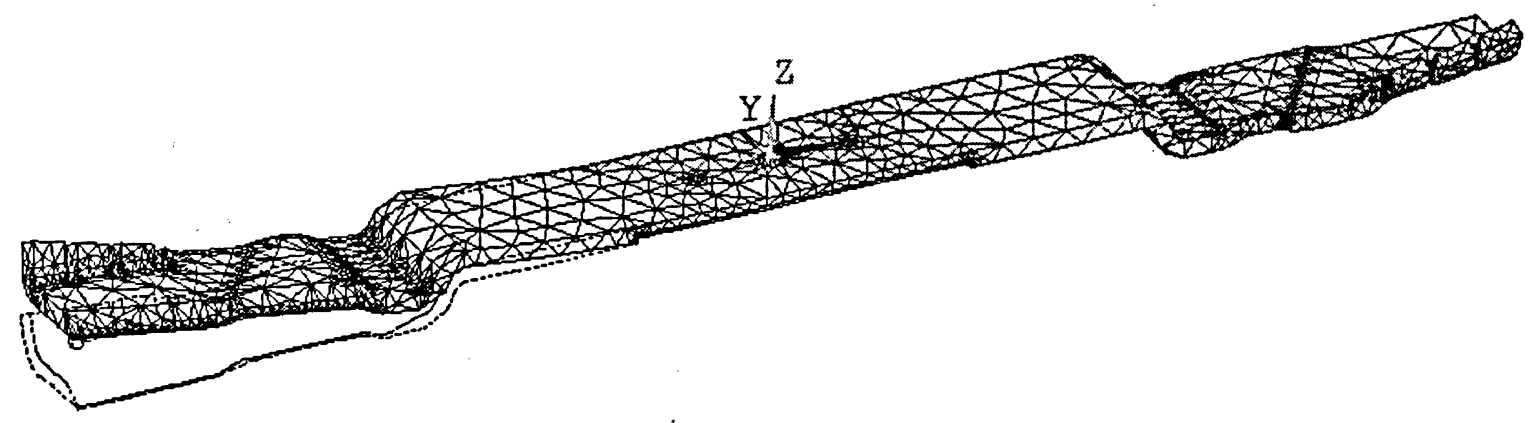

Fig. 60 Mode shape $2,70.38 \mathrm{~Hz}$ 


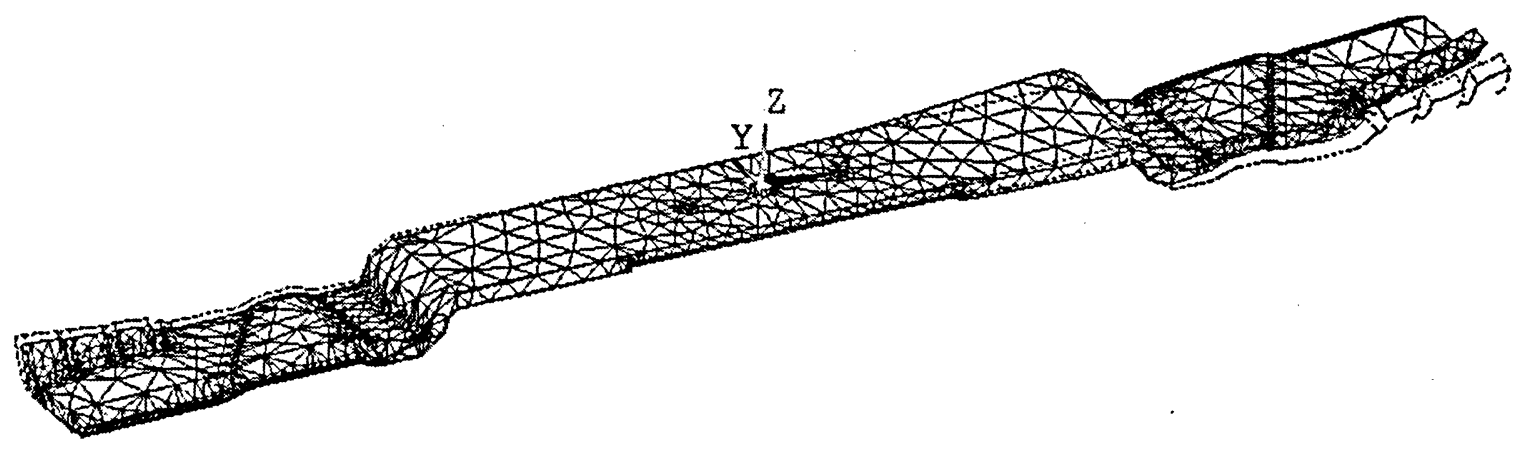

Fig. 61 Mode shape 3, $379.44 \mathrm{~Hz}$

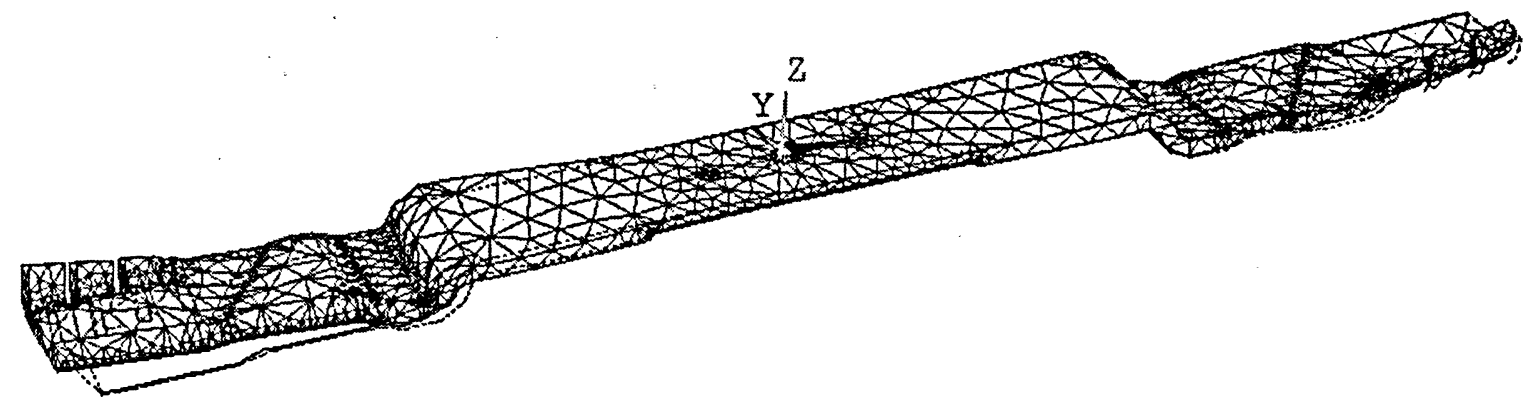

Fig. 62 Mode shape 4, $380.03 \mathrm{~Hz}$

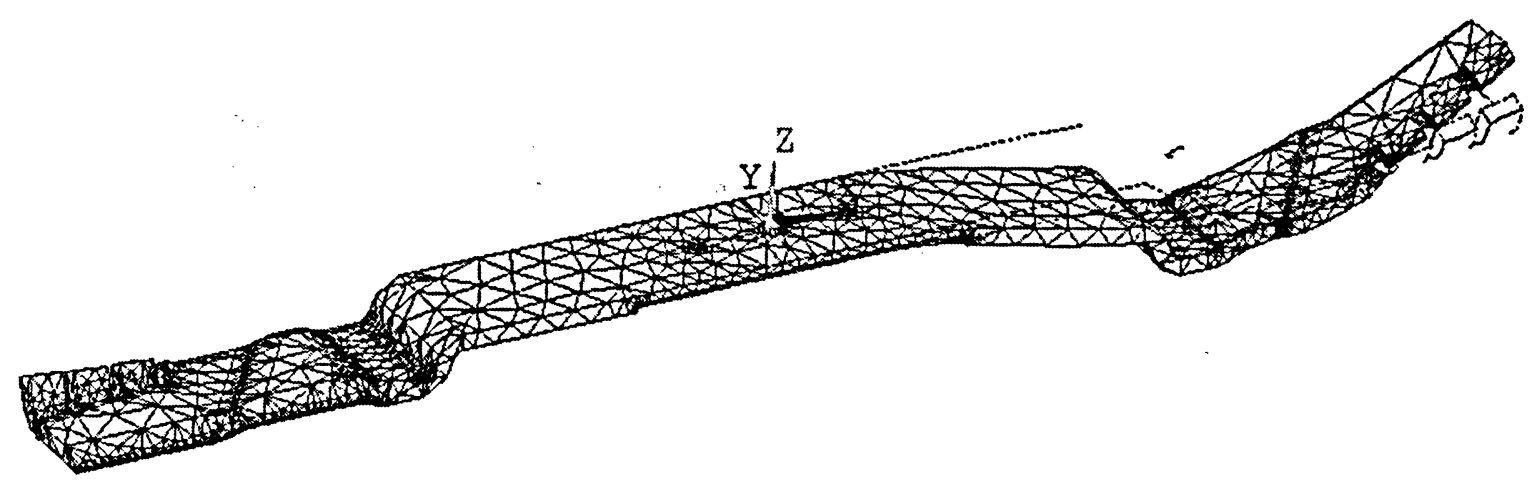

Fig. 63 Mode shape 5, $396.83 \mathrm{~Hz}$

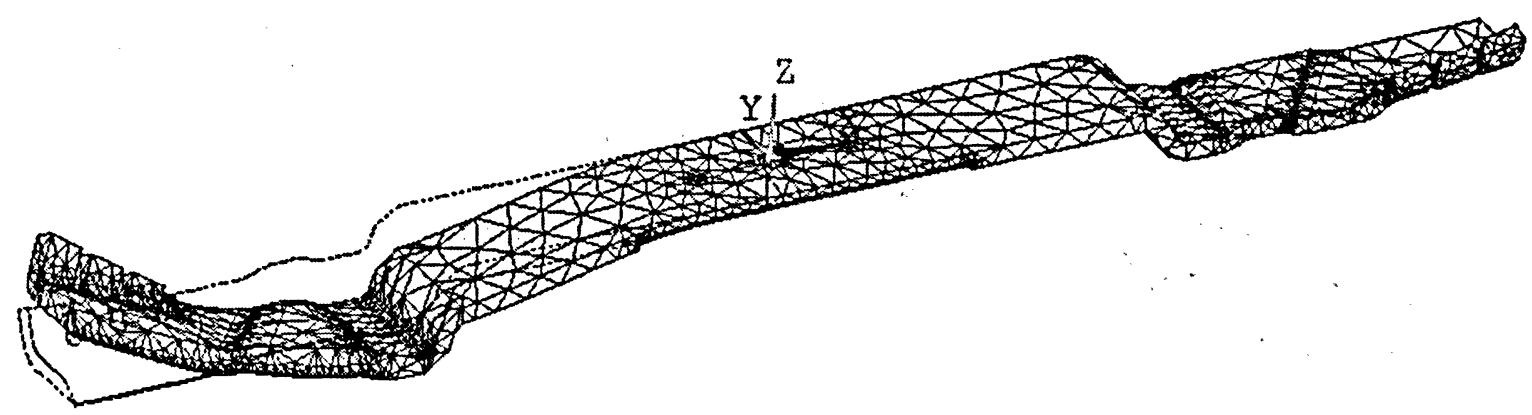

Fig. 64 Mode shape 6, $399.77 \mathrm{~Hz}$ 


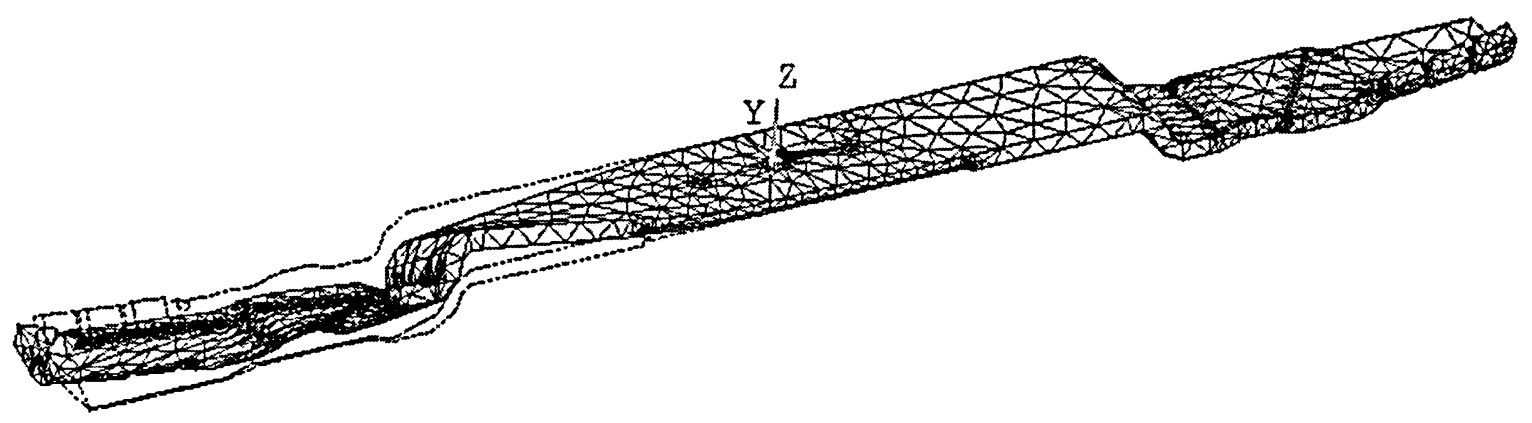

Fig. 65 Mode shape 7, $666.38 \mathrm{~Hz}$

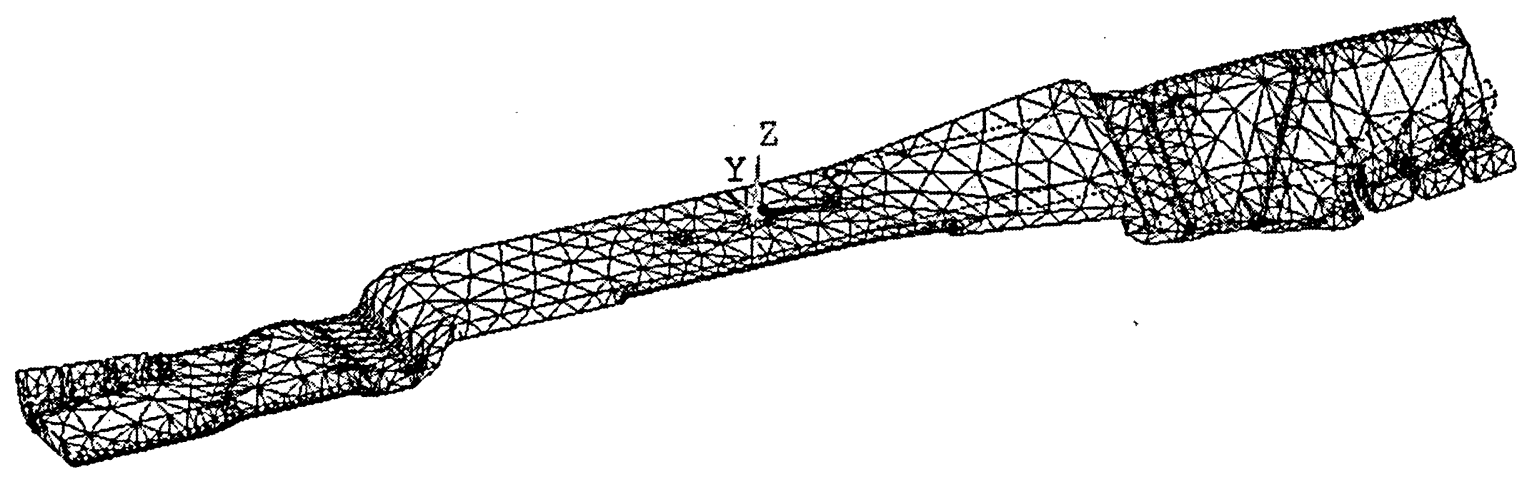

Fig. 66 Mode shape 8, $666.46 \mathrm{~Hz}$

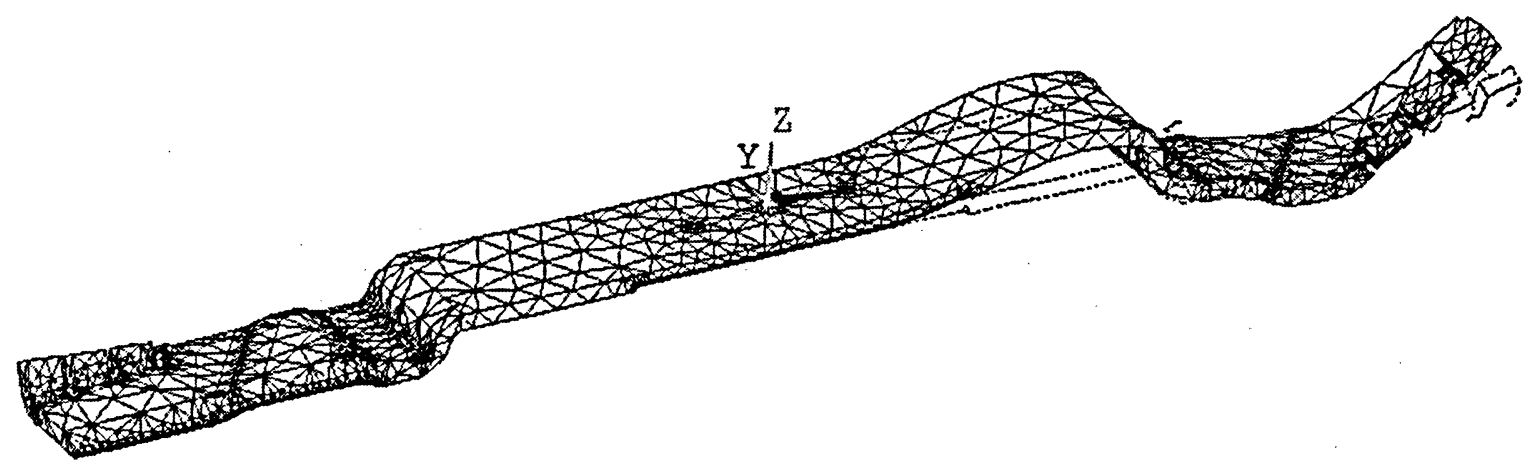

Fig. 67 Mode shape 9, $1023.7 \mathrm{~Hz}$

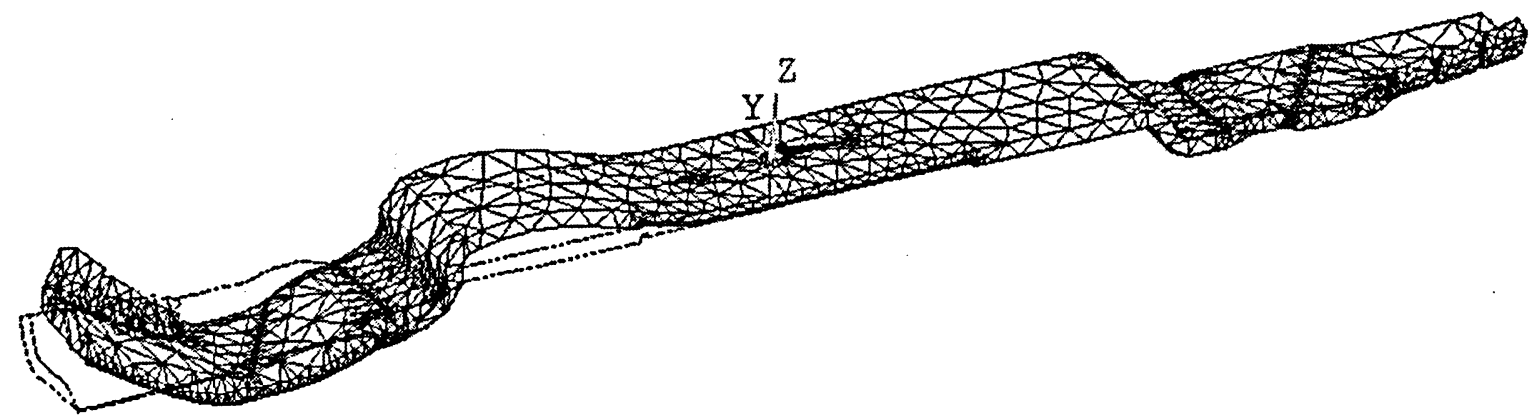

Fig. 68 Mode shape 10, $1030.7 \mathrm{~Hz}$ 


\subsection{Harmonic Analysis Results}

The results of the $0 \mathrm{~Hz}$ to $450 \mathrm{~Hz}$ harmonic analysis is seen in Fig. 69, which shows a high peak at $70 \mathrm{~Hz}$, and a small peak at $400 \mathrm{~Hz}$. The height of the peak at $400 \mathrm{~Hz}$ may be low because the applied force is $4 \mathrm{~cm}$ in from the tip. This would place the force close to the node of the second bending mode, which wouldn't create as strong a vibration. Fig. 70 shows the results of the more compact $60 \mathrm{~Hz}$ to $80 \mathrm{~Hz}$ span, where a high peak at 70 $\mathrm{Hz}$ is observed.

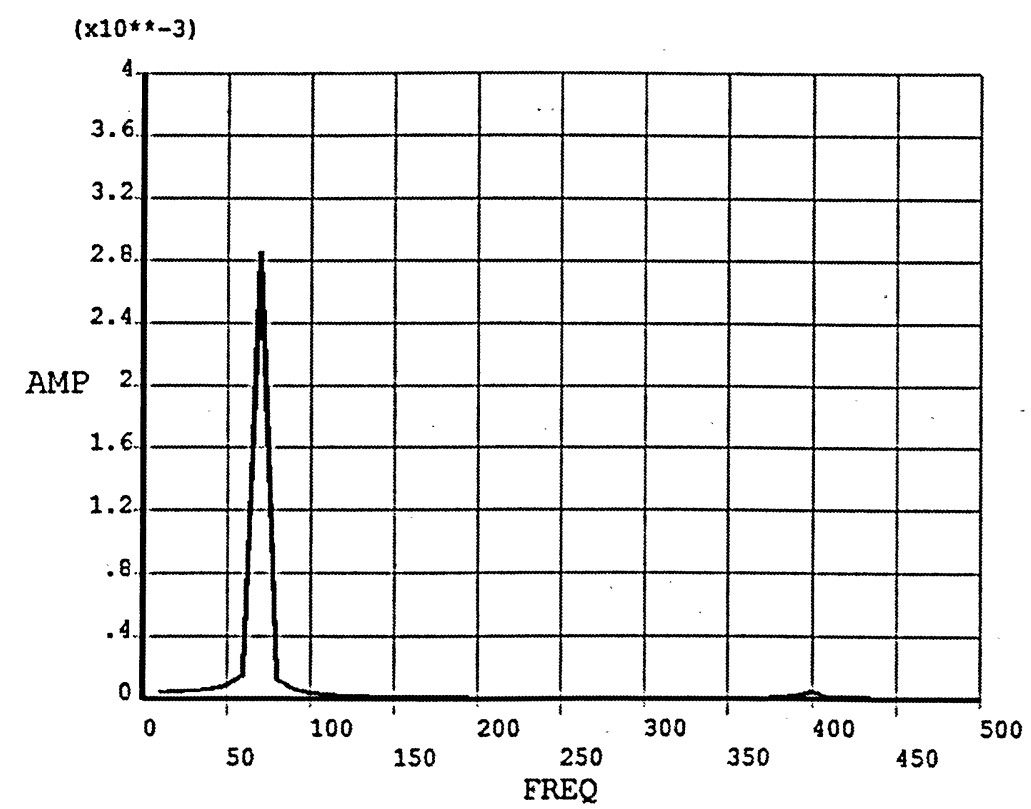

Fig. 69 Harmonic response of blade between $0 \mathrm{~Hz}$ and $500 \mathrm{~Hz}$ 


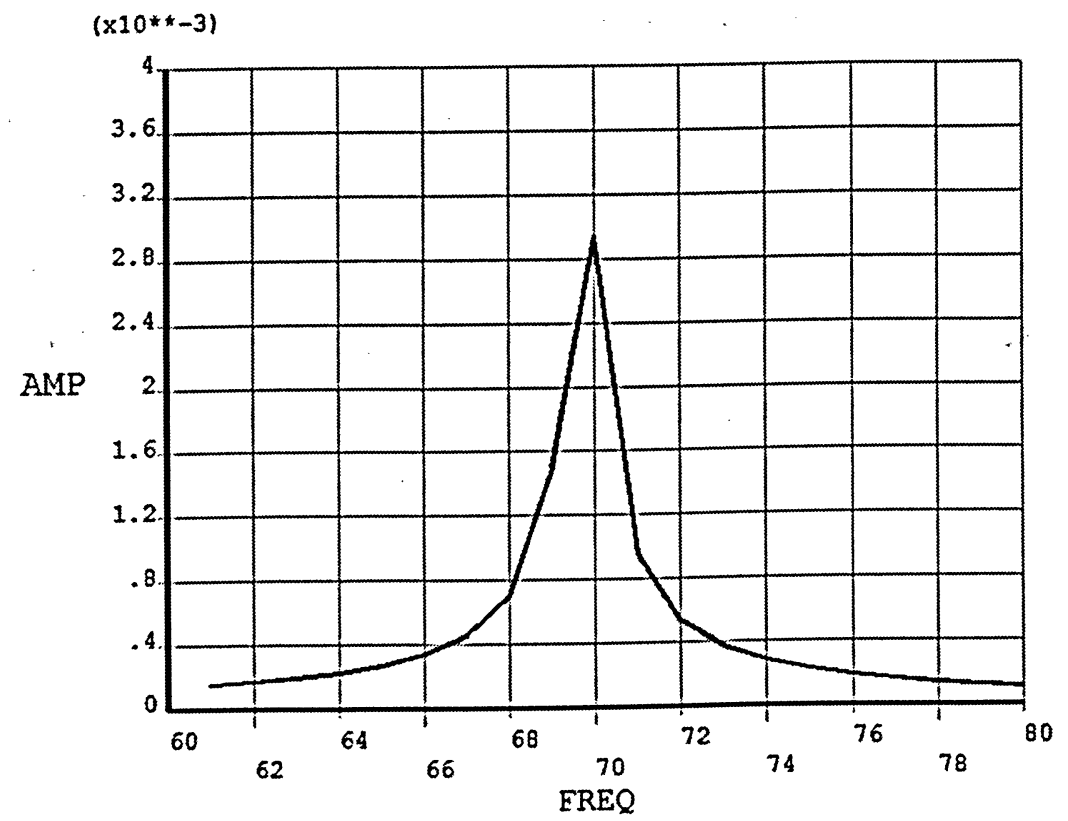

Fig. 70 Harmonic response of blade between $60 \mathrm{~Hz}$ and $80 \mathrm{~Hz}$

\subsection{Modal Analysis Results of Dynamic Frequencies}

The results of the dynamic modal analysis are given in Table 20. The affect of the blade rotation significantly increased the frequencies of the first vertical bending modes ( 1 and 2). The dynamic frequencies increase due to the distributed centrifugal forces that produce tensile stresses in the rotating blades [15].

Table 20 Comparison of Static and Dynamic Frequencies

\begin{tabular}{|c|c|c|c|}
\hline $\begin{array}{c}\text { Mode } \\
\text { Shape }\end{array}$ & $\begin{array}{c}\text { Static } \\
\text { Frequencies } \\
(\mathrm{Hz})\end{array}$ & $\begin{array}{c}\text { Dynamic } \\
\text { Frequencies } \\
(\mathrm{Hz})\end{array}$ & $\begin{array}{c}\% \\
\text { difference }\end{array}$ \\
\hline 1 & 69.76 & 86.27 & $23.7 \%$ \\
\hline 2 & 70.38 & 86.86 & $23.4 \%$ \\
\hline 3 & 379.44 & 380.37 & $0.2 \%$ \\
\hline 4 & 380.03 & 380.97 & $0.2 \%$ \\
\hline 5 & 396.83 & 412.52 & $4.0 \%$ \\
\hline 6 & 399.77 & 415.44 & $3.9 \%$ \\
\hline 7 & 666.38 & 669.77 & $0.5 \%$ \\
\hline 8 & 666.46 & 669.87 & $0.5 \%$ \\
\hline 9 & 1023.7 & 1038.0 & $1.4 \%$ \\
\hline 10 & 1030.7 & 1045.0 & $1.4 \%$ \\
\hline
\end{tabular}




\subsection{Discussion}

The experimental testing showed the first and second static bending modes as $68 \mathrm{~Hz}$ and $380 \mathrm{~Hz}$, respectively. The bending mode results of the computational analysis between the modal and harmonic corresponded with each other. The computational analysis revealed first and second static bending modes at about $70 \mathrm{~Hz}$ and $400 \mathrm{~Hz}$, respectively. There is $3-5 \%$ error between the experiment and computational values, which suggests that the results are good.

The dynamic frequencies found through the computational model included the stressstiffening and spin-softening effects incurred by the angular speed of $269 \mathrm{rad} / \mathrm{s}$. The first two frequencies increased by approximately $24 \%$, resulting in a dynamic frequency of about $86.5 \mathrm{~Hz}$ for the first two modes.

The forcing frequency is $85.6 \mathrm{~Hz}$. The dynamic natural frequency of the blade is found to be approximately $86.5 \mathrm{~Hz}$. This is only a $1 \%$ difference, so the blades will experience resonance under these conditions. Vibration from the blades can travel through the shaft and into the rest of the system and can be a significant source of noise. The $86 \mathrm{~Hz}$ frequency is observed on the tunnel in Fig. 56. Also observed are the $43 \mathrm{~Hz}$ single shaft speed, and $176 \mathrm{~Hz}$ which could be present due to there being two blades ( $86 \mathrm{~Hz}$ doubled). It is likely that blade vibration is a significant contributor to the overall noise of the system. 


\section{Chapter 5: Conclusions}

Experimental studies of airflow inside the cutting/collection system of lawn care equipment were conducted using a test rig set up at Ryerson University. The experimental data for airflow velocities at various locations were used to validate the computer models.

Several three-dimensional twin-blade computational models were developed in this thesis using Fluent. They gave good representations of airflow in the test rig when compared to the experimental results. The results of the models were also used to visualize the flow and obtain readings throughout the cutting pan, which would otherwise be difficult to accomplish from experiments.

The porous jump boundary condition in the twin-blade models successfully simulated the outlet vents on the actual cutting system. The computed flow patterns revealed that the vents prevented strong recirculation by allowing most of the air to escape quickly into the environment. This inhibited maximum filling of regions near the top corners of the collector. Simulations show that when the rear centre vent is closed, the air keeps most of its kinetic energy and causes more airflow into the top corners. This finding is of significant interest to the lawn care industry.

The computational models were successfully used to compare the airflow through the tunnel of both the serrated and paddle style blades. Simulation results show that the paddle blade produced much more airflow compared to the serrated blade, which is verified on the real system.

The preprocessing and solution times for three-dimensional CFD models were significantly longer that those for two-dimensional models. The 3D models should be used only when general flow patterns in the cutting pan, tunnel, or collector are required. 
To design blades efficiently, two-dimensional computational models were developed to simulate airflow inside a cutting pan for many combinations of blade parameters.

The computational modal and harmonic analysis results obtained using the finite element method are in excellent agreement with the experimental static natural frequencies, which validated the computer model. The dynamic frequencies were then found using the prestress effects of spinning the blade at $269 \mathrm{rad} / \mathrm{s}$. The blades operate at a speed very close to the dynamic natural frequencies of the lower vibration modes, so resonance effects are present. It is likely that the blades are vibrating considerably, and this vibration is being carried through the system because the frequencies were detected on the top of the tunnel. The blade vibration is a significant contributor to overall noise. 


\section{Chapter 6: Future Work}

The computer simulation models can be improved by incorporating clippings into an airclipping mixture. Fluent has several multi-phase techniques. One such technique is EulerEuler, where clippings have a large volume fraction and can be treated as a continuum, which is mixed with air. Another technique is Euler-Lagrange, which treats a low-volume fraction of clippings as individual particles interacting with the surrounding air. Use of these techniques requires testing to determine the volume fraction of clippings in the flow.

Two-Dimensional blade flow can be further explored by examining a wide range of shapes. Only three tail angles and three tail lengths were analyzed in this thesis. A full range of angles can be explored so that data can be acquired and applied towards a larger variety of situations, such as different tunnel angles or widths.

The rectangular shape of the tunnel may not be the best shape to promote the highest airflow through the tunnel. As shown in Fig. 24, the airflow speed in the bottom portion of the tunnel is not as high as at the top. A better tunnel design would be one that would match the direction of the velocity coming away from the blade, which would be more easily accomplished by varying the blade tail angle. The tunnel could also be more effective if the tunnel had a more curved shape, which would more likely allow air to follow in a more natural path.

The blade shape requires redesign because the dynamic natural frequency is very close the forcing frequency. If noise persists, later tests could identify the main sources of noise by using a decibel meter to measure the levels of noise at various points around the system. 


\section{Chapter 7: References}

[1] Dixon, S. L., Fluid Mechanics and Thermodynamics of Turbomachinery, $4^{\text {th }}$ Edition. Butterworth-Heinemann, Boston, 1998.

[2] White, Frank M., Fluid Mechanics, 4th edition, McGraw-Hill, Toronto, 1999.

[3] Boctor, Stalin A., et al, Electrical Concepts and Applications, West Publishing Company, New York, 1997.

[4] Fluent Documentation CD, Fluent Inc. 2-D blower model obtained from http://www88.homepage.villanova.edu/kamran.fouladi/images/cfd_HW\&P/blower.msh.

[5] Fluent 6.0 User's Guide, Fluent Inc., 2001. Obtained from http://gong.snu.ac.kr/down/on-line-documents/fluent/help/html/ug/main_pre.htm.

[6] Kuski, Timothy D., Understanding axial fans. Plant Engineering 51(2), pp. 96-98, 1997.

[7] Doyle, M. D. C., Advanced through-flow analysis applied to a low-speed axial flow compressor. Int. J. Mech. Sci. 13, pp. 833-842, 1971.

[8] Saha, U. K., and Roy, B., Experimental investigations on tandem compressor cascade performance at low speeds. Experimental Thermal and Fluid Science 14, pp. 263-276, 1997.

[9] Farn, C. L. S., and Whirlow, D. K., Design estimate of cascade performance. Computers \& Fluids 3, pp. 225-233, 1975.

[10] Carstens, V., Kemme, R., and Schmitt, S. Coupled simulation of flow-structure interaction in turbomachinery. Aerospace Science and Technology 7, pp. 298-306, 2003.

[11] Chen, W. L., Lien, F. S., and Leschziner, M. A. Computation prediction of flow around highly loaded compressor cascade blades with non-linear eddy viscosity models. International Journal of Heat and Fluid Flow 19, pp. 307-319, 1998.

[12] Hilgenfeld, L., Cardamone, P., and Fottner, L., Boundary layer investigations on a highly loaded transonic compressor cascade with shock/laminar boundary layer interactions. Proceedings of the Institution of Mechanical Engineers 217 (4), pp. 349-356, 2003. 
[13] Saha, U. K., Roy, B. Experimental Investigations on Tandem Compressor Cascade Performance at Low Speeds. Experimental Thermal and Fluid Science 14, pp. 263-276, 1997.

[14] Wallis, R. Allan, Axial Flow Fans \& Ducts. John Wiley \& Sons, Inc., Toronto, 1983.

[15] Bruel and Kjaer, Structural Testing, Part 2: Modal Analysis and Simulation, Denmark, 1988.

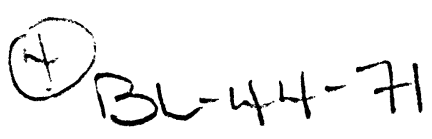

